Universidade de Brasília

Instituto de Geociências

\title{
ANÁLISE MULTIVARIADA DE DADOS GEOQUÍMICOS APLICADA À EXPLORAÇÃO MINERAL DE OURO: ESTUDO DE CASO NO DISTRITO
} AURÍFERO DE ALMAS, TO, BRASIL

\author{
DISSERTAÇÃO DE MESTRADO \\ $\mathbf{N}^{\circ} 346$
}

MARCO ANTÔNIO CAÇADOR MARTINS FERREIRA Orientador: Prof. Dr. JOSÉ ELOI GUIMARÃES CAMPOS Co-orientador: Prof. Dr. AUGUSTO CESAR BITTENCOURT PIRES

Brasília, Julho de 2015. 
Universidade de Brasília

Instituto de Geociências

\title{
ANÁLISE MULTIVARIADA DE DADOS GEOQUÍMICOS APLICADA À EXPLORAÇÃO MINERAL DE OURO: ESTUDO DE CASO NO DISTRITO AURÍFERO DE ALMAS, TO, BRASIL
}

\author{
DISSERTAÇÃO DE MESTRADO \\ $\mathrm{N}^{\circ} 346$
}

MARCO ANTÔNIO CAÇADOR MARTINS FERREIRA

\section{Banca examinadora:}

Professor Dr. José Eloi Guimarães Campos (Orientador)

Professor Dr. Cláudio Gerheim Porto (UFRJ)

Professora Dr ${ }^{\mathrm{a}}$ Adriana Coimbra Horbe (UnB/IG)

Brasília, Julho de 2015. 
"The fact that mathematics does such a good job of describing the Universe is a mystery that we don't understand. And a debt that we will probably never be able to repay."

\section{Lord Kelvin}




\section{AGRADECIMENTOS}

Meus agradecimentos sinceros ao Professor Dr. José Eloi Guimarães Campos, pela orientação e ao Professor Dr. Augusto Cesar Bittencourt Pires pela co-orientação. Aos membros da banca examinadora Professora $\mathrm{Dr}^{\mathrm{a}}$ Adriana Coimbra Horbe e Professor Dr. Cláudio Gerheim Porto pela contribuição com melhorias à dissertação. À Universidade de Brasília e ao Instituto de Geociências pelos meios físicos e técnicos para a realização da presente pesquisa e dissertação, à Rio Novo Mineração LTDA pelos dados fornecidos, ao CNPq pelo auxílio financeiro e a todos os geólogos e professores que tanto me ensinaram e continuam ensinando. 


\section{SUMÁRIO}

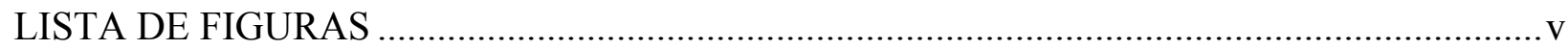

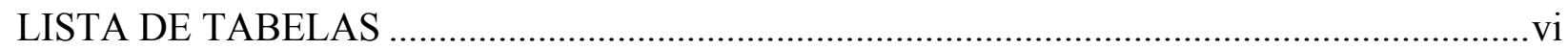

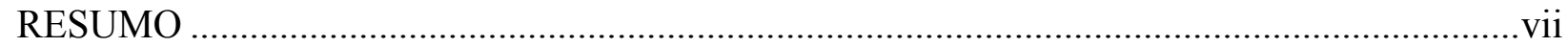

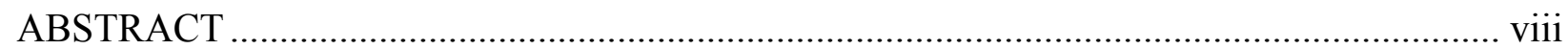

CAPÍTULO 1: INTRODUÇÃO

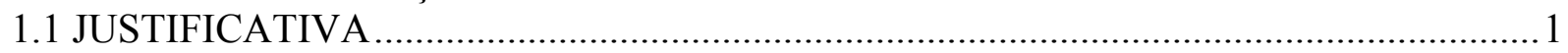

1.2 OBJETIVOS

1.3 LOCALIZAÇÃO E BREVE HISTÓRICO ..............................................................

CAPÍTULO 2: GEOLOGIA REGIONAL E LOCAL .........................................................

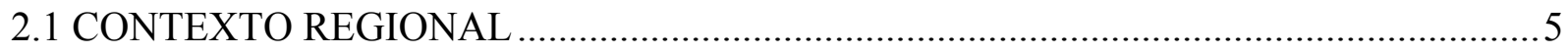

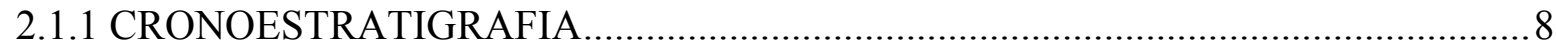

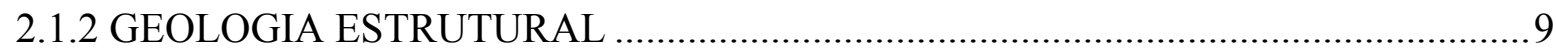

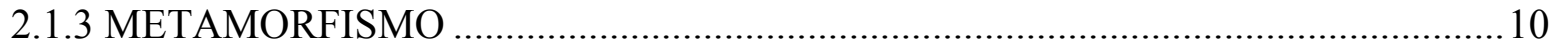

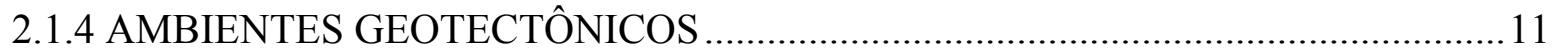

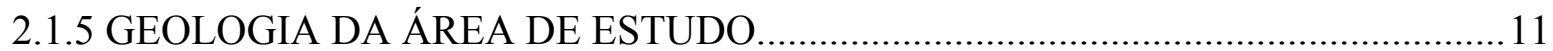

CAPÍTULO 3: MATERIAIS E MÉTODOS …................................................................. 18

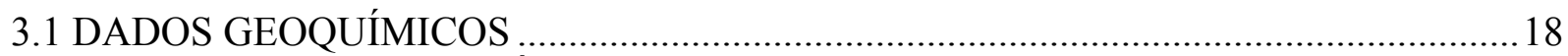

3.2 MICROSSONDA ELETRÔNICA ............................................................................ 19

3.3 MÉTODOS DE ANÁLISE MULTIVARIADA …....................................................... 20

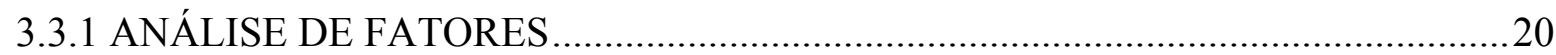

3.3.2 ANÁLISE DE AGRUPAMENTOS HIERÁRQUICOS E K-MÉDIAS .....................22

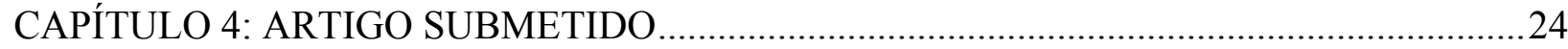

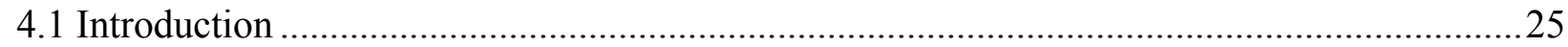

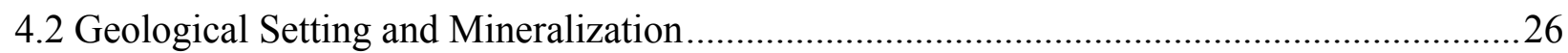

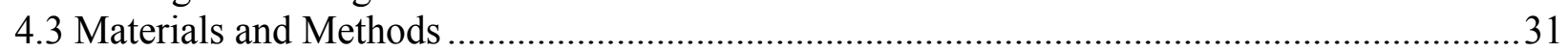

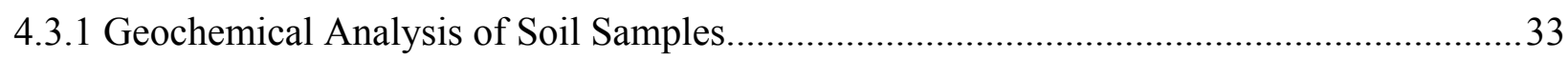

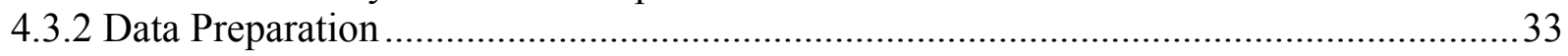

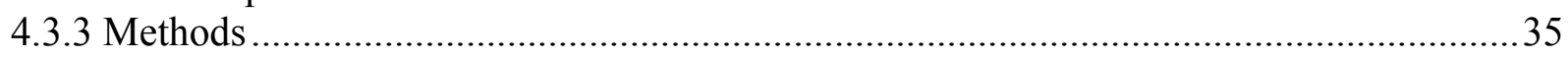

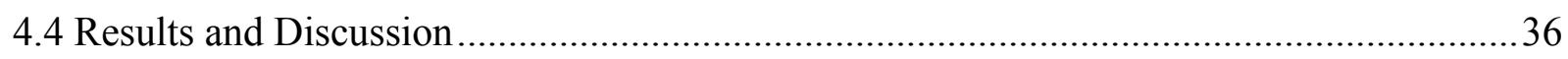

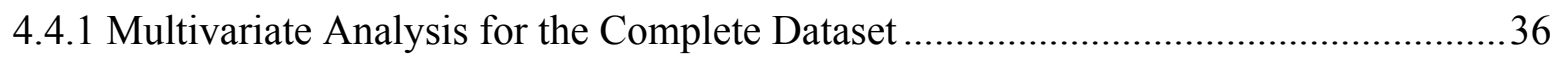

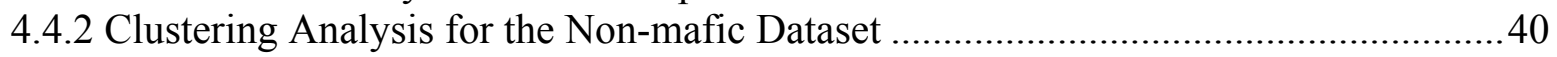

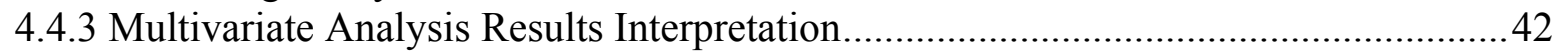

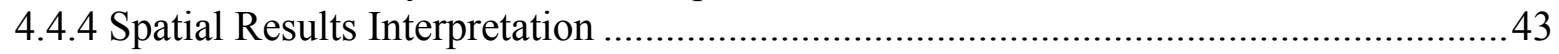

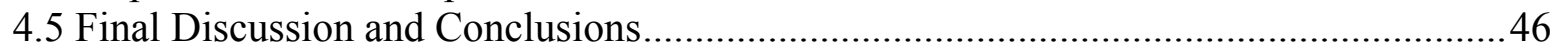

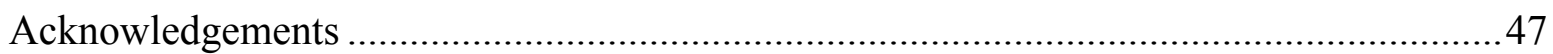

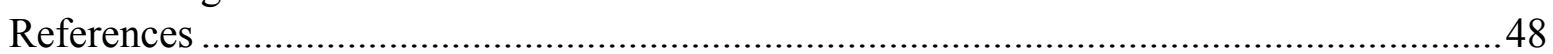

CAPÍTULO 5: DISCUSSÕES FINAIS, CONCLUSÕES E RECOMENDAÇÕES ....................50

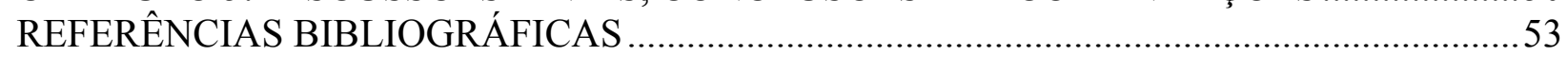

\section{LISTA DE FIGURAS}

Figura 1.1 - Mapa de localização do distrito de Almas, Tocantins, situada a $285 \mathrm{~km}$ a sudeste de Palmas, capital do estado.

Figura 2.1 - Mapa de localização da área de estudo na Faixa Brasília (modificado de Dardenne, 2000 e D'el-Rey Silva, 2008).

Figura 2.2 - Mapa de localização da área de estudo no terreno Almas (atualizado de Bruni et al., 1974)......

Figura 2.3 - Aspecto típico de afloramento dos meta-tonalitos do Bloco Ribeirão das Areias. ..12

Figura 2.4 - Seção esquemática do depósito Vira Saia interpretada com base em dados de sondagem. 
Figura 2.5 - Fotos macroscópicas dos testemunhos de sondagem representativas dos diferentes graus de milonitização das rochas do depósito Vira Saia.

Figura 2.6 - Fotomicrografia com nicois cruzados de lâmina delgada de amostra de ultramilonito coletado em furo de sondagem do depósito Vira Saia evidenciando par S-C de foliação milonítica. Foliação $\mathrm{C}$ em traço azul e $\mathrm{S}$ em traço amarelo. Ms=muscovita, $\mathrm{Q}=$ quartzo, $\mathrm{Cc}=$ calcita.

Figura 2.7 - Perfil típico dos neosolos que recobrem as rochas do Bloco Ribeirão das Areias... 17

Figura 3.1 - A) Mapa da área de estudo e malha de solo. B) Área de controle com projeção em superfície do minério sondado (em preto) e pilha de estéril (em branco).....

Figura 3.2 - Representação esquemática demonstrando os dois tipos de rotação de fatores, ortogonal e oblíquo.

Figure 4.1 - a) Brazilian map showing the distribution of the main cratons, phanerozoic basins and mobile belts. b) Brasília Fold Belt geologic map with the location of the study area (after Dardenne, 2000 and D'el-Rey Silva, 2008).

Figure 4.2 - Schematic section 75-S (location in Figure 4.5A) of the Vira Saia deposit constructed from drill core log data. Note the enveloping of mylonitic zones by protomylonitic zones.

Figure 4.4 - Map of the study area showing soil sampling lines and the location of the control area $(\mathbf{B})$ in relation to the total study area (A).

Figure 4.5 - A) Geologic map of the control area showing the surface projection of drilling results, geological mapping information, the 190 drilling sites and section 75-S (Figure 4.2). B) Geologic map of the control area showing the 501 soil sampling sites over the surface projection of drilling results. Note dense irregular soil sampling over the waste dump, the absence of samples over the abandoned open pit and the NW orientation of mineralization.

. .33

Figure 4.6 - HCA dendrogram for Ward linkage and Euclidean distance. The mafic cluster (4) is outlined in black. Groups 1, 2 and 3 did not correspond to the control area lithological distribution pattern.

Figure 4.7 - A) Geologic map of the control area (see geology legend on Figure 4.4) showing mafic (green) and non-mafic (hollow) clusters classified by HCA. B) Geologic map of the control area showing the three clusters from KMCA: cluster 1 in yellow, cluster 2 in pink and cluster 3 in red. Note the high occurrence of clusters 2 and 3 over the waste dump pile.

Figure 4.8 - Map of the study area showing gold anomalies in the soil geochemical results $(\mathrm{ppm})$

Figure 4.9 - Map of the study area showing both KMCA and HCA cluster results. 45

\section{LISTA DE TABELAS}

Table 4.1 - Descriptive statistics of raw soil data. Removed elements are outlined in gray. $\mathrm{N}=2,908$. $\mathrm{SD}=$ Standard Deviation, $\mathrm{VC}=$ Variation Coefficient, $\mathrm{DL}=$ Detection Limit.

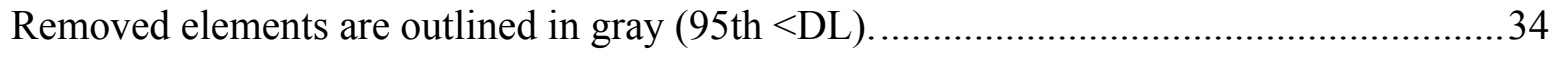

Table 4.2 - Varimax Rotated Factor Loadings and Communalities for the complete dataset. $\mathrm{N}=2,908$.

Table 4.3 - HCA Euclidean-Ward cluster results for the complete dataset. Cluster 4 grouped mafic samples, and the highest normalized means are outlined. $\mathrm{N}=2,908 \ldots \ldots \ldots \ldots \ldots \ldots \ldots . . . . . . . . . . . . . .40$

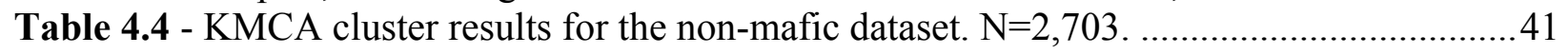




\section{RESUMO}

Métodos estatísticos multivariados como a análise de fatores, análise de agrupamentos hierárquicos e análise de agrupamentos k-médias foram aplicados em dados de geoquímica de solo e identificaram alvos potenciais em uma área com ocorrências de mineralizações de ouro não-expostas nas proximidades da mina do Vira Saia. O estudo envolveu malha de solo composta por 2.908 amostras abrangendo $88 \mathrm{~km}^{2}$ de terreno com potencial prospectivo. A análise de fatores identificou 5 fatores de correlação que representam $71,2 \%$ da variância total dos dados. Esses fatores distinguem associações geoquímicas elementares influenciadas pelos seguintes materiais parentais: rochas máficas, ultramáficas, pegmatitos e alteração hidrotermal distal e proximal. O método de agrupamento hierárquico foi capaz de distinguir corretamente amostras de solo derivadas de rochas máficas/ultramáficas daquelas derivadas de rochas félsicas/intermediárias ou hidrotermais. A aplicação do método de agrupamento K-médias em amostras consideradas não-máficas/ultramáficas, foi eficaz na distinção de 3 grupos de amostras representativas de rocha encaixante, alteração distal e proximal. Os métodos citados permitiram a identificação de uma assinatura geoquímica da alteração distal definida pela associação $\mathrm{Ba}, \mathrm{Ca}$, $\mathrm{La}, \mathrm{Na}, \mathrm{Pb}$ e $\mathrm{Sr}$ e possibilitaram a identificação de novos alvos para exploração em ambiente de near-mine. A análise espacial dos resultados de agrupamentos em comparação com uma área de geologia conhecida, denominada "área de controle" foi bastante eficaz na determinação dos melhores métodos de agrupamento e preparação dos dados. Este processo se mostrou adequado para fins de localização mais precisa de alvos com alto potencial de mineralização dentro da área de estudo. Os resultados obtidos cumprem com os objetivos propostos para o estudo indicando quatro novos alvos e três sub-alvos com precisão suficiente para o futuro planejamento de uma campanha de sondagem de baixo risco. O uso de métodos multivariados se mostrou extremamente eficiente para ambientes de exploração near-mine onde a disponibilidade de áreas com suficiente conhecimento geológico serve como base para testes e garante a acurácia de um dado método.

Palavras-chave: Estatística multivariada, exploração de ouro, distrito aurífero de Almas. 


\begin{abstract}
Multivariate methods such as factor analysis, hierarquical cluster analysis and k-means cluster analysis were employed to analyze soil geochemical data aiming to identify potential prospects in an orogenic gold mineralization area where outcropping ore is no longer available. An objective approach was adopted using a well-known mining area as control for analysis testing. The control area is surrounded by unexplored terrain, which was the target of this study. This unexplored terrain was covered by a soil grid of 2,908 samples, comprising an area of 88 $\mathrm{km}^{2}$. Factor analysis was able to provide 5 correlation factors explaining $71.2 \%$ of the total variance. These factors identified distinct elemental associations with high correlations, influenced by the parental materials: ultramafic, mafic, pegmatitic, distal and proximal hydrothermal alteration. Hierarchical cluster analysis was able to correctly distinguish mafic/ultramafic from non-mafic/ultramafic influenced samples. K-means cluster analysis of a sub-dataset composed only of non-mafic/ultramafic samples provided three groups of observations representative of country rock, distal alteration and proximal alteration. The above methods allowed for the identification of a geochemical fingerprint, defined by the elemental association of $\mathrm{Ba}, \mathrm{Ca}, \mathrm{La}, \mathrm{Na}, \mathrm{Pb}$ and $\mathrm{Sr}$, for distal alteration zones and enabled the mapping of new target areas for near-mine exploration. Spatial analysis of the clustering results, in comparison with the control area, was very effective in determining the best methods of clustering and data preparation. This process proved adequate for the determination of precise locations in the study area with high potential for mineralization. The results obtained fulfilled the aim of the study by indicating four new target areas and three sub areas with sufficient accuracy for future planning of an exploratory drilling program. The use of multivariate methods has been shown to be extremely efficient for near-mine exploration scenarios, where the availability of areas with enough geological knowledge can serve as testing grounds to assure a given method's accuracy.
\end{abstract}

Keywords: Multivariate statistics, gold exploration, Almas gold district. 


\section{CAPÍTULO 1}

\section{INTRODUÇÃO}

\subsection{JUSTIFICATIVA}

Diante das dificuldades na exploração de novas áreas com potencial econômico para metais, principalmente depósitos auríferos, é muito importante que pesquisas aplicadas sejam desenvolvidas para ampliar o potencial de áreas historicamente favoráveis a mineralizações. Todavia depósitos com exposição em superfície são escassos em locais onde a atividade mineira já existe há algum tempo. Este fato gera demanda por métodos alternativos que permitam detectar mineralizações não expostas que tenham deixado alguma forma de indício geoquímico direto ou indireto em superfície.

A geoquímica de solo é procedimento padrão em pesquisa mineral pelo seu baixo custo e facilidade de coleta e por isso é um dado geralmente disponível em abundância em áreas que foram submetidas a pesquisa mineral. $O$ uso de técnicas estatísticas multivariadas com a finalidade de auxiliar a prospecção mineral é comum e remonta da década de 1960 (Nichol et al., 1966; Garrett \& Nichol, 1969) tendo sido todavia sempre mais difundida em estudos regionais. A análise multivariada de dados geoquímicos de solo aliada ao conhecimento geológico detalhado de depósitos já em produção pode permitir a identificação de associações elementares indicadoras de alteração hidrotermal, mesmo em áreas não mineralizadas em Au.

A presente pesquisa em nível de mestrado acadêmico se insere neste contexto em escala de detalhe, isto é, para fins de exploração em ambientes near-mine. A proposta de estudo surgiu quando a empresa Rio Novo Mineração LTDA (RNM), detentora da maior parte dos requerimentos de pesquisa da região disponibilizou os dados geoquímicos de solo e amostras de sondagem ao autor da presente dissertação, que atuou como geólogo de exploração na empresa nos anos de 2012 e 2013. Durante este período foi adquirido o conhecimento necessário para guiar a presente pesquisa com critérios embasados em um detalhado e vasto acervo de dados relativos às mineralizações e à geologia local. A RNM iniciou as pesquisas nos depósitos do Paiol e Vira Saia no ano de 2010 com intensas campanhas de sondagem e geoquímica de solo e foi forçada a cessar as operações no ano de 2013 antes de entrar em fase de produção devido à crise no setor da mineração que se instaurou no país e no mundo.

Técnicas multivariadas de análise de dados funcionam bem quando o pesquisador que as aplica possui critérios bem definidos para guiar algumas decisões fundamentais para resultados satisfatórios. Por isso adotou-se um método objetivo de trabalho onde o conhecimento geológico 
detalhado adquirido durante a exploração e produção de um depósito serve como critério de validação dos resultados gerados durante a aplicação de análises estatísticas a uma ampla base de dados geoquímicos de solo. Pretende-se verificar a validade do método em determinar novos alvos prioritários para exploração de ouro nas áreas circundantes ao depósito Vira Saia, na região do distrito aurífero de Almas.

\subsection{OBJETIVOS}

Os objetivos do estudo são:

- Definir uma metodologia eficaz de análise dos dados geoquímicos de solo com base em comparações de resultados em áreas conhecidas (denominadas áreas de controle);

- Estabelecer, por meio de técnicas estatísticas multivariadas, as relações de concentração inter-elementares a fim de encontrar grupos de elementos farejadores para diferentes zonas hidrotermais;

- Apontar áreas com potencial prospectivo para futuras campanhas de sondagem;

- Delinear características específicas da mineralização estudada, incluindo aspectos metalogenéticos;

- Identificar conjuntos de elementos característicos para o tipo de depósito estudado e

- Definir meios de tratamento e interpretação do dado geoquímico a fim de direcionar os futuros trabalhos de prospecção na área.

\subsection{LOCALIZAÇÃO E BREVE HISTÓRICO}

A área de estudo está localizada no município de Almas, região sudeste do estado do Tocantins a aproximadamente $285 \mathrm{~km}$ da capital Palmas na direção sudeste (Figura 1.1).

A região de Almas é considerada um distrito aurífero pelas inúmeras ocorrências de mineralizações em ouro em distintos contextos geológicos distribuídos pela região. São conhecidas mineralizações em rochas máficas, ultramáficas, graníticas e sedimentares químicas e clásticas, sempre com forte controle estrutural. Apesar da abundância de ocorrências, os depósitos apresentam baixa tonelagem e apenas os depósitos do Paiol e Vira Saia foram explotados em escala industrial. O ouro na região de Almas é conhecido desde o século XVIII, época da incursão de bandeirantes pela região. A produção de ouro durante muito tempo limitouse a atividades garimpeiras, sem, contudo, apresentar resultados expressivos. 


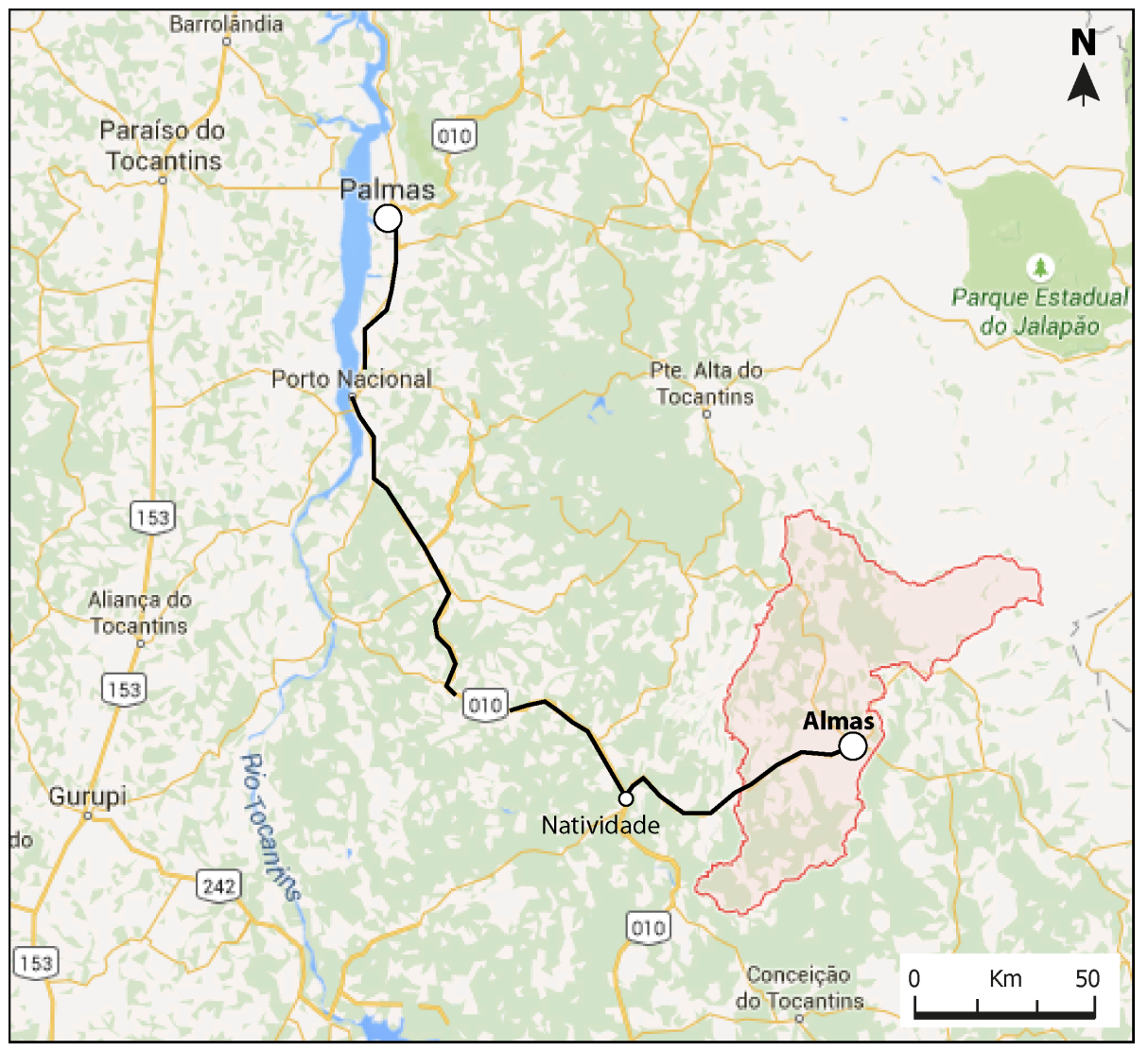

Figura 1.1 - Mapa de localização do distrito de Almas, Tocantins, situada a $285 \mathrm{~km}$ a sudeste de Palmas, capital do estado.

$\mathrm{Na}$ região de Almas as pesquisas geológicas tiveram início somente em 1977, pela Companhia Vale do Rio Doce - CVRD (atual VALE), por meio da da Rio Doce Geologia e Mineração S/A -DOCEGEO, com a implementação do Projeto Pindorama, cujo objetivo era pesquisar metais básicos e ouro, associados aos possíveis greenstone belts na região, que englobava os municípios de Almas, Pindorama de Goiás, Natividade, Conceição do Norte e Dianópolis.

Em 1985 a CVRD celebrou acordo com a Metais de Goiás S.A - METAGO, para que esta última continuasse os trabalhos de pesquisa. Como resultado das campanhas de prospecção decorrentes, a jazida do Paiol foi descoberta em 1987 como depósito de baixo teor médio e alta tonelagem, encaixado em zona de cisalhamento que corta a faixa de greenstone adjacente ao Bloco Ribeirão das Areias, objeto deste estudo. O depósito do Paiol é o maior conhecido até hoje na região e foi descoberto por meio de resultados anômalos em amostras de sedimento de corrente em local onde não havia indício algum de atividade garimpeira. Os trabalhos de pesquisa conduzidos pela METAGO até 1989 avaliaram uma reserva de 800.000 toneladas de minério oxidado com teor de $1,80 \mathrm{~g} / \mathrm{t}$, e reservas de ouro em minério primário da ordem de 5.000 $\mathrm{kg}$. Durante o período sob controle da CVRD foram produzidas neste depósito aproximadamente 86.000 onças de ouro $(2.674 .600 \mathrm{~kg})$ a partir da extração de cerca de 2 milhões de toneladas de 
minério processado pelo método de lixiviação em pilha, com recuperação de apenas $52 \%$ em média (Companhia Vale do Rio Doce, 2005).

Já o depósito Vira Saia (VS) foi descoberto por garimpeiros muito antes da chegada da CVRD e foi usado informalmente pela estatal, a partir de 1994, como gerador de recursos financeiros com o objetivo de custear a fase de implantação da mina do Paiol. Foram produzidas 5.226 onças de ouro no depósito Vira Saia e o mesmo foi abandonado gradualmente após o início da produção no Paiol. Apesar do menor volume de minério, o depósito VS apresenta maior teor médio de Au e ocorrência predominante de ouro livre, de fácil recuperação. Além disso, os controles estruturais do depósito são mais simples e possui grande extensão lateral. 


\section{CAPÍTULO 2}

\section{GEOLOGIA REGIONAL E LOCAL}

\subsection{CONTEXTO REGIONAL}

A área de estudo está inserida no extremo norte da zona externa da Faixa de Dobramentos Brasília (Dardenne, 2000), Província Tocantins, que foi afetada pela Orogênese Brasiliana no Neoproterozoico (Pimentel et al., 1999). Em exposições do embasamento Paleoproterozoico da Faixa Brasília setentrional ocorre o terreno granito-greenstone do Tocantins (Figura 2.1), onde a área estudada se localiza. A região é também conhecida como Terreno Almas-Dianópolis, Almas-Conceição ou Almas-Natividade, dependendo da especificidade de localização indicada pelo autor. No presente estudo, para fins de simplificação é designada doravante de "Terreno Almas".

A região vem sendo estudada desde a década de 1970 por diversos autores nos seus aspectos litológicos, tectônicos e metalogenéticos. Os pioneiros Nilson \& Valle (1973), Costa et al. (1976), Correia Filho \& Sá (1980), Costa (1984), Padilha (1984), Arthaud (1988) descreveram as bases do conhecimento sobre o terreno Almas. Seus estudos de mapeamento geológico e análise estrutural foram o ponto de partida para as seguintes gerações que, à partir da década de 1990 detalharam a evolução tectono-estrutural, metamorfismo, hidrotermalismo e metalogênese (Silva et al., 1990), (Borges, 1993), (Cruz 1993), (Thomsen \& Kuyumjian, 1994a), (Cruz \& Kuyumjian, 1998, 1999), (Cruz, 2001), (Kuyumjian \& Araújo Filho, 2005). Os estudos que se seguiram fizeram uso das tecnologias de análise geoquímica, isotópica, geocronologia, geotermobarometria, sensoriamento remoto e inclusões fluídas com o objetivo de contribuir com dados quantitativos (Cruz et al., 2003), (Ferrari \& Choudhuri, 2004), (Cruz \& Kuyumjian, 2006), (Alvarez, 2007). Uma síntese do conhecimento sobre a região foi publicada por Kuyumjian et al. (2012) na qual nova análise de inclusões fluídas é apresentada com interpretações baseadas em todo o conhecimento adquirido ao longo de três décadas. 


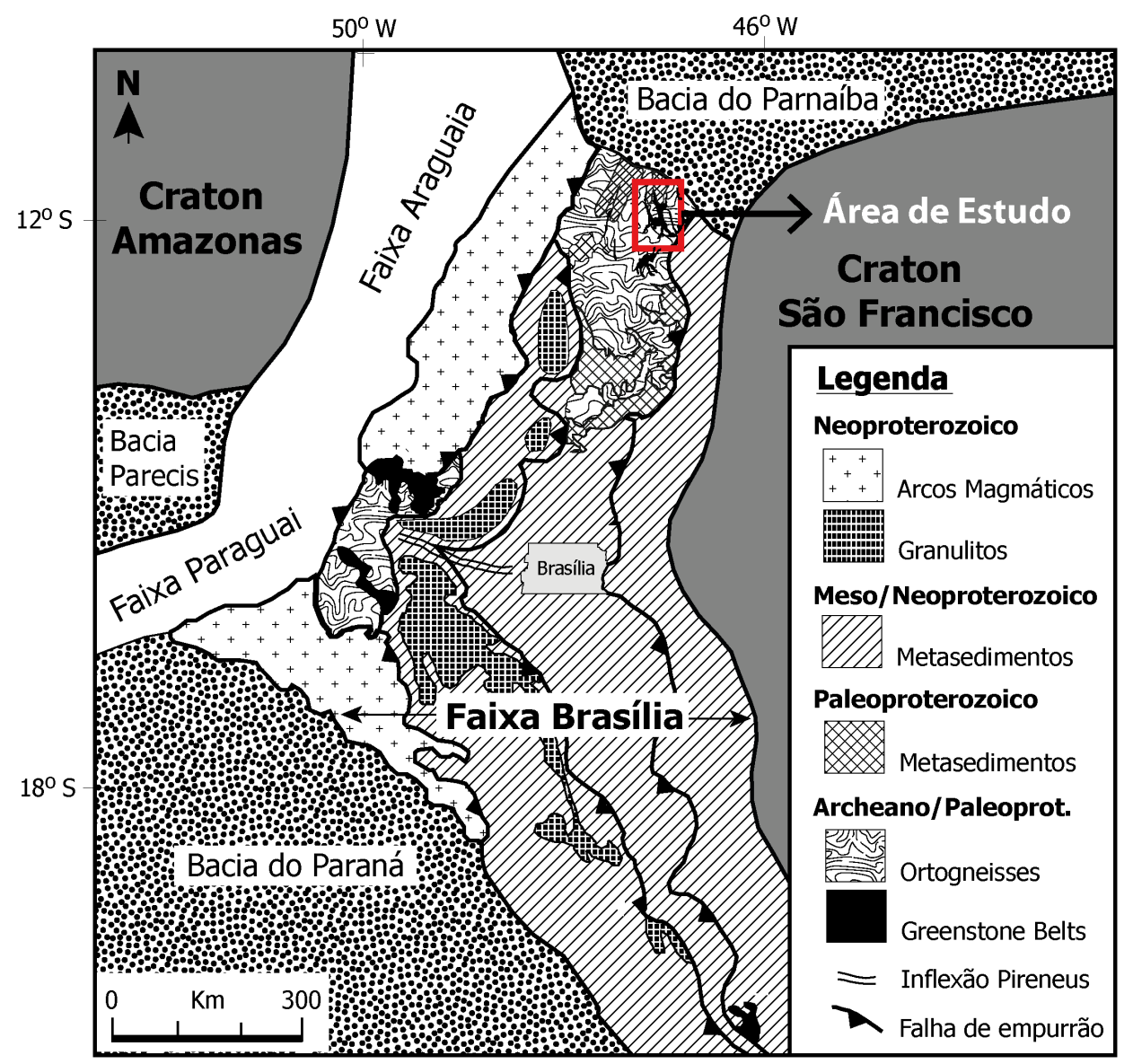

Figura 2.1 - Mapa de localização da área de estudo na Faixa Brasília (modificado de Dardenne, 2000 e D'el-Rey Silva, 2008).

O Terreno Almas compreende faixas de greenstone de espessura variada que envolvem domos elípticos de gnaisses e migmatitos de composição predominantemente tonalítica e localmente granodiorítica e trondhjemítica (domos TTG). A presença de um embasamento anterior aos greenstones é incerta e sem fundamentação sólida na literatura, sendo o complexo gnáissico-migmatítico um possível candidato a embasamento (Borges et al., 1991, Borges, 1993). Os greenstone belts formam o Grupo Riachão do Ouro definido por Costa (1984), constituído por uma unidade basal meta-vulcânica e unidade de topo predominantemente metasedimentar, conforme proposto por Cruz \& Kuyumjian (1998), respectivamente a Formação Córrego do Paiol (raras rochas meta-ultrabásicas, abundantes meta-basaltos e meta-dacitos subordinados), e Formação Morro do Carneiro (filitos sericíticos predominantes, localmente carbonosos com intercalações de rochas meta-vulcânicas félsicas, intermediárias e máficas, quartzitos, meta-conglomerados e formação ferrífera bandada). Em trabalho de análise geoquímica de rocha total, Cruz \& Kuyumjian, (1998) concluem que os domos TTG apresentam filiação cálcio-alcalina de baixo $\mathrm{K}$ e os dividem em duas suítes. A Suíte 1, de baixo $\mathrm{Al}_{2} \mathrm{O}_{3}$ (anfibólio granodiorito metaluminoso) e a Suíte 2 de alto $\mathrm{Al}_{2} \mathrm{O}_{3}$ (biotita tonalito peraluminoso). O Bloco Ribeirão das Areias (Figura 2.2), um dos domos que ocorrem na área e objeto do 
presente estudo, foi inicialmente classificado como pertencente à Suíte 2 (Cruz \& Kuyumjian, 1999), mas posteriormente diferenciado de ambas as suítes (Cruz, 2001) por ter obtido idade U$\mathrm{Pb}$ mais antiga. Em Cruz et al. (2003) as rochas do Bloco Ribeirão das Areias foram descritas como biotita tonalitos sem menção de anfibólios, todavia, todas as amostras de sondagem de meta-tonalitos do Bloco Ribeirão das Areias analisadas por microscopia ótica e microssonda eletrônica no presente estudo contêm até $15 \%$ de anfibólios e menos de $2 \%$ de biotita, enquadrando-se portanto na descrição da Suíte 1.

Além da associação greenstone/TTG, ocorrem na área de estudo corpos intrusivos tardios de rochas ácidas a intermediárias e básico-ultrabásicas de escala quilométrica. As rochas Paleoproterozoicas do embasamento encontram-se recobertas pelos grupos Natividade, do Paleo/Mesoproterozoico, Bambuí, do Neoproterozoico e Urucuia, do Eocretáceo (Figura 2.2).

Uma coluna estratigráfica com a representação da geologia da área não foi confeccionada devido aos seguintes fatos:

- Até o presente não se conhece a posição cronoestratigráfica precisa do complexo gnáissico-migmatítico, se este constitui o embasamento regional ou se intrude as rochas do greenstone belt;

- Ainda não se conhece de forma assertiva se o complexo granito-gnáissico intrude a porção de topo do greenstone belt ou apenas sua seção basal;

- Ainda se desconhece se existe uma discordância entre as Formações Córrego do Paiol e Morro do Carneiro, respectivamente sequências basal e de topo do greenstone belt;

- Não existem dados confiáveis sobre a espessura das distintas unidades de rochas supracrustais.

Assim, a construção de uma coluna estratigráfica ainda carece de maior volume de dados confiáveis. De qualquer modo a legenda do mapa geológico (Figura 2.2) traz a visão geral do empilhamento inferido para a região. 


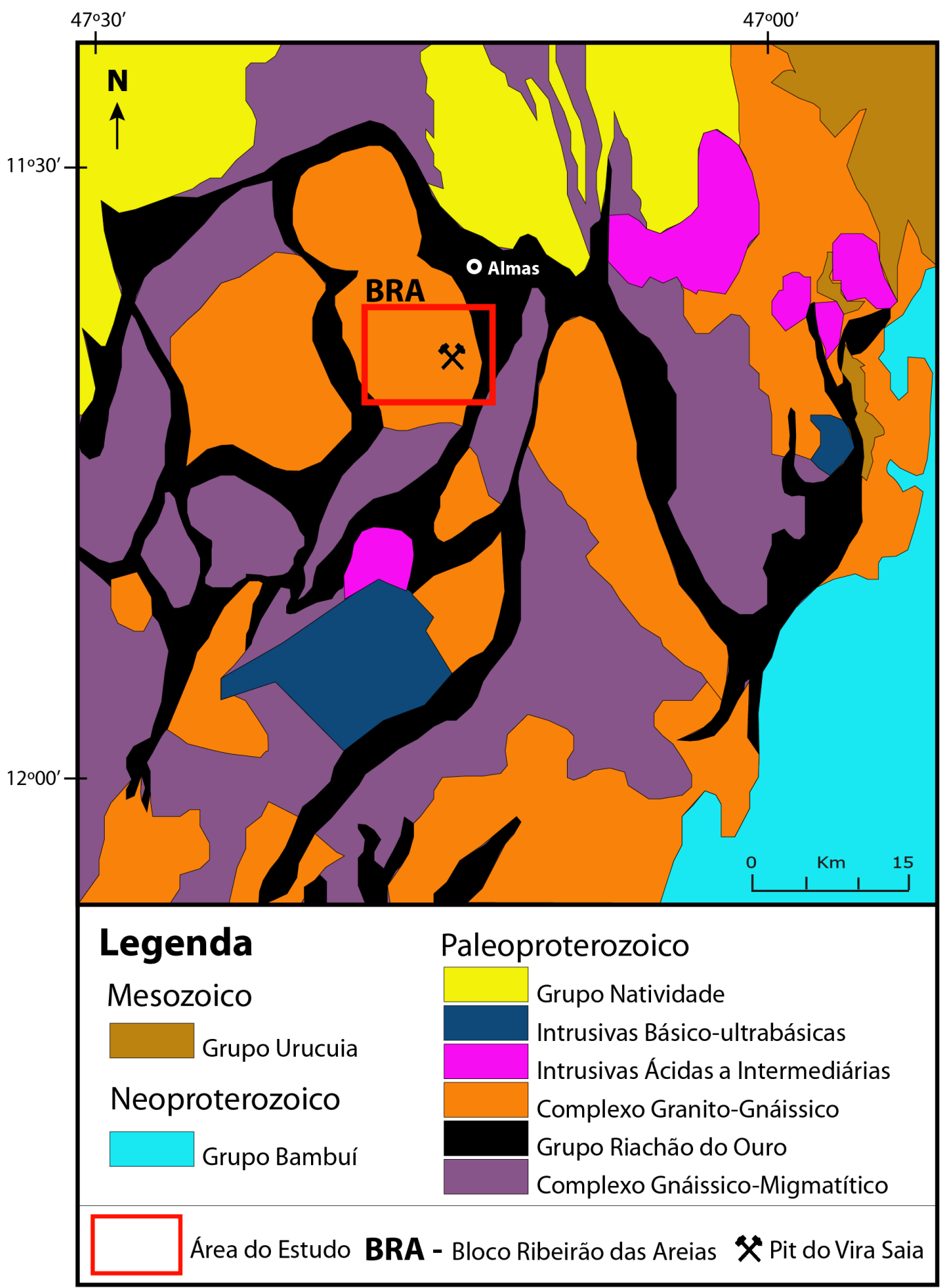

Figura 2.2 - Mapa de localização da área de estudo no terreno Almas (atualizado de Bruni et al., 1974).

\subsubsection{CRONOESTRATIGRAFIA}

Os estudos geocronológicos realizados no terreno Almas são relativamente escassos, considerando-se a grande importância da região para a compreensão dos processos geológicos que dominaram o planeta na transição entre o Arqueano e o Paleoproterozoico. A Formação Córrego do Paiol possui apenas idade Sm-Nd de 2.58 Ga (Cruz \& Kuyumjian, 2006) indicando fonte Arqueana para os diques de riodacito analisados e permanecendo ainda com idade de 
cristalização incerta. A Formação Morro do Carneiro possui idade U-Pb em zircão de $2.2 \mathrm{Ga}$ (Dardenne et al., 2009) realizada em amostra de metavulcânica intermediária coletada em superfície. Os domos TTG possuem idades Sm-Nd entre 2,53 e 2,50 Ga (Cruz \& Kuyumjian, 1999) e idades U-Pb SHRIMP de 2,2 Ga para as suítes 1 e 2 e 2,45 Ga para o Bloco Ribeirão das Areias (Cruz, 2001), indicando fontes neoarqueanas e idades de cristalização com intervalo aproximado de $250 \mathrm{Ma}$ entre os domos TTG (suítes 1 e 2) e o Bloco Ribeirão das Areias, mais antigo. Segundo Cruz et al., (2001), idades $\mathrm{Ar}^{40}-\mathrm{Ar}^{39}$ em clorita e muscovita hidrotermais da mina do Paiol posicionam o hidrotermalismo responsável pela mineralização em Au em 563 +/$15 \mathrm{Ma}$, durante evento descompressivo em fase de resfriamento ao final da orogênese brasiliana.

Segundo Cruz \& Kuyumjian (1999), os corpos tonalíticos da Suíte 2 contêm xenólitos da Suíte 1 e ambos contêm xenólitos máficos pertencentes ao greenstone próximo às zonas de contato. No presente estudo foi detectado por análise geoquímica e confirmado em campo que o Bloco Ribeirão das Areias também contém xenólitos máficos do greenstone. Pelas idades obtidas e as relações de campo mapeadas pode-se afirmar que a Suíte 1 é anterior à Suíte 2 e ambas são crono-correlatas à Formação Morro do Carneiro, possivelmente fonte das rochas vulcânicas intercaladas nesta formação. É possível inferir ainda que haja um lapso temporal significativo entre a Formação Morro do Carneiro e a Formação Córrego do Paiol, já que no tempo de cristalização do Bloco Ribeirão das Areias $(2,45 \mathrm{Ga})$ as vulcânicas máficas dos greenstones já existiam para ceder xenólitos e a Formação Morro do Carneiro levaria ainda 250 Ma para ser gerada.

\subsubsection{GEOLOGIA ESTRUTURAL}

O Terreno Almas possui geometria similar à de domos e quilhas, com domos TTG elipsoidais circundados por faixas de greenstone formando contatos curvos. Esses contatos são frequentemente obliterados por zonas de cisalhamento direcionais (Cruz \& Kuyumjian, 1999). Borges et al. (1991) e Borges (1993) procuraram relacionar essas estruturas a um único evento tectônico, mas conforme previamente observado por Gorayeb et al. (1988), algumas dessas zonas de cisalhamento cortam coberturas mais jovens, enquanto outras são restritas ao embasamento. Os trabalhos pioneiros na região realizados por Arthaud (1985) evidenciam duas fases de deformação, uma primeira fase contracional dúctil de cisalhamento simples prébrasiliana e outra também de caráter contracional, mas de cisalhamento puro e idade brasiliana. Os estudos que se seguiram identificaram ainda uma terceira fase de deformação tardia, em regime distensivo caracterizado como exclusivamente rúptil por Ferrari \& Choudhuri (2000) e dúctil-rúptil por Kuyumjian \& Araújo Filho (2005), conhecida em ambos os trabalhos por afetar as estruturas que hospedam as mineralizações seja com fraturas ou boudinagem. 
Segundo Ferrari \& Choudhuri (2004), a primeira fase deformacional $D_{n}$ ou $D_{1}$ possui caráter dúctil e gera foliação caracterizada pela orientação preferencial de anfibólios, piroxênios e plagioclásios com atitude $040^{\circ}-060^{\circ} / 50^{\circ}-70^{\circ}$, e estão contidas em zonas de cisalhamento oblíquas de médio a alto ângulo. No plano da foliação Sn ocorre lineação de estiramento Ln horizontal a oblíqua de baixo ângulo. $\mathrm{O}$ evento $\mathrm{D}_{\mathrm{n}+1}$ ou $\mathrm{D}_{2}$ é praticamente coaxial ao evento anterior e por isso oblitera com frequência a foliação $S_{n}$. Caracteriza-se por um evento em regime dúctil-rúptil que gera zonas de cisalhamento transcorrentes de direções preferenciais $\mathrm{N} 20^{\circ}-40^{\circ} \mathrm{E}$ e subsidiárias $\mathrm{N}-10^{\circ} \mathrm{E}$ e $\mathrm{N} 10^{\circ}-30^{\circ} \mathrm{W}$ com $\mathrm{L}_{\mathrm{n}}$ sub-horizontal e foliação milonítica marcante. $\mathrm{D}_{\mathrm{n}+1}$ é identificado como o evento mais fortemente associado à mineralização aurífera na região (Kuyumjian \& Araújo Filho, 2005; Ferrari \& Choudhuri, 2004). O último evento, $\mathrm{D}_{\mathrm{n}+2}$ ou $\mathrm{D}_{3}$ gera enxames de veios de quartzo rúpteis, localmente penteados, estéreis e truncados por juntas (Kuyumjian et al., 2012) e falhas de escala métrica em cujos planos ocorrem slickensides com trend para NE ou NNE e mergulhos de $80^{\circ}$ (Ferrari \& Choudhuri, 2004).

\subsubsection{METAMORFISMO}

As paragêneses minerais encontradas no terreno Almas evidenciam dois eventos metamórficos principais. $\mathrm{O}$ mais antigo $\left(\mathrm{M} 1\right.$ ou $\left.\mathrm{D}_{\mathrm{n}}\right)$ atingiu fácies anfibolito e sua amplitude é considerada restrita aos greenstones para Cruz \& Kuyumjian (1998) e considerada de escala regional para Ferrari \& Choudhuri (2000), sendo identificado pela paragênese anfibólio + andesina \pm clorita \pm epidoto. $\mathrm{O}$ evento que se seguiu $\left(\mathrm{M} 2\right.$ ou $\left.\mathrm{D}_{\mathrm{n}+1}\right)$ foi responsável pelo retrometamorfismo em fácies xisto verde em escala regional, mas preservou zonas de fácies anfibolito do evento anterior e é caracterizado pela imposição da paragênese anfibólio + albita + epidoto \pm muscovita \pm clorita (Cruz \& Kuyumjian, 1998). A progressão de $D_{n+1}$ gerou zonas de cisalhamento dúcteis nas faixas máficas e a continuação tardia deste evento, descrito como $\mathrm{D}_{\mathrm{n}+2}$, gerou zonas de cisalhamento dúcteis-rúpteis especialmente nos domos TTG, dado o contraste reológico dessas rochas.

Os eventos que geraram zonas de cisalhamento são identificados por Cruz \& Kuyumjian (1998) e Ferrari \& Choudhuri (2000) como os responsáveis pela alteração hidrotermal mineralizante na região, já que os corpos mineralizados encontram-se encaixados nessas zonas. Todavia as possibilidades de aproveitamento das zonas de cisalhamento por eventos mineralizantes posteriores e retrabalhamento de mineralizações para gerar corpos secundários ou processos de concentração não são ainda bem exploradas na literatura, e, portanto, carecem de estudos sistemáticos com foco no tema.

Dados isotópicos de enxofre em sulfetos do depósito do Paiol indicaram fonte magmática para o enxofre (Ferrari \& Choudhuri, 2004). Entretanto, resultados mais amplos obtidos em Cruz 
(2001) não permitiram a interpretação de uma fonte específica, o que pode indicar a possibilidade de fontes mistas, magmáticas e metamórficas, para os fluídos hidrotermais mineralizantes ou até mais de uma fase de fluídos. Estudos de inclusões fluídas no depósito do Paiol (Ferrari \& Choudhuri, 2004; Kuyumjian et al., 2012) concluem que a fonte principal dos fluídos mineralizantes foi o processo de devolatilização metamórfica ocorrido em $\mathrm{D}_{\mathrm{n}+1}$ ou $\mathrm{M}_{2}$ que gerou fluídos aquo-carbônicos responsáveis pela expressiva alteração de carbonatação das rochas estudadas (Kuyumjian et al., 2012). Contudo, fluídos tardios de baixa temperatura de fontes provavelmente mantélicas foram detectados em algumas inclusões e podem ter sido responsáveis pela remobilização ou reconcentração da mineralização (Ferrari \& Choudhuri, 2004). Kuyumjian et al. (2012), concluem que tais fluídos secundários foram submetidos a intensa homogeneização com a rocha encaixante, o que provavelmente acarretou na mobilização de elementos.

\subsubsection{AMBIENTES GEOTECTÔNICOS}

A interpretação de dados litogeoquímicos de diversos estudos no terreno Almas permitem a indicação de possíveis ambientes geotectônicos para a geração das rochas mapeadas na região. Os meta-basaltos da Formação Córrego do Paiol podem apresentar afinidades tanto com ambientes de rifte continental (Ferrari \& Choudhuri, 2000) quanto arcos de ilha (Silva et al., 1990) e foram divididos em dois grupos principais, um primeiro grupo de alto ferro e alto titânio e um segundo grupo de alto magnésio e baixo titânio (Cruz, 1993 e Cruz \& Kuyumjian, 1996). O primeiro grupo foi interpretado como basaltos toleíticos formados em ambiente de subducção, equivalentes aos estudados por Silva et al. (1990) e o segundo grupo de basaltos, localmente almofadados, interpretado como pertencente a ambientes de rifte ou retroarco continental, equivalentes aos estudados por Ferrari \& Choudhuri (2000).

De acordo com os estudos de Thomsen \& Kuyumjian (1994b), Cruz e Kuyumjian (1998) e Cruz et al. (2003), os domos TTG metaluminosos da Suíte 1 podem ser interpretados como possíveis produtos de fusão parcial do manto e os peraluminosos da Suíte 2 como produto de fusão parcial de meta-basaltos em ambiente de subducção oceânica. Os metagabros tardios que intrudem os domos TTG possuem composição semelhante ao magmatismo básico típico de ambientes de colisão continental (Cruz, 1993).

\subsubsection{GEOLOGIA DA ÁREA DE ESTUDO}

A área de estudo abrange, em sua maior extensão, os meta-tonalitos do Bloco Ribeirão das Areias (Figura 2.3), além de uma pequena porção da faixa de greenstone adjacente ao bloco, formada pela Formação Córrego do Paiol, que hospeda o homônimo depósito do Paiol. O Bloco 
Ribeirão das Areias ocupa uma área de aproximadamente $180 \mathrm{~km}^{2}$ sendo delimitado por faixas de rochas máficas e ultramáficas do greenstone belt de Almas. O bloco é constituído predominantemente por meta-tonalitos que podem ser localmente caracterizados como metatrondhjemitos ou meta-granodioritos devido à variação na proporção dos minerais constituintes. As variações de fácies internas ao Bloco Ribeirão das Areias não apresentam relações de contato ou corte, mas obedecem a relações estruturais e morfológicas do corpo intrusivo.

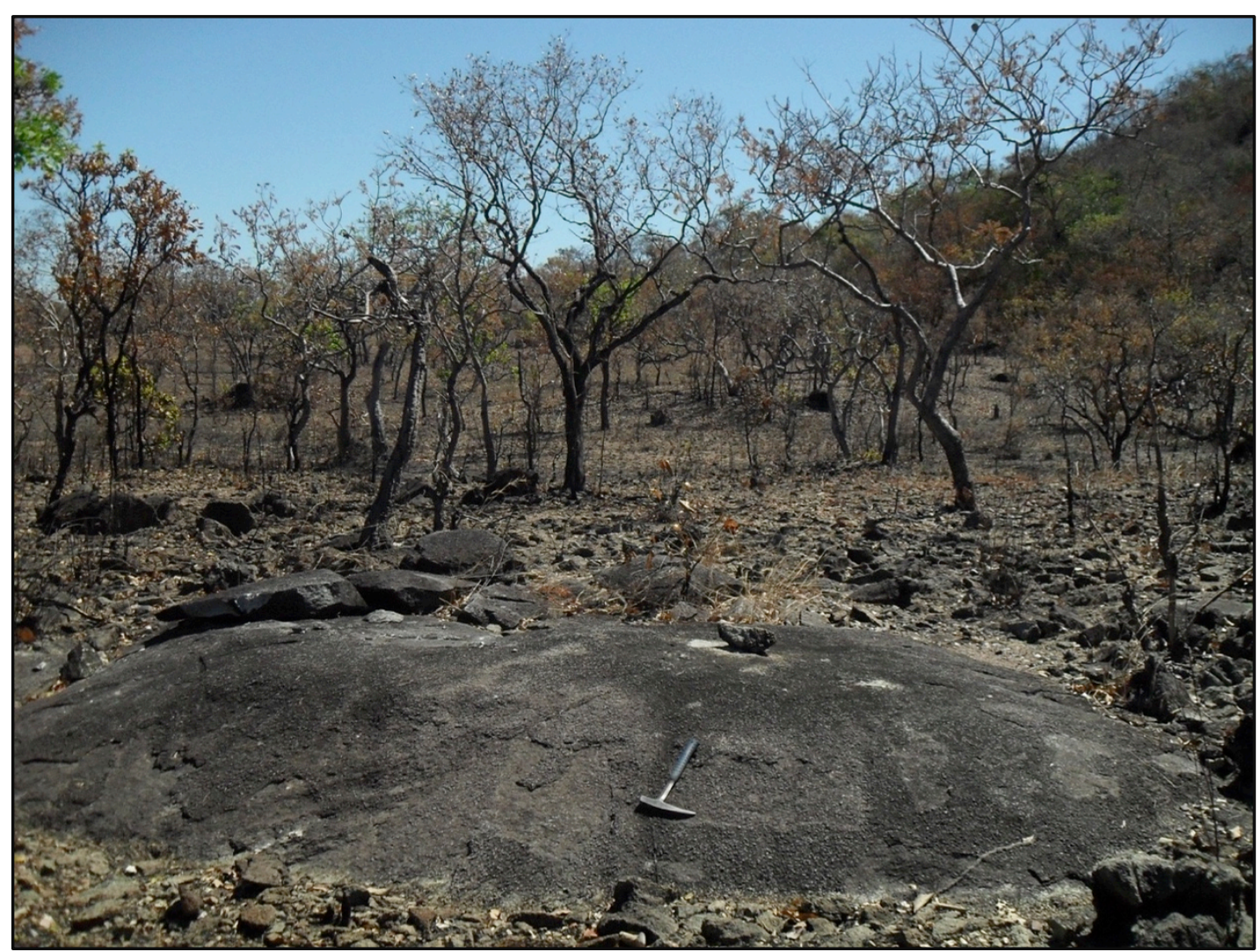

Figura 2.3 - Aspecto típico de afloramento dos meta-tonalitos do Bloco Ribeirão das Areias.

Os mapeamentos geológicos realizados durante os trabalhos de pesquisa mineral da Rio Novo Mineração revelaram que as variações composicionais podem ocorrer tanto perpendicularmente às zonas de cisalhamento NW, responsáveis pelo hidrotermalismo mineralizante (devido aos processos de albitização, silicificação, potassificação e carbonatação), como também do núcleo para as bordas do corpo (devido à evolução da câmara magmática), sendo que de maneira geral observam-se fácies mais ricas em elementos incompatíveis próximo às bordas do corpo. As dimensões e a falta de relações de contato ou corte que o separem em diferentes corpos permitem caracterizar o Bloco Ribeirão das Areias como um batólito com variações composicionais tanto ígneas, contemporâneas à evolução de cristalização da câmara magmática, quanto hidrotermais, geradas pela percolação de fluídos durante a deformação dúctil-rúptil sofrida posteriormente. 
A mineralização em ouro no depósito Vira Saia ocorre controlada por um sistema de zonas de cisalhamento de caráter dúctil-rúptil predominantemente sinistral com atitude modal de $230^{\circ} / 70^{\circ}$ (dip angle). Os protomilonitos ocorrem encapsulando os milonitos e ultramilonitos, que possuem forma tabular ou (mais frequentemente) lenticular (Figura 2.4). O formato lenticular dos corpos ocorre tanto verticalmente quanto horizontalmente e é interpretado como produto da cinemática de cisalhamento simples que os gerou. De maneira geral a intensidade da milonitização é diretamente proporcional ao teor médio de Au. Os protomilonitos que ocorrem nas porções mais distais da alteração hidrotermal são geralmente estéreis, mas dados de análise geoquímica de rocha total em centenas de amostras de sondagem revelam que podem apresentar teores máximos de até 15g/t@ $\mathrm{Au}$ e médios de 0,7g/t@, Au, sendo que os milonitos possuem teor máximo de 23g/t@Au e médio de 1,6g/t@Au e os ultramilonitos apresentam teor máximo de 57g/t@Au e médio de 2,3g/t@Au, excluídas amostras consideradas influenciadas por efeito pepita.

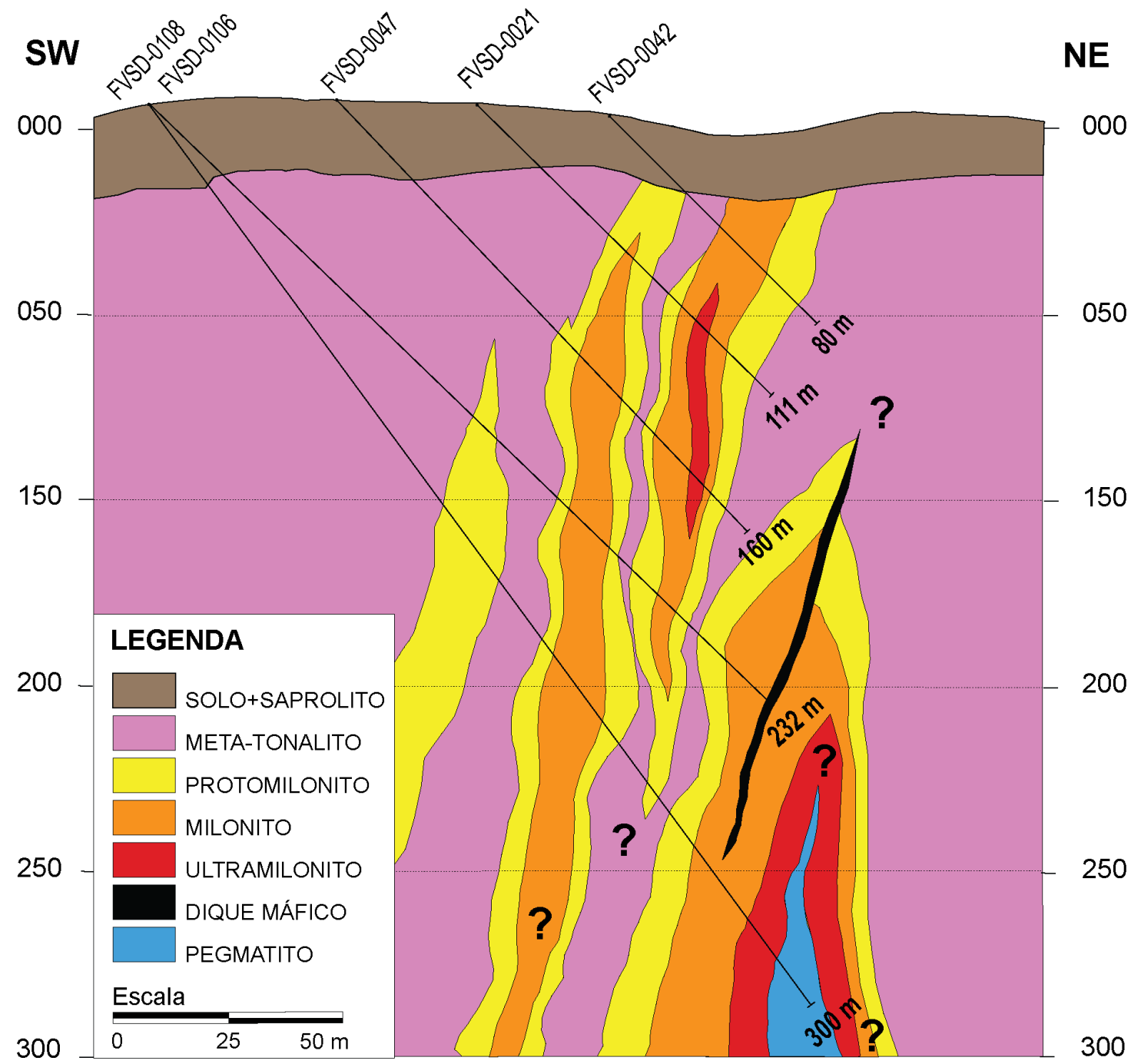

Figura 2.4 - Seção esquemática do depósito Vira Saia interpretada com base em dados de sondagem. 
O grau de milonitização foi classificado de acordo com a penetratividade da foliação milonítica bem como pelo grau de preservação da textura e composição meta-ígnea prémilonitização (Figura 2.5). A rocha encaixante da mineralização, classificada como metatonalito, apresenta textura meta-ígnea preservada. Microscopicamente observam-se cristais euédricos de plagioclásio andesina, quartzo intersticial, actinolita euédrica geminada, apatita, biotita, titanita, alanita, calcita e zircão, em certas regiões podem ocorrer cristais intersticiais de microclínio (meta-granodioritos). Os protomilonitos apresentam mineralogia próxima à dos meta-tonalitos exceto pela albitização dos feldspatos, geralmente oligoclásio (trondhjemitos), e pelo aparecimento de clorita e epidoto, além de indícios de sulfetação (pirita e galena) e ocorrência localizada de ouro e calcita. Ocorrem lamelas de muscovita orientadas que localmente marcam planos de foliação pouco penetrativos envolvendo feldspatos levemente estirados e pouco rotacionados. Os milonitos contêm muscovita e quartzo em abundância e ocasionais cristais de plagioclásio (albita pura) bastante rotacionados, podem ocorrer cristais reliquiares de actinolita, apatita e muito raramente cristais anédricos de calcita, além de pirita, galena e ouro. A foliação milonítica é bem pronunciada e a quantidade de sílica é bastante inferior à dos ultramilonitos. Os ultramilonitos são constituídos essencialmente por muscovita "verde limão" e quartzo com foliação muito bem marcada ao longo da qual ocorrem cristais euédricos de pirita e ocasionalmente galena. 


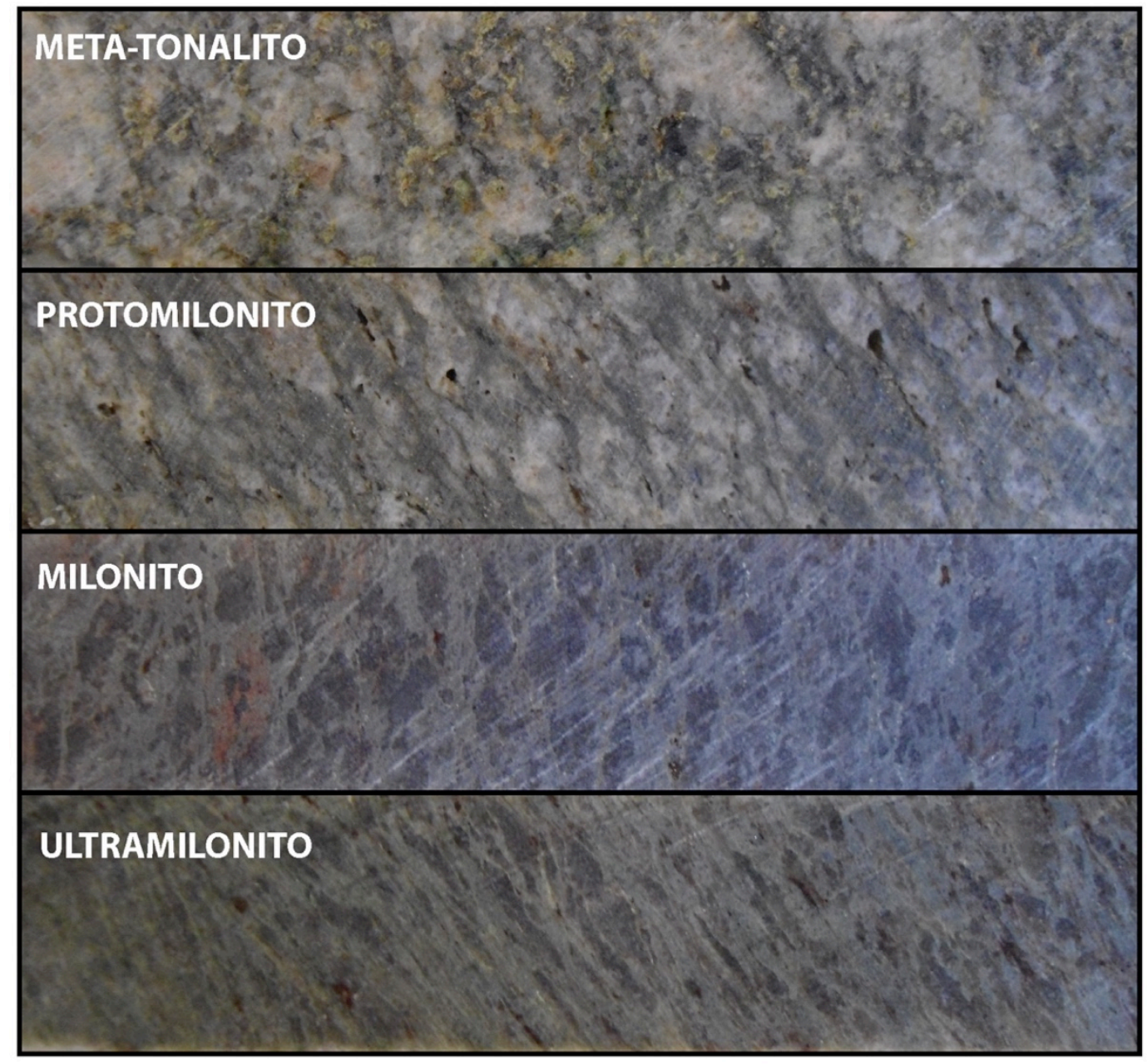

Figura 2.5 - Fotos macroscópicas dos testemunhos de sondagem representativas dos diferentes graus de milonitização das rochas do depósito Vira Saia.

O ouro nos ultramilonitos ocorre associado ao quartzo e ocasionalmente aos sulfetos. Ocorre em flocos micrométricos livres disseminados, mas também ocasionalmente bordejando cristais de piritas oxidadas. Em microscópio ótico o quartzo ocorre em forma de matriz muito fina formando "olhos" de quartzo microcristalino envoltos por lamelas orientadas de muscovita que definem com muita nitidez o par S-C da foliação milonítica (Figura 2.6). Os dados de sondagem do depósito Vira Saia permitem medir as dimensões do corpo mineralizado de acordo com o seu grau de milonitização. Cada fase milonítica mede em média 3,5 m, podendo variar entre $15 \mathrm{~m}$ e $0,5 \mathrm{~m}$, de forma que toda a sequência típica - protomilonito-milonito-ultramilonitomilonito-protomilonito tem em média $17,5 \mathrm{~m}$ de espessura e pode chegar a mais de $50 \mathrm{~m}$ nas regiões mais espessas do corpo sondado. 


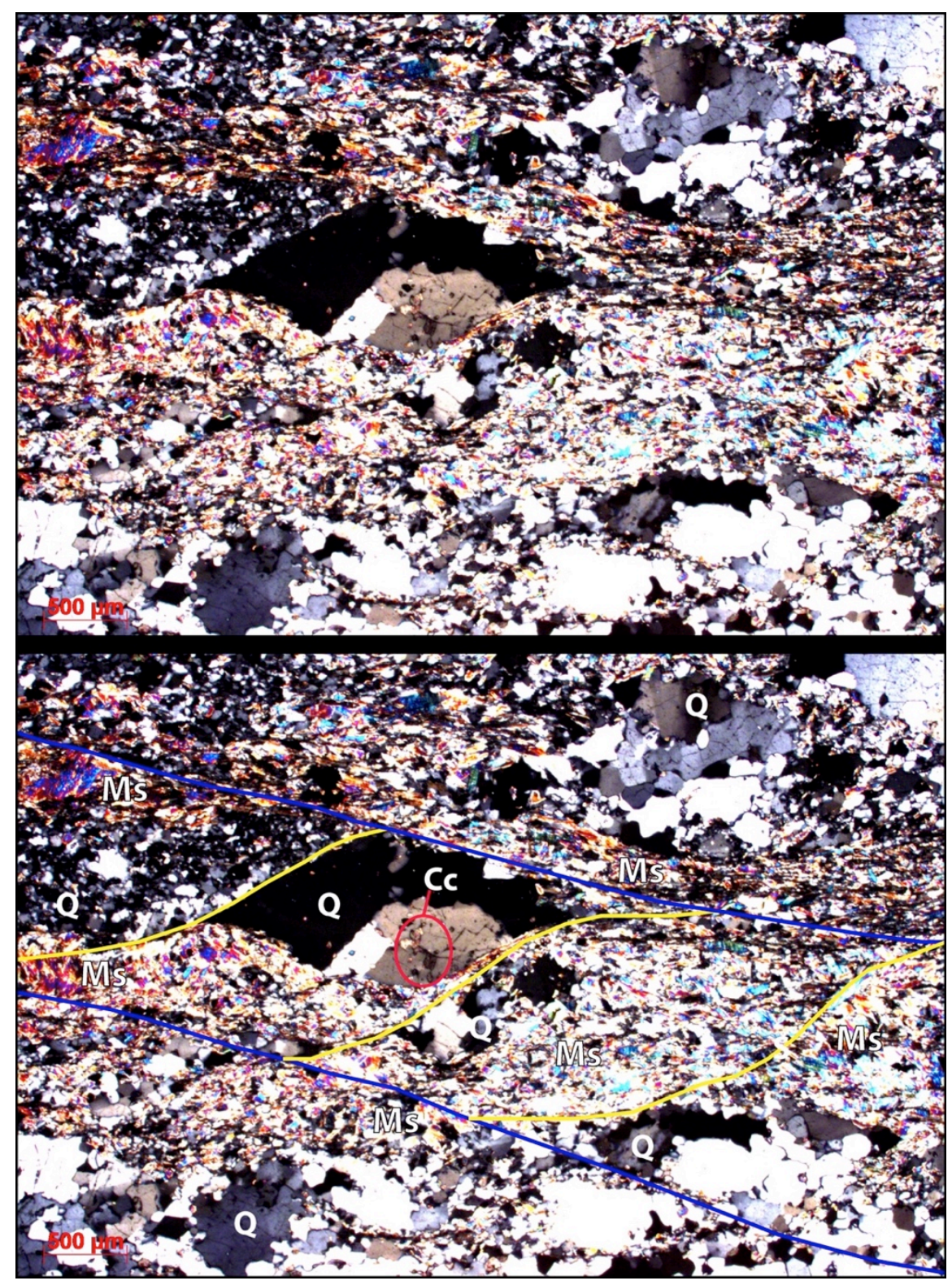

Figura 2.6 - Fotomicrografia com nicois cruzados de lâmina delgada de amostra de ultramilonito coletado em furo de sondagem do depósito Vira Saia evidenciando par S-C de foliação milonítica. Foliação $\mathrm{C}$ em traço azul e $\mathrm{S}$ em traço amarelo. Ms=muscovita, $\mathrm{Q}=$ quartzo, $\mathrm{Cc}=$ calcita.

Os solos que recobrem a região do depósito Vira Saia (Figura 2.7) são do tipo neossolo litólico [Lithic Entisol (Soil Survey Staff, 1999)], de caráter eluvionar, originados por meio da ação do intemperismo químico in situ ou com mínimo transporte, preservando as características geoquímicas gerais das rochas parentais subjacentes. Tais características foram de grande importância para o sucesso na obtenção de resultados satisfatórios para a localização de corpos de rocha hidrotermalizada. A eventual aplicação do método de pesquisa aqui apresentado em locais onde ocorrem solos coluvionares deve também considerar os vetores de transporte e contaminação físicos e químicos desses solos. 


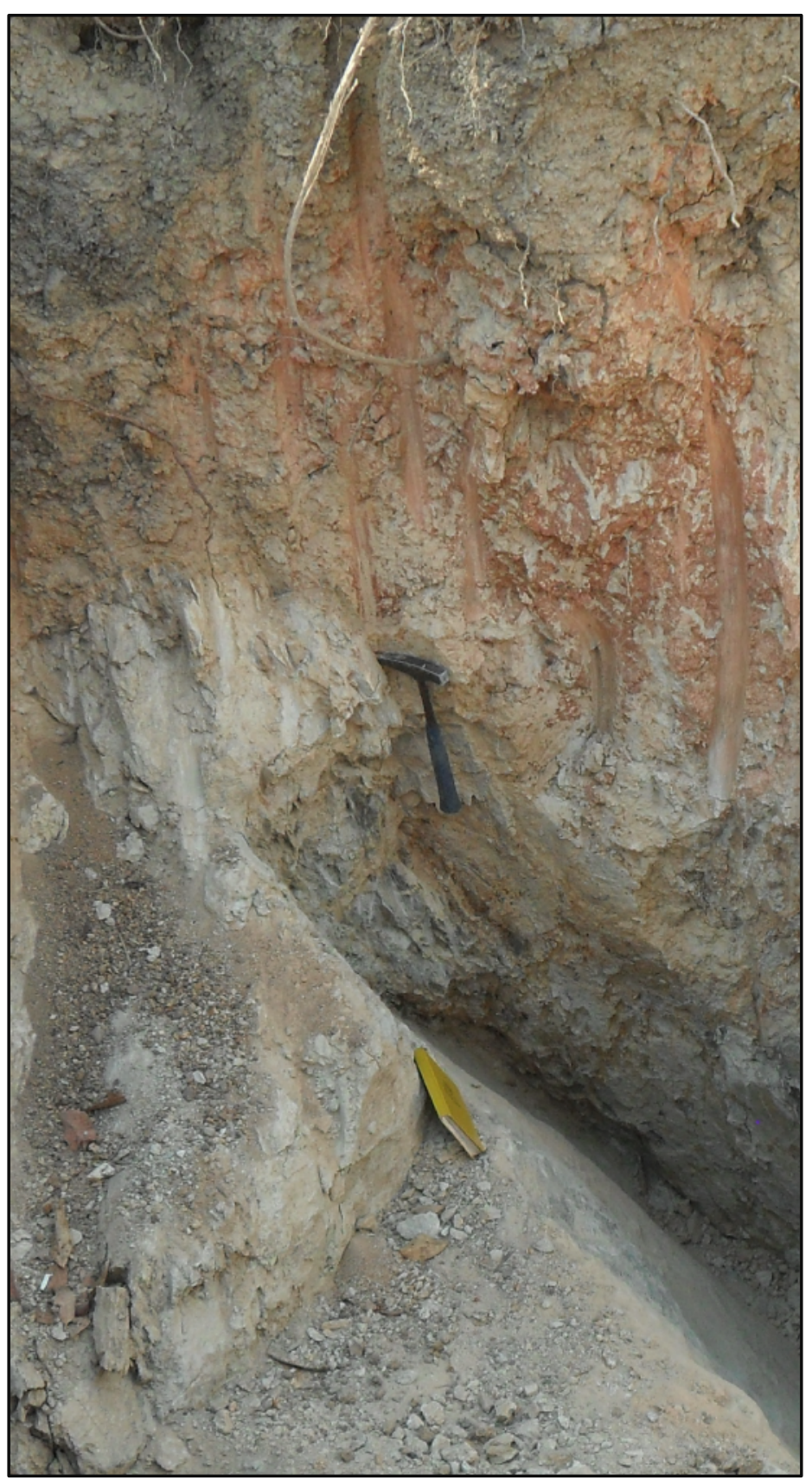

Figura 2.7 - Perfil típico dos neosolos que recobrem as rochas do Bloco Ribeirão das Areias. 


\section{CAPÍTULO 3}

\section{MATERIAIS E MÉTODOS}

\subsection{DADOS GEOQUÍMICOS}

Os dados disponibilizados somam 2.908 análises geoquímicas de solo da região que circunda o depósito Vira Saia, bem como trechos estratégicos de amostras de sondagem que tipificam os diferentes padrões de mineralização presentes no depósito. Os dados de solo são provenientes de análises por ICP-MS de 35 elementos, e de Au por metallic screen em amostras com resultados de ICP-MS superiores a $10 \mathrm{ppm} / \mathrm{Au}$. Todas as análises foram realizadas nos laboratórios SGS Geosol com padrões certificados pelo Instituto de Tecnologia August Kekulé (ITAK). A abertura das amostras foi realizada por digestão com água régia e os elementos analisados foram: $\mathrm{Au}, \mathrm{Ag}, \mathrm{Al}, \mathrm{As}, \mathrm{Ba}, \mathrm{Be}, \mathrm{Bi}, \mathrm{Ca}, \mathrm{Cd}, \mathrm{Co}, \mathrm{Cr}, \mathrm{Cu}, \mathrm{Fe}, \mathrm{Hg}, \mathrm{K}, \mathrm{La}, \mathrm{Li}, \mathrm{Mg}, \mathrm{Mn}$, Mo, Na, Ni, P, Pb, S, Sb, Sc, Sn, Sr, Ti, V, W, Y, Zn e Zr.

A malha de solo cobre uma área de $88 \mathrm{~km}^{2}(11 \mathrm{~km}$ x $8 \mathrm{~km})$ e conta com 52 linhas de coleta com espaçamento variável entre linhas de 100 a $400 \mathrm{~m}$ e espaçamento constante entre amostras de $50 \mathrm{~m}$ (Figura 3.1A). Os dados de solo foram integrados aos dados geológicos, tendo em vista o possível transporte localizado dos solos, movimentação dos elementos imóveis e atitudes das foliações, de forma que possíveis rebatimentos dos solos sobre a eventual zona mineralizada foram corrigidos em função destes parâmetros.

Dentro da área de estudo está localizada a área de controle (Figura 3.1B), que compreende área de $6 \mathrm{~km}^{2}$ ao redor da mina abandonada do Vira Saia. A área possui 190 furos de sondagem diamantada e é recoberta por 501 amostras do total de 2.908 amostras de solo que compreendem a malha de solo realizada em toda a área de estudo. $\mathrm{Na}$ área de controle ocorre a pilha de estéril gerada pela Vale durante a fase de produção da mina do Vira Saia. A pilha de estéril é composta basicamente por fragmentos de meta-tonalitos e protomilonitos, estes últimos são mais abundantes na pilha pois representam a alteração distal e consequentemente envelopam o minério. 


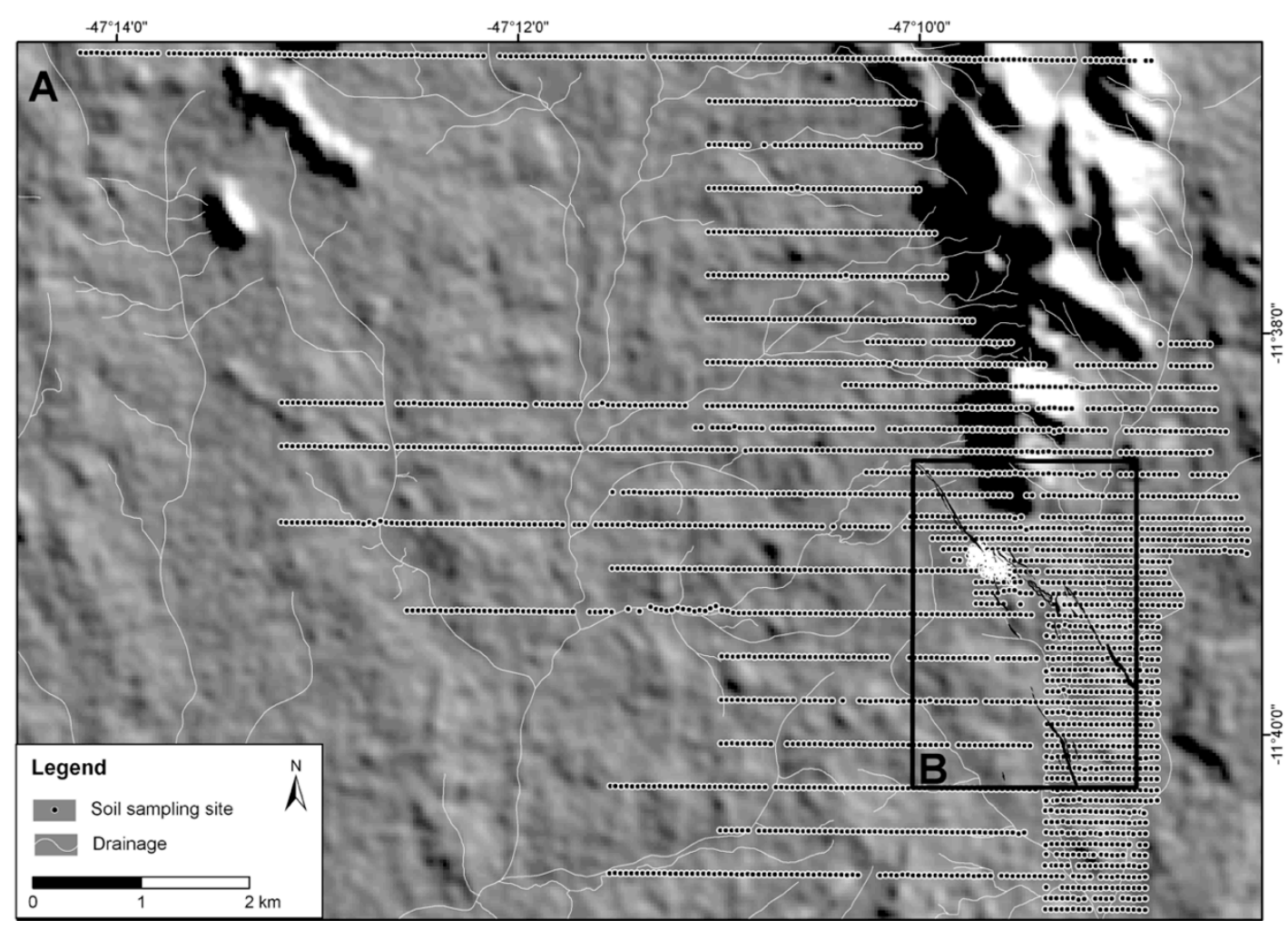

Figura 3.1 - A) Mapa da área de estudo e malha de solo. B) Área de controle com projeção em superfície do minério sondado (em preto) e pilha de estéril (em branco).

\subsection{MICROSSONDA ELETRÔNICA}

As análises por microssonda eletrônica foram realizadas no laboratório da Universidade de Brasília com equipamento da marca JEOL, modelo JXA-8230, operando com 5 espectrômetros.

Foram analisados sulfetos com voltagem de aceleração de $20 \mathrm{kV}$ e corrente de $2^{-8} \mathrm{~A}$ e silicatos com $15 \mathrm{kV} \mathrm{e} 1^{-8} \mathrm{~A}$ com tempo de contagem de 5 segundos para ambos. O padrão utilizado para calibragem da análise dos sulfetos compreende os elementos As, Zn, Ga, Se, S, $\mathrm{Pb}, \mathrm{Bi}, \mathrm{Te}, \mathrm{Cd}, \mathrm{Fe}, \mathrm{Co}, \mathrm{Cu}, \mathrm{Sb}, \mathrm{Hg}, \mathrm{Mo}, \mathrm{Au}, \mathrm{Ag}, \mathrm{In}, \mathrm{Pd}$ e para silicatos inclui os elementos $\mathrm{Na}$, $\mathrm{Mg}, \mathrm{F}, \mathrm{Al}, \mathrm{Si}, \mathrm{K}, \mathrm{Cl}, \mathrm{Ca}, \mathrm{Ti}, \mathrm{Mn}, \mathrm{Sr}, \mathrm{P}, \mathrm{Cr}, \mathrm{Zn}, \mathrm{Fe}, \mathrm{V}, \mathrm{Ba}, \mathrm{Ni}$.

As amostras analisadas foram selecionadas de rocha fresca proveniente de testemunhos de sondagem exploratória do depósito Vira Saia. As amostras constituem ultramilonitos e protomilonitos montados em lâminas delgadas polidas com espessura aproximada de $30 \mu \mathrm{m}$ metalizadas com grafita para aumentar a condutividade.

Os objetivos da análise por microssonda eletrônica foram a identificação da composição química dos minerais que compõe a alteração proximal ou minério (ultramilonitos e milonitos) e a alteração distal, geralmente estéril em Au, (protomilonitos) com o objetivo de auxiliar na interpretação das análises estatísticas dos dados geoquímicos de solo. 


\subsection{MÉTODOS DE ANÁLISE MULTIVARIADA}

Devido à característica multivariada e ao grande volume dos dados de solo disponíveis, uma abordagem estatística multivariada foi adotada para analisar a correlação de concentração entre os diversos elementos que compõe a base de dados. Para tanto, foram usados aplicativos de análise estatística que comportam os métodos selecionados para o estudo, são eles: MINITAB ${ }^{\circledR} \mathrm{e}$ IBM SPSS $^{\circledR}$. A alimentação dos dados nos aplicativos supracitados se deu por intermédio de planilhas geradas no MS EXCEL ${ }^{\circledR}$ a partir de consultas à base de dados original, armazenada em banco de dados relacional no formato MS ACCESS ${ }^{\circledR}$.

Os métodos multivariados são poderosos, permitindo ao pesquisador manipular diversas variáveis simultaneamente. São, porém, bastante complexos, tanto na sua estrutura teórica como na metodologia operacional (Davis, 1986). Segundo Landim (2000), em alguns casos os testes estatísticos exigem requisitos muito rígidos e em outros, ao relacioná-los com problemas reais, não apresentam base estatística teórica, impossibilitando a realização de testes estatísticos de significância. De qualquer modo, são métodos extremamente promissores para a análise de dados geológicos tendo em vista que normalmente a maioria das situações geológicas envolve um conjunto complexo de fatores atuando no sistema, sendo impossível estudá-los isoladamente.

\subsubsection{ANÁLISE DE FATORES}

A análise de fatores é uma técnica estatística amplamente usada nas análises de dados multivariados e possui a capacidade de identificar fatores de comportamento comum entre variáveis em termos de sua correlação ou covariância $(R-M o d e)$ ou a inter-relação entre as amostras $(Q-M o d e)$. No presente estudo o método $R$-Mode foi aplicado no intuito de encontrar associações geoquímicas elementares em amostras de solo representativas de diferentes litotipos parentais. A técnica é baseada em operações lineares em matrizes de dados de correlação entre as $n$ variáveis analisadas para os $n$ registros disponíveis. A existência de grupos de observações com altos coeficientes de correlação sugerem que tais variáveis podem estar medindo aspectos da mesma dimensão subjacente. Tais dimensões subjacentes são conhecidas como "variáveis latentes" e apelidadas de "fatores". Os fatores representam novas variáveis, não observáveis diretamente, e revelam a inter-relação entre variáveis em bases de dados multivariadas (Davis, 1986).

A técnica da análise de fatores possui três usos principais: 1) possibilita a compreensão da estrutura da base de dados; 2) permite definir e medir as dimensões subjacentes que descrevem o comportamento multivariado do dado, e 3) reduz a base de dados a uma dimensão mais administrável mantendo o máximo possível da informação original. Pioneiros como 
Thurstone (1947), Eisenck (1953), Cattel (1966), entre outros, usaram a análise de fatores para fins científicos, mas com propósitos diversos.

A padronização dos dados é processo fundamental para a aplicação da análise de fatores em uma base de dados multivariada. Os dados frequentemente possuem escalas variadas e podem ter sido medidos em unidades distintas. Existem diversos métodos de padronização e o mais comum deles, o z-scores (Davis, 1986), foi adotado no presente estudo já que no método cada variável do conjunto de dados é padronizada usando-se sua própria média e desvio padrão. Para uma dada variável, do valor de cada observação subtrai-se a média de todas as observações e divide-se pelo desvio padrão, obtendo-se um novo valor, padronizado pelo próprio dado. Os novos valores terão uma média de 0 e um desvio padrão igual a 1 . Dessa forma a matriz de covariância e a matriz de correlação serão idênticas.

A escolha do método de extração de fatores deve considerar o tipo de abordagem e objetivos do estudo, bem como as características da base de dados, mas o critério mais efetivo é, sem dúvida, a coerência dos resultados com o problema estudado. O método dos componentes principais foi eleito como método de extração de fatores no presente estudo, pois foi o único que apresentou resultados bastante coerentes com os dados disponíveis na área de controle e a sua expansão para áreas menos conhecidas apresentou resultados coesos e de fácil interpretação.

A determinação do número de fatores a conservar pode ser realizada por diversos critérios. Não há um consenso quanto ao melhor critério e geralmente se utiliza uma combinação de critérios que se mostrem mais adequados à realidade da pesquisa em questão. O critério de Kaiser (1960) é bastante difundido para tal finalidade e estabelece que devem ser conservados todos os fatores que possuam autovalores maiores que 1. O scree test (Catell, 1966) também é amplamente usado e consiste em analisar a representação gráfica dos autovalores do conjunto de fatores gerados buscando quebras naturais na curva e considerar apenas o número de fatores anteriores à quebra, desconsiderando os fatores posicionados na porção mais plana da curva. Em ambos os casos se está escolhendo apenas os fatores mais representativos ou em outras palavras, que tenham altos índices de correlação entre as variáveis que o compõe. No presente estudo o critério de Kaiser não se mostrou eficaz já que o número de fatores que atendem ao critério seria muito alto e em sua maioria pouco representativos. Foi adotado, portanto, o método de análise do scree test, além do critério de interpretação de resultados, geralmente mais eficaz que os demais em situações que o dado e o modelo adotados permitem bons resultados.

Os fatores são entidades estatísticas e podem ser visualizados graficamente como eixos de classificação ao longo dos quais variáveis de medida podem ser plotadas. A intensidade de correlação entre cada variável e um fator é dada pela sua coordenada com relação aos eixos. A rotação de fatores é uma transformação matricial usada para facilitar a interpretação dos 
resultados gerados pela análise de fatores. Existem dois tipos de rotação: a rotação ortogonal, usada em fatores considerados não relacionados e a rotação oblíqua, para fatores relacionados que permite que os eixos, inicialmente ortogonais, deixem de ser ortogonais e com isso encontra correlações entre os fatores (Figura 3.2). No caso estudado, como o objetivo foi distinguir tipos de rochas parentais distintos (máficas, ultramáficas, pegmatitos, meta-tonalitos e hidrotermalitos) não correlacionados, o método Varimax (Kaiser, 1958) de rotação ortogonal foi selecionado. O algoritmo Varimax busca uma combinação linear que maximize a variância entre os carregamentos dos fatores, facilitando a interpretação, além de manter os fatores não correlacionados, diferenciando com maior eficácia as rochas parentais das amostras de solo.

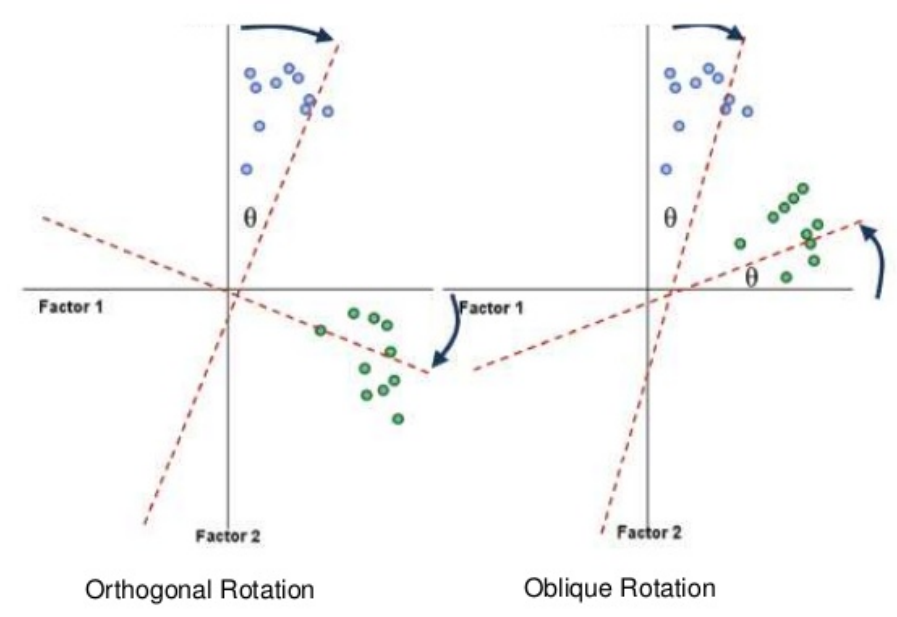

Figura 3.2 - Representação esquemática demonstrando os dois tipos de rotação de fatores, ortogonal e oblíquo.

\subsubsection{ANÁLISE DE AGRUPAMENTOS HIERÁRQUICOS E K-MÉDIAS}

O objetivo da aplicação do método de agrupamento hierárquico consistiu em analisar as concentrações elementares do conjunto de amostras de modo a buscar possibilidades de agrupamentos por características multi-elementares similares. $\mathrm{O}$ algoritmo de agrupamento hierárquico opera iniciando a análise de $n$ amostras com $n$ grupos distintos, cada grupo contendo apenas uma amostra. No segundo passo são unidas as duas amostras mais similares de todo o conjunto de dados, formando $\frac{n}{2}$ grupos distintos e o ponto central entre as amostras de cada grupo (o centroide) é calculado. No terceiro passo os dois grupos com centroides mais próximos se unem (ligação), e novamente o centroide do grupo é calculado. Dessa maneira o método repete as iterações até que todos os grupos estejam unidos em um só grupo e uma árvore do histórico de 
agrupamentos (dendrograma) é gerada. O dendrograma é analisado pelo pesquisador, que decide onde parar a sequência de agrupamentos para se obter um número de grupos que seja representativo do problema estudado.

A análise de dados por agrupamento hierárquico pode ser aplicada com diferentes métodos de ligação e cálculo de distância de centroides. Segundo Landim (2000), em estudos de análise estatística multivariada o melhor método é aquele que fornece os resultados mais coerentes com a realidade geológica em estudo. A partir de testes reais com todas as combinações de métodos de ligação e distância possíveis, foram selecionados o método de ligação de Ward (1963) e distância Euclidiana para o cálculo dos centroides. O método de Ward usa a análise de variância como meio para avaliar as distâncias entre os grupos (clusters), em outras palavras, minimiza a soma dos quadrados de quaisquer dois grupos que possam ser formados a cada passo do processo de agrupamento. Trata-se de um método considerado bastante efetivo, mas que, no entanto tende a gerar grupos pequenos, dependendo das características da base de dados analisada. A medida de distância Euclidiana é a mais simples e também a mais popular, por ser muito eficaz. Trata-se da distância geométrica entre os centroides de dois grupos no espaço multidimensional.

O método de agrupamento K-médias (K-means) foi utilizado para suprir as deficiências apresentadas pelo método de agrupamento hierárquico na função de distinguir os padrões geoquímicos dos diferentes tipos parentais hidrotermais. $\mathrm{O}$ método inicia suas iterações com um número $(\mathrm{K})$ de grupos pré-definido pelo usuário e atribui os $\mathrm{K}$ primeiros registros lidos como os centroides iniciais e vai ajustando os grupos até gerar $\mathrm{K}$ grupos com a maior distância euclidiana possível entre os centroides, de modo que a variabilidade seja maximizada entre grupos e minimizada internamente aos grupos. Ao contrário do agrupamento hierárquico, o K-médias permite que duas amostras sejam separadas após estarem unidas em um mesmo grupo. O método é útil quando se conhece bem a natureza do dado analisado, como no caso abordado neste estudo. 


\title{
CAPÍTULO 4
}

\section{ARTIGO SUBMETIDO}

\section{Objective-based multivariate analysis of soil geochemistry data for near-mine exploration at the Almas gold province, Brazil: a case study}

\author{
Marco Antonio Caçador Martins-Ferreira ${ }^{1}$ \\ marcoc@unb.br (Corresponding Author) \\ José Eloi Guimarães Campos ${ }^{1}$ \\ eloi@unb.br \\ Augusto Cesar Bittencourt Pires ${ }^{1}$ \\ acbpires@unb.br \\ 1. Instituto de Geociências, Universidade de Brasília, Campus Universitário Darcy Ribeiro, Asa Norte, \\ CEP 70.910-900, Brasília - DF - Brasil.
}

\begin{abstract}
Multivariate methods such as factor analysis, hierarquical cluster analysis and k-means cluster analysis were employed to analyze soil geochemical data aiming to identify potential prospects in a gold mineralized area where outcropping ore is no longer available. Microprobe analysis was used to identify the elemental concentrations in each mineral phase. The main objective is to demonstrate the importance of adapting the methods to the specific geological reality at each studied site. An objective approach was adopted using a well-known mining area as control for analysis testing. The control area is surrounded by unexplored terrain, which was the target of this study. This unexplored terrain was covered by a soil grid of 2,908 samples, comprising an area of $88 \mathrm{~km}^{2}$. Factor analysis was able to provide 5 correlation factors explaining $71.2 \%$ of the total variance. These factors identified distinct elemental associations with high correlations, influenced by the parental materials: ultramafic, mafic, pegmatitic, distal and proximal hydrothermal alteration. Hierarchical cluster analysis was able to correctly distinguish mafic/ultramafic from non-mafic/ultramafic influenced samples. K-means cluster analysis of a sub-dataset composed only of non-mafic samples provided groups of observations representative of country rock, distal alteration and proximal alteration. The above methods allowed for the identification of a geochemical fingerprint, defined by the elemental association $\mathrm{Ba}, \mathrm{Ca}, \mathrm{La}, \mathrm{Na}, \mathrm{Pb}$ and $\mathrm{Sr}$, for distal alteration zones and enabled the mapping of new target areas for near-mine exploration. Spatial analysis of the clustering results, in comparison with the control area, was very effective in determining the best methods of clustering and data preparation. This process proved adequate for the determination of precise locations in the study
\end{abstract}


area with high potential for mineralization. The results obtained fulfilled the aim of the study by indicating four new target areas and three sub areas with sufficient accuracy for future planning of an exploratory drilling program. The use of multivariate methods has been shown to be extremely efficient for near-mine exploration scenarios, where the availability of areas with enough geological knowledge can serve as testing grounds to assure a given method's accuracy.

Keywords: Near-mine exploration, multivariate statistics, factor analysis, hierarchical cluster analysis, K-means cluster analysis, soil geochemistry.

\subsection{Introduction}

Centuries of mineral exploration have exhausted surface ore anomalies in known mineralized regions, but the demand for minerals has increased. Modern approaches for mineral exploration require that deep-seated mineralization or its evidences can somehow be detected. Brazilian tropical climates have produced an extensive regolith cover that complicates the exploration scenario in most regions. Outcrops are scarce and soil geochemical studies are important exploration tools for most cases, even in near-mine situations.

The efforts of the study are concentrated on prospectivity and bedrock mapping of the Vira Saia gold deposit surrounding areas through the identification of elemental associations in soil geochemical data, representative of the of different parental rock-types covered by those soils. Data processing is done by applying a common combination of multivariate statistical methods such as factor analysis, hierarchical clustering analysis and k-means clustering analysis and by characterizing the proximal and distal alteration elemental content via microprobe analysis on drillcore samples.

Several authors have successfully used multivariate methods for mineral exploration and mapping purposes with different approaches. Factor analysis was early pointed out to be a successful method for data analysis in geochemical exploration (Nichol et al., 1966, 1969; Garret and Nichol, 1969; Woodsworth, 1971; Tripathi, 1979). Lin et al. (2014) examined the usefulness of integrated multivariate methods in the field of deep-penetrating geochemistry over arid desert terrains and was able to improve the interpretation of the geochemical patterns in the area. Sadeghi et al. (2014) demonstrated the successful use of combined multivariate technics for soil geochemical data processing and interpretation for both bedrock mapping and gold exploration at the Giyani greenstone belt. De Sa et al. (2014) used factor analysis and microprobe analysis to describe metallogenic differences and classify the deposits according to their elemental content. Roshani et al., (2013) adopted an objective approach for anomaly detection using discriminant analysis on "real" pre-defined "anomaly" and "background" datasets. 
Emphasis to the results quality was a priority in the present study and was conducted by adopting an objective approach. The objective method proposed makes use of geological data from a well-known area (control area) at the center of the study site, where extensive drilling, geological mapping and mining data serve as objects for validity criteria to assure quality for the testing phase as well as for the final processing phase. Despite the great amount of data, soil samples where not previously discriminated, therefore discriminant analysis of samples is not suitable in this case. Instead, cluster analysis results were compared to previously discriminated areas of occurrence of proximal alteration, distal alteration, country rock and mafic rock, delivering excellent results.

Because gold anomalies are no longer available at the surface of the regolith covers, the study focuses on the identification of potentially mineralized areas by targeting distal alteration soil anomalies, found to be indicative of ore at depth by the specific characteristics of Vira Saia's ore bodies. Therefore, the aim of this paper is to show, via a study case, how combined multivariate methods for soil geochemistry data processing can be extremely successful for nearmine exploration if the methods are strictly adapted to the specific geological scenario (objects) studied.

\subsection{Geological Setting and Mineralization}

The Almas gold province is an early-Paleoproterozoic greenstone/TTG association terrain located in the northernmost section of the Brasília Fold Belt (Dardenne, 2000), which represents a Neoproterozoic orogen developed during the Brasiliano-Panafricano orogenic cycle, in central Brazil. The Paleoproterozoic basement of the Brasilia Belt is largely exposed at the northern portion, where the study area is located (Figure 4.1). It was first subjected to a midPaleoproterozoic orogeny known as the Transamazonic cycle, undergoing amphibolite facies metamorphism grade and later affected by the Neoproterozoic Brasiliano Orogenic cycle that imprinted greenschist facies retro-metamorphism paragenesis (Ferrari \& Choudhuri 2004). 


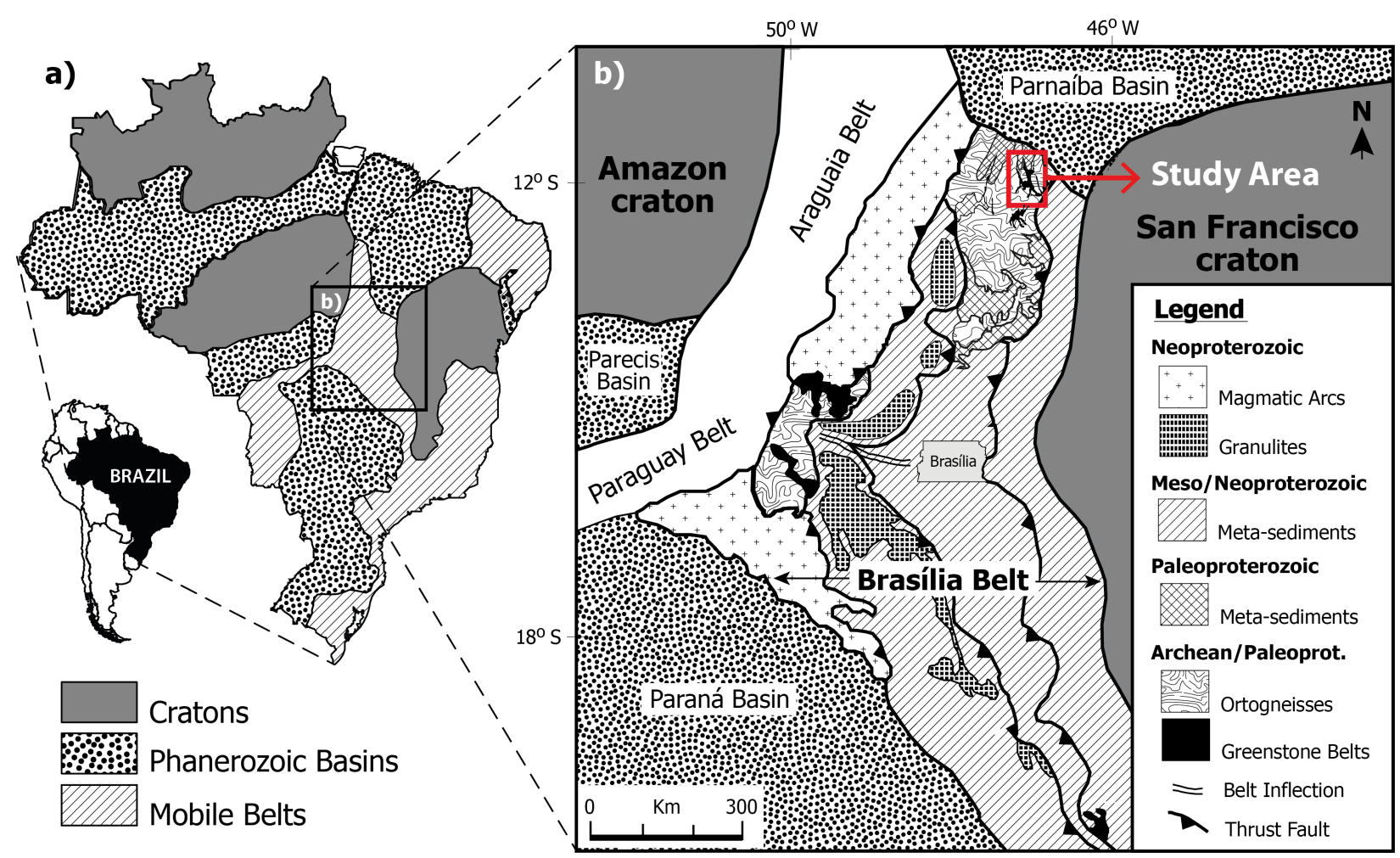

Figure 4.1 - a) Brazilian map showing the distribution of the main cratons, phanerozoic basins and mobile belts. b) Brasília Fold Belt geologic map with the location of the study area (after Dardenne, 2000 and D'el-Rey Silva, 2008).

The Almas Greenstone/TTG terrain can be briefly described as a meta-volcanic sequence followed by a meta-volcano-sedimentary succession intruded by TTG bodies. The basal metavolcanic sequence is predominantly composed of meta-basalts and subordinated metaultrabasics, meta-dacites and meta-andesites and is of uncertain age. The meta-volcanosedimentary sequence is composed of meta-pelites, quartzites, meta-banded iron formations, meta-conglomerates and acidic to intermediate meta-volcanics. This succession was dated by Dardenne et al. (2009) at 2.2Ga (U-Pb zircon ages). The greenstone sequence is intruded by the TTG, composed of meta-tonalites, meta-granites, meta-trondjemites and meta-granodiorites bodies. The TTG is distinguished in two suites, predominantly metaluminous (Suite 1) and predominantly peraluminous (Suite 2), dated by Cruz et al. (2003) as $2.2 \mathrm{Ga}$ and $2.45 \mathrm{Ga}$, respectively. Small xenoliths composed of greenstone rocks with evidence of contact metamorphism are often intercepted by trenches near the border between greenstone belts and TTG bodies, confirming the intrusive nature of these bodies. Mafic, ultramafic and pegmatitic bodies also occur as late intrusions. Mafic dikes cut across the basement at an approximate N-S trend.

The Paiol deposit is the largest in the region and was the only deposit to be mined at an industrial scale with 2 Mt of processed ore at $2.5 \mathrm{~g} / \mathrm{t} @ \mathrm{Au}$ from 1996 to 2001. The mineralization is hosted in a ductile shear zone that cuts across the greenstone meta-mafic volcanic sequence 
(Ferrari \& Choudhuri, 2000; Cruz \& Kuyumjian, 2006). It is known to be a gold only (Cruz \& Kuyumjian, 1993) or lode type (Kwitko et al., 1995; Cruz \& Kuyumjian, 1999) alteration zone that generates a tabular ore body 1400 meters long and 330 meters wide and was detected up to a depth of 400 meters.

The Vira Saia deposit is only $5 \mathrm{~km} \mathrm{NW}$ of Paiol and is hosted on a predominantly metatonalitic body, showing different structural and geochemical controls. The outcropping Au anomaly was discovered and mined by the Brazilian mining company Vale in 1994 as a secondary deposit to finance the construction phase for the much larger volume Paiol deposit. Despite its low tonnage, Vira Saia was chosen to finance the large project due to its proximity, its reasonably shallow mineralization, the higher Au grades, and the occurrence of free gold. These factors assured greater recovery rates at a provisory plant and pushed the investment on Vira Saia's resources until Paiol started producing larger volumes, but at a lower recovery rate, in 1996. Vale stopped operations due to the metal price world crisis in 2001. In 2010, Rio Novo Gold resumed exploration at the site but never achieved production. Further exploration campaigns included soil sampling and drilling surveys, which showed that the Vira Saia deposit has higher tonnage than expected once it extends to the NW and SE along the shear zone forming a narrow but long deposit. Despite being mentioned by some researchers (Cruz \& Kuyumjian, 1998; Cruz et al., 2003; Ferrari, 2004), no specific detailed scientific studies have been conducted in the surroundings of the Vira Saia thus far.

The Vira Saia area was chosen as the target for this study for the following reasons: the wide coverage of the soil sample grid, and the availability of a control area with detailed geologic knowledge and the occurrence of shallow soil cover, in comparison with the deep and leached oxisols that cover the nearby greenstone belts. The Vira Saia area is located at the Ribeirão das Areias Body (RAB), a predominantly tonalitic meta-igneous body (peraluminous suite 2) of early Paleoproterozoic age (Cruz, 2001). Studies about RAB's heterogeneity are superficial and thus controversial; some categorize RAB as a complex with multiple tonalitic, trondjemitic and granodioritic bodies (Cruz \& Kuyumjian, 1998; Cruz et al., 2003) and others as a unique batholith (Ferrari \& Choudhuri, 2004). Extensive exploration research in the area indicates that a great portion of the mineralogical variations inside the complex was most likely formed by intense differential hydrothermal alteration that affected the entire region and, in some cases, due to the natural magmatic evolution of the magma chamber. This assumption is supported by a simple fact: the mineralogical variation trend most often obeys a similar orientation as the $\mathrm{Au}$ mineralization. In other cases, mineralogy varies from the body center to the borders, with the more evolved rocks located at the borders. The very gradual change in mineralogy and its controlled spatial distribution plus the lack of distinct contact zones between 
the suppositional intrusive bodies also indicate that the RAB is in fact a unique body. It shows inner magmatic heterogeneities and wide hydrothermal alteration zones, rather than a complex of different intrusive bodies and its wide proportions (over $180 \mathrm{~km}^{2}$ ) allow its classification as a batholith.

Vira Saia mineralization is controlled by a sinistral brittle-ductile shear zone system that produces a $\mathrm{C}$ foliation commonly oriented at $230^{\circ} / 70^{\circ}$ (dip angle) and transposes a preexisting N-S oriented foliation. These shear zones deform meta-tonalitic rocks that host innumerous diabase dikes, approximately N-S oriented, that displace the ore and are thus important controls in addition to the NW shear zones. The mineralization is characterized by a progression in the degree of mylonitization in which non-mylonitic meta-tonalites are Au barren, protomylonites can be $\mathrm{Au}$ enriched or barren, and mylonites and ultramylonites are most frequently $\mathrm{Au}$ mineralized. Protomylonites generally envelope mylonites and ultramylonites, forming horizontally and vertically lenticular-shaped ore bodies (Figure 4.2). The identification of protomylonites near the surface is generally indicative of higher-grade ore bodies at depth, as noted after the trenching and drilling programs at the Vira Saia NW extensions.

Electron Microprobe Analysis was conducted for both silicates and sulfides over polished thin sections of mineralized mylonites (proximal alteration) and barren protomylonites (distal alteration) from drilling core samples, revealing important information: the mineralization is characterized by the presence of very low sulfidation (i.e., lower than 1\%), where pyrite and galena are the main sulfides, but chalcopyrite occasionally occurs. Gold was mainly observed as free flakes but was occasionally found bordering oxidizing pyrite crystals (Figure 4.3). Muscovite, quartz, albite, apatite, calcite and pyrite are the main minerals in all samples analyzed. Titanite, actinolite, epidote and chlorite are the main minerals found exclusively on barren protomylonites. Galena and gold are the main minerals found exclusively on mineralized mylonites.

Hydrothermal potassium enrichment is responsible for the formation of greenish muscovite containing up to $6 \% \mathrm{FeO}, 1.5 \% \mathrm{MgO}, 1 \% \mathrm{BaO}$ and $0.2 \% \mathrm{Cr}_{2} \mathrm{O}_{3}$. Intense silicification formed decametric to millimetric-scaled quartz lenses and fine quartz matrix rich in free gold crystals on ultramylonites. Carbonation is mainly found in the form of calcite and occurs on both hydrothermal altered rock (mylonites) and unaltered metamorphic country rock but contains higher concentrations of $\mathrm{Mn}$ (up to $1 \% \mathrm{MnO}$ ) and $\mathrm{Sr}$ (up to $0.5 \% \mathrm{SrO}$ ) in mylonites than in country rock. Chlorite is a characteristic mineral of distal alteration protomylonites and contains up to $15 \% \mathrm{FeO}, 0.6 \% \mathrm{MnO}$ and $0.2 \% \mathrm{SrO}$. Epidote is another characteristic mineral of distal alteration protomylonites and contains up to $14 \% \mathrm{FeO}, 1.5 \% \mathrm{SrO}$ and $0.6 \% \mathrm{MnO}$. 


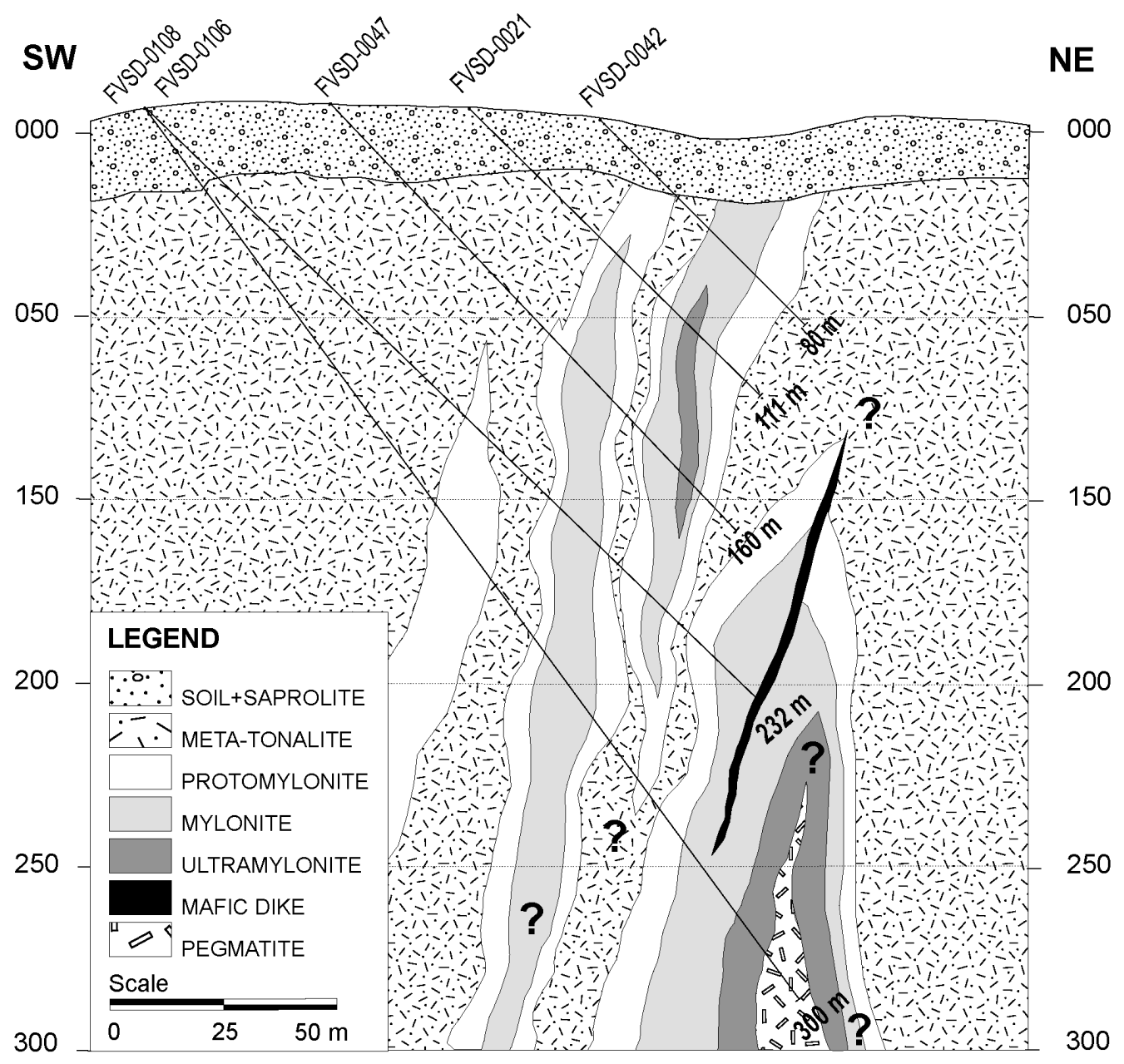

Figure 4.2 - Schematic section 75-S (location in Figure 4.5A) of the Vira Saia deposit constructed from drill core log data. Note the enveloping of mylonitic zones by protomylonitic zones. 


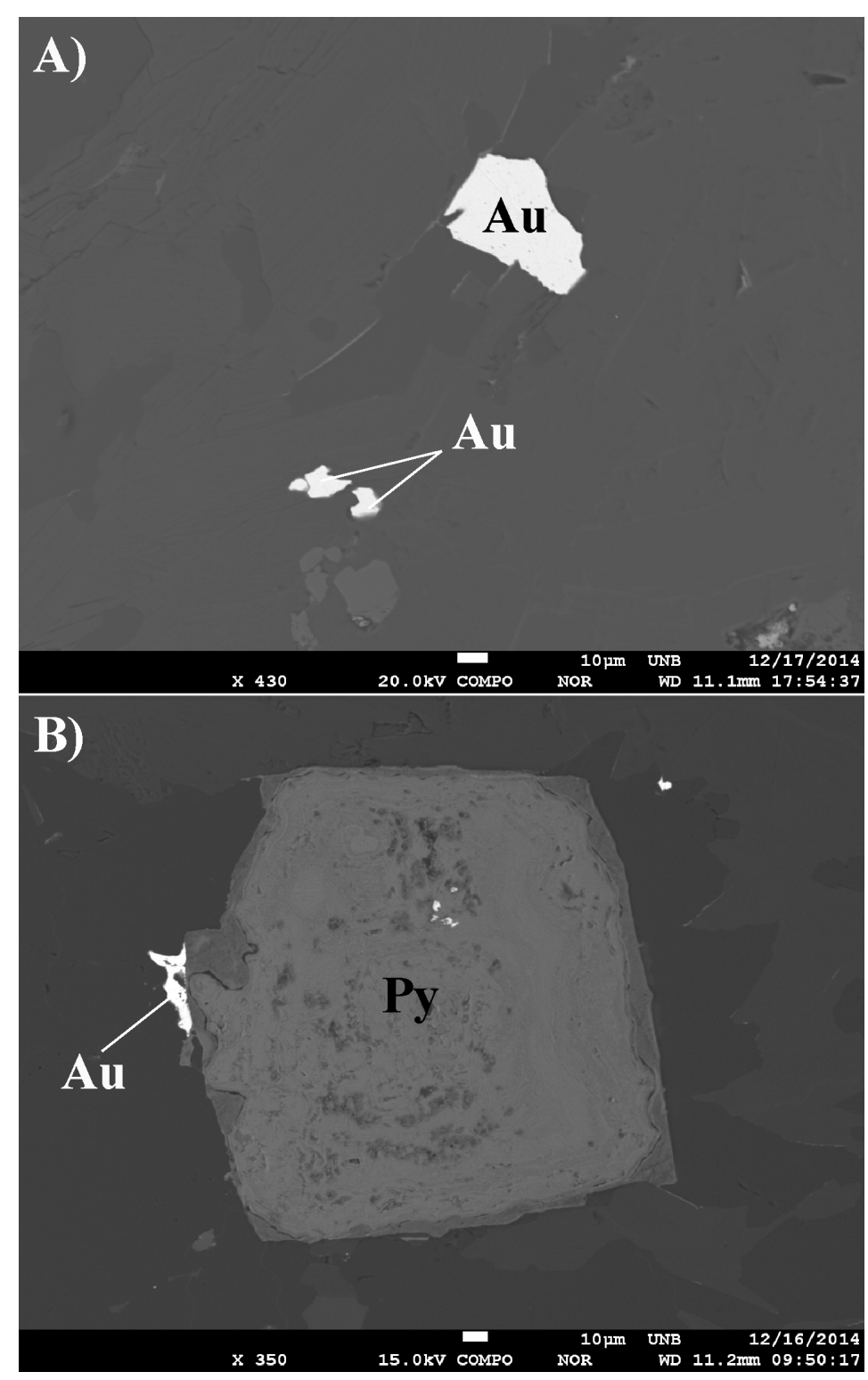

Figure 4.3 - Scanning electron microscope images from Vira Saia samples of A) free gold flakes in ultramylonites $(430 \mathrm{x} / 20 \mathrm{kV})$ and $\mathrm{B})$ gold bordering an oxidizing pyrite crystal in mylonites $(350 \mathrm{x} / 15 \mathrm{kV})$.

\subsection{Materials and Methods}

The study area (Figure 4.4A) covers a total of $88 \mathrm{~km}^{2}(11 \mathrm{~km} \mathrm{x} 8 \mathrm{~km})$, and most of its geology is poorly known in detail, except for a small area of $6 \mathrm{~km}^{2}(2 \mathrm{~km} \times 3 \mathrm{~km})$, called the control area, located around the abandoned mining pit left by Vale (Figure 4.4B). At the control area, 190 recent diamond drilling holes (Figure 4.5A) and geological mapping have generated plenty of data, in addition to soil samples that cover the area. The geological knowledge from the control area is intended to serve as the criteria source to judge the significance of the multivariate analysis results. 
Soil samples were collected in an irregular grid composed of $52 \mathrm{E}-\mathrm{W}$ lines of different length but constant sample spacing (50 meters), except for gaps where samples could not be collected and are thus absent. Due to exploration priorities, the soil line spacing varies from 100 $\mathrm{m}$ to $400 \mathrm{~m}$, as observed in Figure 4.4. The old waste dump pile, created in 1994 by the previous mining activities of Vale, was also sampled with irregular spacing (Figure 4.5B) and serves as an important testing control. The sampling in the whole study area was conducted from 2010 to 2013, resulting in a large dataset composed of 2,908 soil samples. From those, 501 samples are located within the control area and were used as the training dataset for all analysis previous testing. The sampling was executed by technicians instructed to collect samples bellow the stone line, when present, to avoid dislocated material and to focus on the "B" soil horizon. The sampling depth varied from $0.1 \mathrm{~m}$ to $1.4 \mathrm{~m}$ with an average of $0.55 \mathrm{~m}$. Only a few samples at the eastern end of the area were collected over the greenstone belt and represent oxisols. The soil material collected was most frequently described as a gravel-rich sandy-silty ochre lithic entisol. The approach adopted takes into account that lithic entisols (Soil Survey Staff, 1999) are recent soil formations composed of rock fragments that underwent minimum horizontal transportation, thus providing more reliable information about the geology beneath than other soil types. This fact was confirmed by the present study via objective testing on soil samples collected over wellknown geologic features inside the control area.

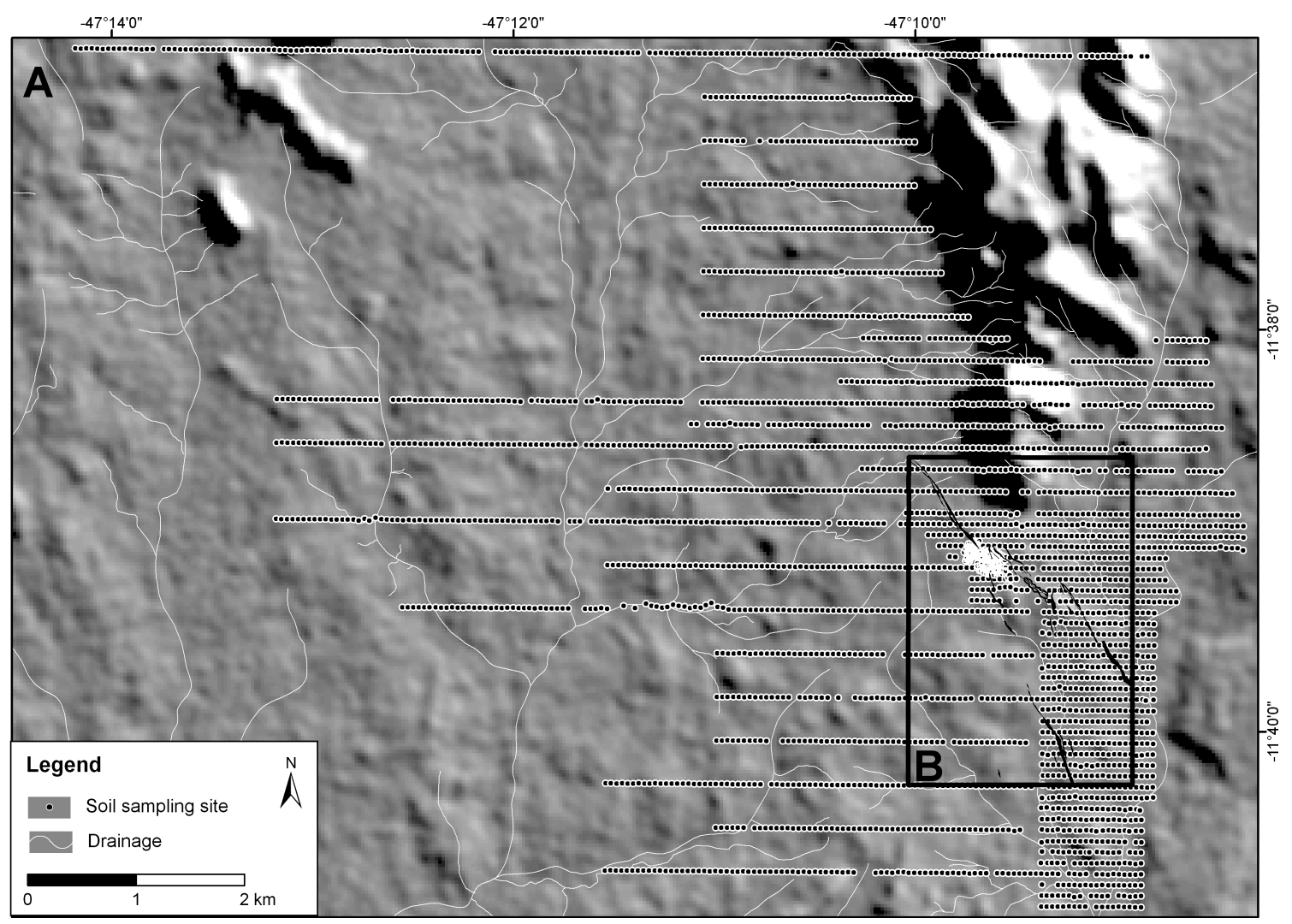

Figure 4.4 - Map of the study area showing soil sampling lines and the location of the control area (B) in relation to the total study area (A). 

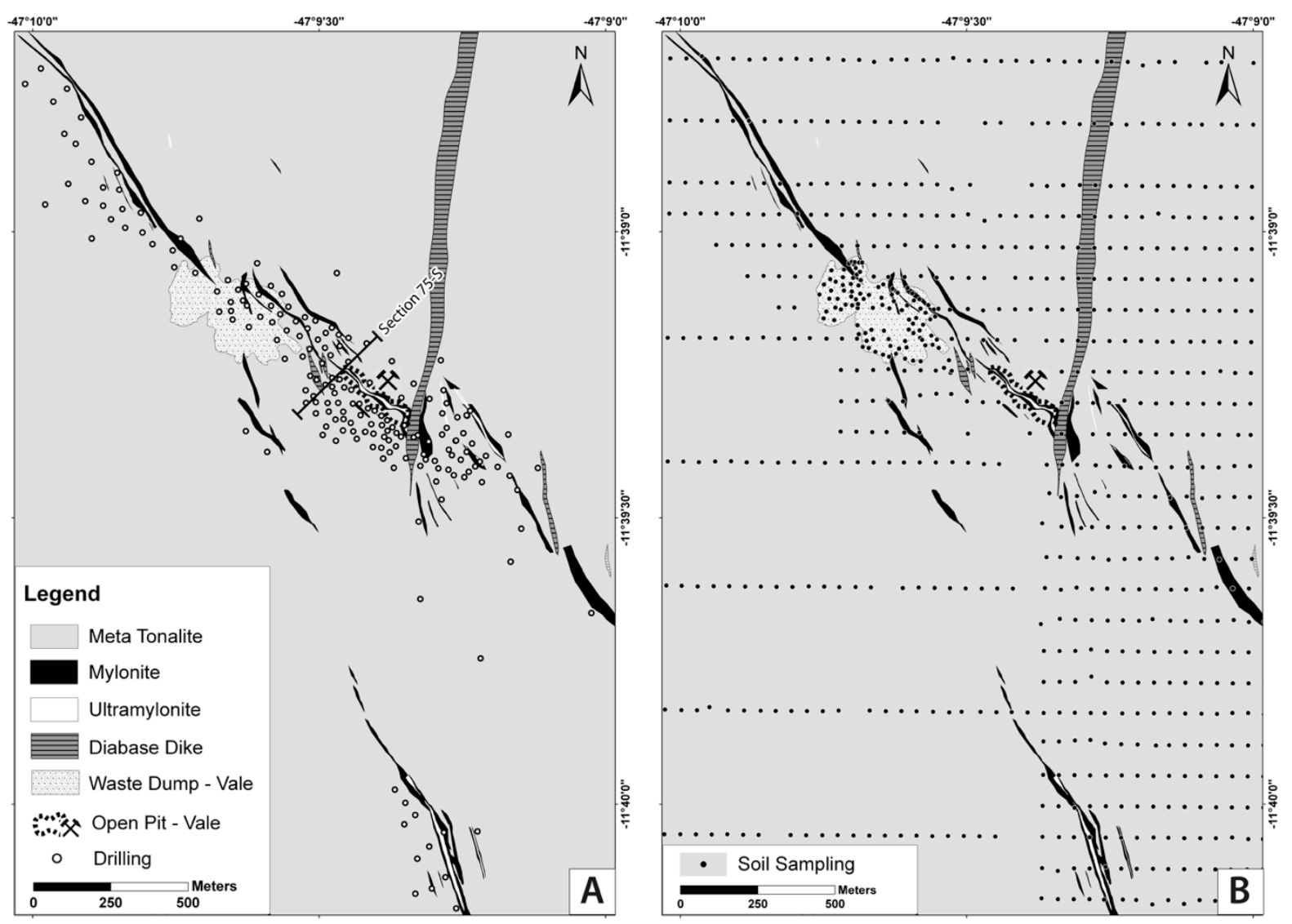

Figure 4.5 - A) Geologic map of the control area showing the surface projection of drilling results, geological mapping information, the 190 drilling sites and section 75-S (Figure 4.2). B) Geologic map of the control area showing the 501 soil sampling sites over the surface projection of drilling results. Note dense irregular soil sampling over the waste dump, the absence of samples over the abandoned open pit and the NW orientation of mineralization.

\subsubsection{Geochemical Analysis of Soil Samples}

All samples were digested by aqua regia and analyzed by fire assay (Atomic Absorption by fusion of $50 \mathrm{~g}$ ) determination for gold, and additional 34 elements, analyzed by ICP-MS. Every sample with Au grade higher than $10.000 \mathrm{ppb}$ was also assayed by Metallic Screen.

The 35 elements analyzed were $\mathrm{Au}, \mathrm{Ag}, \mathrm{Al}, \mathrm{As}, \mathrm{Ba}, \mathrm{Be}, \mathrm{Bi}, \mathrm{Ca}, \mathrm{Cd}, \mathrm{Co}, \mathrm{Cr}, \mathrm{Cu}, \mathrm{Fe}, \mathrm{Hg}$, K, La, Li, Mg, Mn, Mo, Na, Ni, P, Pb, S, Sb, Sc, Sn, Sr, Ti, V, W, Y, Zn and Zr. Blank and duplicate samples were added at a 20:1 ratio in addition to the laboratory-accredited international ITAK standards to assure quality control.

\subsubsection{Data Preparation}

Before multivariate statistical methods could be applied, blank and duplicate samples were removed and descriptive univariate statistics were produced for each variable in the whole soil dataset (Table 4.1). No missing values were detected. Data preparation procedures reduced the number of variables in the dataset from 35 to 22 , the elements with $95 \%$ results below their 
detection limits (DL) were removed, leaving only relevant elements for the proposed study: Au, $\mathrm{Al}, \mathrm{Ba}, \mathrm{Ca}, \mathrm{Co}, \mathrm{Cr}, \mathrm{Cu}, \mathrm{Fe}, \mathrm{K}, \mathrm{La}, \mathrm{Li}, \mathrm{Mg}, \mathrm{Mn}, \mathrm{Na}, \mathrm{Ni}, \mathrm{Pb}, \mathrm{Sc}, \mathrm{Sr}, \mathrm{V}, \mathrm{Y}, \mathrm{Zn}$, and $\mathrm{Zr}$. Nonparametric tests revealed that the remaining elements display normal distributions.

Because automatic detection techniques are sensitive to outliers, all elements were scanned for exceptionally high values. Detecting low outliers was not a concern once the lowest values were always equal to the detection limit. The inspection for high outliers was carried out by analyzing each element in decreasing order for intervals or "jumps" greater than the standard deviation (Table 4.1). For the study dataset, the elements that contained outliers presented only one jump near the top 5 observations, and all values above the jump were considered outliers. No observations were excluded from the dataset in the process. Instead, outlying values were replaced by the greatest value before the jump. Outlying values were found for $69 \%$ of the variables, of which 1 to 4 observations for each variable were considered outliers. The "Standard Deviation Jump" method was able to prevent the loss of observations and maintain important highly anomalous values without erroneously influencing the multivariate analysis results. The technique was developed after other methods such as those proposed by Tukey, (1977); Hoaglin et al., (1987); Filzmoser et al., (2005); Filzmoser et al., (2012) failed to address the specific outlier problem of the dataset, due to its characteristics and the study objectives.

Because the data units and ranges are not uniform between variables, the complete dataset was submitted to z-score standardization as a feature scaling method prior to the application of multivariate analysis procedures.

Table 4.1 - Descriptive statistics of raw soil data. Removed elements are outlined in gray. $\mathrm{N}=2,908$. $\mathrm{SD}=$ Standard Deviation, $\mathrm{VC}=$ Variation Coefficient, $\mathrm{DL}=$ Detection Limit. Removed elements are outlined in gray $(95 \mathrm{th}<\mathrm{DL})$.

\begin{tabular}{|c|c|c|c|c|c|c|c|c|c|c|}
\hline Variable & Mean & SD & VC (\%) & Min & Max & Q1 & Q3 & 95th & DL & Skew \\
\hline $\mathbf{A u}$ & 0.04 & 0.09 & 257.38 & 0.00 & 2.70 & 0.00 & 0.03 & 0.16 & $0.015 \mathrm{ppm}$ & 10.98 \\
\hline Ag & 1.00 & 0.22 & 22.08 & 0.99 & 10.00 & 0.99 & 0.99 & 0.99 & $1.0 \mathrm{ppm}$ & 31.66 \\
\hline Al & 0.94 & 0.52 & 55.93 & 0.06 & 4.34 & 0.58 & 1.16 & 1.92 & $0.1 \%$ & 1.76 \\
\hline As & 5.08 & 0.97 & 19.11 & 4.99 & 46.00 & 4.99 & 4.99 & 4.99 & $5.0 \mathrm{ppm}$ & 29.21 \\
\hline Ba & 73.96 & 59.01 & 79.79 & 4.00 & 958.00 & 37.00 & 93.00 & 177.55 & $1.0 \mathrm{ppm}$ & 3.41 \\
\hline Be & 0.99 & 0.03 & 2.67 & 0.99 & 2.00 & 0.99 & 0.99 & 0.99 & $1.0 \mathrm{ppm}$ & 38.07 \\
\hline $\mathbf{B i}$ & 9.99 & 0.00 & 0.00 & 9.99 & 9.99 & 9.99 & 9.99 & 9.99 & $10 \mathrm{ppm}$ & - \\
\hline $\mathrm{Ca}$ & 0.06 & 0.11 & 194.30 & 0.00 & 2.51 & 0.00 & 0.07 & 0.20 & $0.1 \%$ & 8.64 \\
\hline Cd & 0.99 & 0.00 & 0.02 & 0.99 & 1.00 & 0.99 & 0.99 & 0.99 & $1.0 \mathrm{ppm}$ & 53.93 \\
\hline Co & 5.40 & 11.76 & 217.67 & 2.99 & 443.00 & 2.99 & 2.99 & 14.00 & $3.0 \mathrm{ppm}$ & 20.50 \\
\hline $\mathrm{Cr}$ & 7.25 & 17.58 & 242.49 & 0.99 & 420.00 & 2.00 & 6.00 & 29.00 & $1.0 \mathrm{ppm}$ & 10.57 \\
\hline $\mathrm{Cu}$ & 4.87 & 9.10 & 186.78 & 0.99 & 91.00 & 0.99 & 4.00 & 19.00 & $1.0 \mathrm{ppm}$ & 4.94 \\
\hline $\mathrm{Fe}$ & 1.56 & 1.59 & 102.00 & 0.04 & 14.06 & 0.67 & 1.83 & 4.57 & $1.0 \%$ & 3.26 \\
\hline
\end{tabular}




\begin{tabular}{|l|r|r|r|r|r|r|r|r|r|r|}
\hline $\mathbf{H g}$ & 1.01 & 0.16 & 16.22 & 0.99 & 4.00 & 0.99 & 0.99 & 0.99 & $1.0 \mathrm{ppm}$ & 9.85 \\
\hline $\mathbf{K}$ & 0.10 & 0.08 & 79.49 & 0.00 & 0.79 & 0.04 & 0.14 & 0.26 & $0.1 \%$ & 1.46 \\
\hline $\mathbf{L a}$ & 20.89 & 15.99 & 76.56 & 9.99 & 278.00 & 9.99 & 25.00 & 48.00 & $10 \mathrm{ppm}$ & 4.23 \\
\hline $\mathbf{L i}$ & 2.28 & 1.52 & 66.88 & 0.99 & 31.00 & 1.00 & 3.00 & 5.00 & $1.0 \mathrm{ppm}$ & 4.42 \\
\hline $\mathbf{M g}$ & 0.05 & 0.07 & 146.13 & 0.00 & 0.76 & 0.02 & 0.05 & 0.14 & $0.1 \%$ & 5.08 \\
\hline $\mathbf{M n}$ & 0.01 & 0.02 & 295.50 & 0.00 & 0.51 & 0.00 & 0.00 & 0.04 & $0.1 \%$ & 7.01 \\
\hline $\mathbf{M o}$ & 1.01 & 0.40 & 39.10 & 0.99 & 13.00 & 0.99 & 0.99 & 0.99 & $1.0 \mathrm{ppm}$ & 23.58 \\
\hline $\mathbf{N a}$ & 0.01 & 0.03 & 308.63 & 0.00 & 0.39 & 0.00 & 0.00 & 0.08 & $0.1 \%$ & 4.76 \\
\hline $\mathbf{N i}$ & 2.81 & 6.35 & 226.31 & 0.99 & 157.00 & 0.99 & 2.00 & 10.00 & $1.0 \mathrm{ppm}$ & 10.49 \\
\hline $\mathbf{P}$ & 0.00 & 0.01 & 437.84 & 0.00 & 0.19 & 0.00 & 0.00 & 0.01 & $0.1 \%$ & 10.11 \\
\hline $\mathbf{P b}$ & 5.92 & 3.22 & 54.43 & 2.99 & 42.00 & 3.00 & 7.00 & 12.00 & $3.0 \mathrm{ppm}$ & 2.60 \\
\hline $\mathbf{S}$ & 0.00 & 0.00 & 691.62 & 0.00 & 0.03 & 0.00 & 0.00 & 0.00 & $0.1 \%$ & 8.05 \\
\hline $\mathbf{S b}$ & 5.00 & 0.20 & 4.00 & 4.99 & 12.00 & 4.99 & 4.99 & 4.99 & $5.0 \mathrm{ppm}$ & 24.78 \\
\hline $\mathbf{S c}$ & 3.91 & 3.67 & 93.75 & 2.99 & 41.00 & 2.99 & 2.99 & 9.00 & $3.0 \mathrm{ppm}$ & 5.42 \\
\hline Sn & 9.99 & 0.00 & 0.00 & 9.99 & 9.99 & 9.99 & 9.99 & 9.99 & $10 \mathrm{ppm}$ & - \\
\hline Sr & 16.70 & 21.82 & 130.65 & 0.99 & 312.00 & 4.00 & 20.00 & 59.00 & $1.0 \mathrm{ppm}$ & 3.89 \\
\hline Ti & 0.00 & 0.01 & 553.65 & 0.00 & 0.20 & 0.00 & 0.00 & 0.01 & $0.1 \%$ & 8.50 \\
\hline $\mathbf{V}$ & 25.41 & 39.34 & 154.82 & 2.99 & 404.00 & 9.00 & 23.00 & 88.55 & $3.0 \mathrm{ppm}$ & 4.71 \\
\hline $\mathbf{W}$ & 9.99 & 0.00 & 0.00 & 9.99 & 9.99 & 9.99 & 9.99 & 9.99 & $10 \mathrm{ppm}$ & - \\
\hline $\mathbf{Y}$ & 3.90 & 3.76 & 96.50 & 0.99 & 40.00 & 2.00 & 5.00 & 10.00 & $1.0 \mathrm{ppm}$ & 3.70 \\
\hline $\mathbf{Z n}$ & 9.06 & 9.86 & 108.88 & 0.99 & 101.00 & 3.00 & 10.00 & 31.00 & $1.0 \mathrm{ppm}$ & 3.12 \\
\hline $\mathbf{Z r}$ & 2.67 & 1.52 & 56.92 & 0.99 & 15.00 & 2.00 & 3.00 & 5.00 & $1.0 \mathrm{ppm}$ & 1.47 \\
\hline
\end{tabular}

\subsubsection{Methods}

The use of Factor Analysis (FA) in the present study had three main objectives: 1) to reveal the behavior of elemental concentrations by describing the correlation among the variables in terms of a few underlying factors, 2) to compare the FA results with Hierarchical Cluster Analysis (HCA) and K-Means Cluster Analysis (KMCA) results to aid in their interpretation, and 3) to reduce the number of elements required for near-mine geochemical exploration by finding geochemical fingerprints for the mineralization. After preliminary tests with a training dataset composed of 501 observations that cover only the control area, FA was chosen to be applied using the correlation matrix and Principal Component Analysis as the method of factor extraction (Costello \& Osborne, 2005). The main criteria for choosing the number of factors to retain were the scree test analysis (Cattell, 1966), analysis of total variance explained by the factors (Davis, 1986), and the interpretation of the factor solutions, whereas the generally used Kaiser criterion (Kaiser, 1960) has been shown to be inadequate for the studied case. Evidence suggests that different rotation methods can have a substantial influence on the solutions generated (Gaskin \& Happell, 2014). The varimax orthogonal rotation (Kaiser, 1958) 
was chosen because of the uncorrelated geology of the studied soil parental rocks (e.g., mafic, ultramafic, tonalitic, and hydrothermal) and was used to maximize the variance and approximate to a simple structure for ease of results interpretation.

HCA and KMCA were tested for two main objectives: 1) to differentiate samples that occur over mafic parental rocks from those over non-mafic parental rocks and 2) to detect elemental associations on soil that could indicate the spatial distribution of distinct parental lithologies and hydrothermal alteration types in the study area. Both HCA and KMCA were first conducted on a training dataset composed of 501 soil samples that covered only the control area. For the HCA tests, from all of the combinations of distance measure and linkage methods tested, the Euclidean distance combined with the Ward linkage returned the most accurate grouping of samples if compared to the geology of the control area. For KMCA, the testing was applied to the control dataset with a different number of clusters and the results were compared to the geology of the control area (Figure 4.6) until the best number (k) of clusters could be determined. Only then were HCA and KMCA applied to the complete dataset.

\subsection{Results and Discussion}

\subsubsection{Multivariate Analysis for the Complete Dataset}

Factor analysis, run for the complete dataset with the 22 variables selected after data preparation, was able to reduce the data to five main factors that explain $71.2 \%$ of the total data variance (Table 4.2). Factor 1 accounts for $27 \%$ of the variance and is clearly influenced by the mafic samples, with the highest loadings observed for $\mathrm{Co}, \mathrm{Cr}, \mathrm{Cu}, \mathrm{Fe}, \mathrm{Mn}, \mathrm{Sc}, \mathrm{V}, \mathrm{Y}$ and intermediate loads for $\mathrm{Al}$ and Ni. Factor 2 explains $15.3 \%$ of the data variance and is believed to be influenced by the distal alteration samples, with high loads of $\mathrm{Ba}, \mathrm{Ca}, \mathrm{La}, \mathrm{Na}, \mathrm{Sr}$ and intermediate loads of Y. Factor 3 explains $11.3 \%$ of the total variance and is clearly influenced by the pegmatitic intrusions, having high loads of $\mathrm{Al}, \mathrm{K}, \mathrm{Li}, \mathrm{Zr}$ and intermediate loads of $\mathrm{Pb}$. The intermediate loadings of $\mathrm{Pb}$ in factor 3 are believed to be influenced by hydrothermal protoliths, once pegmatites intrude the same shear zones as the mineralizing fluid. Factor 4 explains $10.6 \%$ of the variance and is influenced by the ultramafic rocks occurring on samples over the greenstone belt terrain, with high loads of $\mathrm{Mg}, \mathrm{Ni}, \mathrm{Zn}$ and intermediate loads of $\mathrm{Cr}$. Factor 5 explains $7.1 \%$ of the data variance and is influenced by the outcropping ore, with the highest loads of $\mathrm{Au}$ and $\mathrm{Pb}$ and intermediate loads of $\mathrm{K}, \mathrm{Co}$ and $\mathrm{Mn}$. 
Table 4.2 - Varimax Rotated Factor Loadings and Communalities for the complete dataset. $\mathrm{N}=2,908$.

\begin{tabular}{|c|c|c|c|c|c|c|}
\hline Variable & Factor1 & Factor2 & Factor3 & Factor4 & Factor5 & Comm. \\
\hline $\mathbf{A u}$ & -0.056 & 0.105 & 0.170 & -0.108 & -0.592 & 0.405 \\
\hline $\mathbf{P b}$ & 0.152 & -0.319 & -0.448 & 0.115 & -0.578 & 0.672 \\
\hline Mg & 0.120 & -0.293 & -0.230 & -0.836 & -0.131 & 0.869 \\
\hline $\mathbf{N i}$ & 0.547 & -0.051 & 0.019 & -0.718 & 0.015 & 0.819 \\
\hline $\mathbf{Z n}$ & 0.299 & -0.359 & -0.253 & -0.657 & -0.282 & 0.793 \\
\hline Al & 0.525 & 0.054 & -0.660 & -0.160 & 0.147 & 0.761 \\
\hline $\mathbf{K}$ & -0.285 & -0.217 & -0.648 & -0.182 & -0.329 & 0.690 \\
\hline $\mathbf{L i}$ & 0.165 & 0.029 & -0.649 & -0.307 & 0.092 & 0.552 \\
\hline $\mathbf{Z r}$ & 0.091 & 0.076 & -0.724 & 0.072 & 0.110 & 0.554 \\
\hline Ba & 0.011 & -0.802 & -0.173 & -0.199 & -0.214 & 0.759 \\
\hline $\mathbf{C a}$ & 0.135 & -0.739 & 0.177 & -0.302 & 0.097 & 0.696 \\
\hline La & -0.042 & -0.616 & -0.307 & -0.002 & -0.231 & 0.529 \\
\hline $\mathbf{N a}$ & -0.018 & -0.627 & 0.207 & 0.077 & 0.281 & 0.521 \\
\hline $\mathbf{S r}$ & -0.053 & -0.893 & 0.025 & -0.112 & -0.014 & 0.813 \\
\hline Co & 0.602 & $-0,100$ & 0.127 & -0.184 & -0.451 & 0.625 \\
\hline $\mathbf{C r}$ & 0.647 & 0.146 & -0.012 & -0.378 & 0.110 & 0.595 \\
\hline $\mathbf{C u}$ & 0.880 & -0.043 & -0.065 & -0.206 & -0.033 & 0.824 \\
\hline $\mathbf{F e}$ & 0.909 & 0.022 & -0.204 & -0.027 & 0.013 & 0.869 \\
\hline Mn & 0.682 & -0.209 & 0.124 & -0.323 & -0.431 & 0.814 \\
\hline Sc & 0.928 & 0.058 & -0.069 & -0.054 & 0.075 & 0.878 \\
\hline $\mathbf{V}$ & 0.951 & 0.076 & -0.094 & 0.015 & 0.048 & 0.922 \\
\hline $\mathbf{Y}$ & 0.692 & -0.364 & -0.195 & -0.187 & -0.173 & 0.714 \\
\hline Variance & 5.93 & 3.36 & 2.47 & 2.33 & 1.55 & 15.67 \\
\hline$\%$ Var & 27 & 15.3 & 11.3 & 10.6 & 7.1 & 71.2 \\
\hline
\end{tabular}

Both HCA and KMCA were conducted on the complete dataset for different numbers of clusters and linkage-distance combinations, aiming to classify the soil samples in terms of their parental material. The first approach was to distinguish between mafic/ultramafic (hereafter, mafic) and felsic/hydrothermal (hereafter, non-mafic). The HCA results using the Euclidean distance and Ward linkage methods showed very good accuracy in the discrimination of mafic and non-mafic soil samples but failed to distinguish the mineralized areas from barren areas. None of the KMCA results delivered such accuracy. The resulting HCA dendrogram (Figure 4.6) outlines (in black) the cluster that best represents the mafic samples if compared to the known occurrence of mafic dikes in the control area (Figure 4.7A). The dendrogram was cut with four clusters, with the mafic cluster indicated by the most distant centroid (cluster 4). HCA 
clusters 1, 2 and 3 did not match the control area occurrences of ore, distal alteration and unaltered country rock, both ore and distal alteration were grouped in cluster 3 , with high means of $\mathrm{Au}, \mathrm{Ba}, \mathrm{Ca}, \mathrm{K}, \mathrm{La}, \mathrm{Na}, \mathrm{Pb}$ and $\mathrm{Sr}$ (Table 4.3). The samples clustered as mafic generally occur at known greenstone areas or over large mafic dikes mapped on the surface or intercepted by drilling and indicate a continuation of these non-outcropping dikes covered by soil. These partial results allowed the mapping of unknown mafic dikes, contact zones with the greenstone belt and a large greenstone xenolith outside the control area (checked in the field). The 205 samples identified as being of mafic origin presented high (i.e., above 1 normalized) mean concentrations of $\mathrm{Al}, \mathrm{Co}, \mathrm{Cu}, \mathrm{Fe}, \mathrm{Mg}, \mathrm{Mn}, \mathrm{Sc}, \mathrm{V}, \mathrm{Y}$, and $\mathrm{Zn}$ and very low $\mathrm{Au}, \mathrm{Ba}, \mathrm{K}, \mathrm{La}, \mathrm{Na}$ and $\mathrm{Sr}$. The relatively high $\mathrm{Zr}$ content is expected and explained by the occurrence of Zr-rich mafics at some levels of the greenstone sequence, commonly intercepted by drilling in the Paiol deposit. 


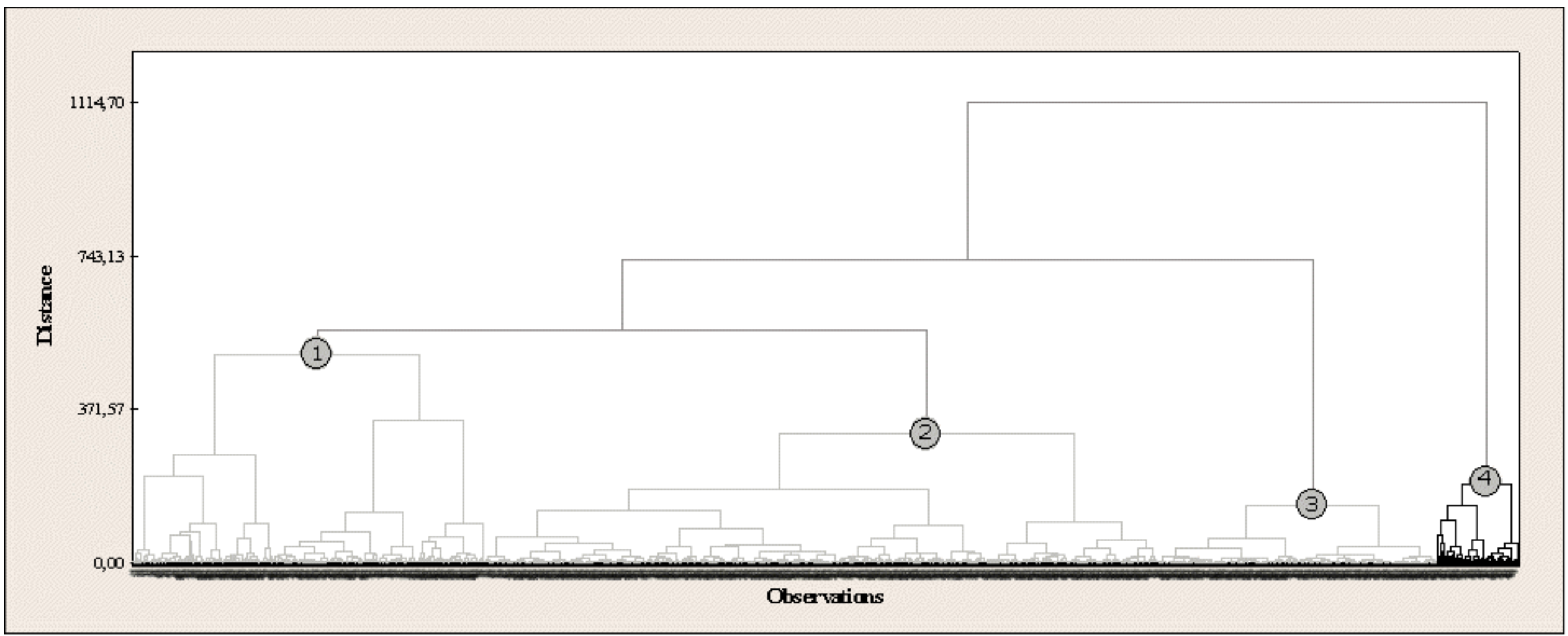

Figure 4.6 - HCA dendrogram for Ward linkage and Euclidean distance. The mafic cluster (4) is outlined in black. Groups 1,2 and 3 did not correspond to the control area lithological distribution pattern. 
Table 4.3 - HCA Euclidean-Ward cluster results for the complete dataset. Cluster 4 grouped mafic samples, and the highest normalized means are outlined. $\mathrm{N}=2,908$.

\begin{tabular}{|l|r|r|r|r|}
\hline Var. & Cluster1 & Cluster2 & Cluster3 & $\begin{array}{r}\text { Cluster4 } \\
(\mathbf{n = 2 0 5})\end{array}$ \\
\hline $\mathbf{A u}$ & 0,01 & $-0,23$ & 0,11 & $-0,07$ \\
\hline $\mathbf{A l}$ & $-0,04$ & $-1,01$ & 0,12 & $\mathbf{2 , 0 2}$ \\
\hline $\mathbf{B a}$ & $-0,22$ & $-0,87$ & 1,15 & 0,15 \\
\hline $\mathbf{C a}$ & $-0,19$ & $-0,38$ & 0,72 & 0,45 \\
\hline $\mathbf{C o}$ & $-0,15$ & $-0,21$ & $-0,01$ & $\mathbf{2 , 1 3}$ \\
\hline $\mathbf{C r}$ & $-0,09$ & $-0,29$ & $-0,23$ & $\mathbf{2 , 4 1}$ \\
\hline $\mathbf{C u}$ & $-0,21$ & $-0,38$ & $-0,03$ & $\mathbf{3 , 1 8}$ \\
\hline $\mathbf{F e}$ & $-0,10$ & $-0,64$ & $-0,16$ & $\mathbf{3 , 0 0}$ \\
\hline $\mathbf{K}$ & $-0,07$ & $-0,89$ & 0,95 & $-0,68$ \\
\hline $\mathbf{L a}$ & $-0,19$ & $-0,64$ & 1,07 & $-0,28$ \\
\hline $\mathbf{L i}$ & $-0,02$ & $-0,77$ & 0,26 & 0,80 \\
\hline $\mathbf{M g}$ & $-0,22$ & $-0,58$ & 0,73 & 1,05 \\
\hline $\mathbf{M n}$ & $-0,22$ & $-0,34$ & 0,18 & $\mathbf{2 , 4 9}$ \\
\hline $\mathbf{N a}$ & $-0,17$ & $-0,31$ & 0,80 & $-0,24$ \\
\hline $\mathbf{N i}$ & $-0,17$ & $-0,27$ & 0,01 & $\mathbf{2 , 4 3}$ \\
\hline $\mathbf{P b}$ & $-0,17$ & $-0,83$ & 0,90 & 0,40 \\
\hline $\mathbf{S c}$ & $-0,18$ & $-0,25$ & $-0,24$ & $\mathbf{3 , 3 8}$ \\
\hline $\mathbf{S r}$ & $-0,25$ & $-0,56$ & 1,20 & $\mathbf{- 0 , 2 2}$ \\
\hline $\mathbf{V}$ & $-0,13$ & $-0,41$ & $-0,27$ & $\mathbf{3 , 2 3}$ \\
\hline $\mathbf{Y}$ & $-0,22$ & $-0,70$ & 0,47 & $\mathbf{2 , 2 7}$ \\
\hline $\mathbf{Z n}$ & $-0,28$ & $-0,68$ & 0,90 & 1,37 \\
\hline $\mathbf{Z r}$ & 0,08 & $-0,86$ & 0,11 & 0,46 \\
\hline
\end{tabular}

\subsubsection{Clustering Analysis for the Non-mafic Dataset}

The samples identified as mafic by HCA where removed from the dataset, producing a non-mafic dataset composed of 2,703 samples. Both HCA and KMCA clustering were applied to the non-mafic dataset and compared to the control area. This time, KMCA showed better results, being able to spatially distinguish from ore, distal alteration and country rock regions but still without the desired precision. KMCA is commonly known to be more influenced by the first observations of the dataset, so the accuracy of the method was improved by arranging the dataset by decreasing order of $\mathrm{Au}$ values. The K-means algorithm was then able to correctly group the samples: cluster 1) samples with anomalous gold concentrations were over the known 
outcropping ore (ultramylonites and mylonites); cluster 2) unaltered country rock areas (metatonalites); and cluster 3) areas of known distal alteration (protomylonites), as shown in Figure 4.7B. As shown by the KMCA results in Table 4.4, soil samples occurring over protomylonitic zones (cluster 3) are enriched in $\mathrm{Al}, \mathrm{Ba}, \mathrm{Ca}, \mathrm{Co}, \mathrm{Cr}, \mathrm{Cu}, \mathrm{Fe}, \mathrm{La}, \mathrm{Mg}, \mathrm{Mn}, \mathrm{Na}, \mathrm{Pb}$ and $\mathrm{Sr}$, whereas barren country rock (cluster 2) is relatively poor in those elements. The highest standardized means of $\mathrm{V}$ and $\mathrm{Zn}$ are too low to be securely interpreted. Mylonites and ultramylonites (cluster 1) are enriched in $\mathrm{Au}, \mathrm{K}, \mathrm{Pb}, \mathrm{Y}$, and $\mathrm{Zr}$, with intermediate values of $\mathrm{Cu}, \mathrm{La}$ and $\mathrm{Mn}$. The ore is more silicified and thus presents lower concentrations of the elements encountered in protomylonites, except for the elements listed above. The presence of pegmatitic bodies intruding the shear zones might explain the $\mathrm{Y}$ and $\mathrm{Zr}$ enrichment in these samples.

Table 4.4 - KMCA cluster results for the non-mafic dataset. $\mathrm{N}=2,703$.

\begin{tabular}{|l|r|r|r|}
\hline Var. & $\begin{array}{r}\text { Cluster1 } \\
(\mathbf{n}=\mathbf{6 2})\end{array}$ & $\begin{array}{r}\text { Cluster2 } \\
(\mathbf{n}=\mathbf{2 1 4 3})\end{array}$ & $\begin{array}{r}\text { Cluster3 } \\
(\mathbf{n}=\mathbf{4 9 8})\end{array}$ \\
\hline $\mathbf{A u}$ & $\mathbf{4 . 8 3}$ & -0.18 & 0.19 \\
\hline $\mathbf{K}$ & $\mathbf{0 . 4 4}$ & -0.03 & 0.15 \\
\hline $\mathbf{P b}$ & $\mathbf{0 . 4 6}$ & -0.10 & $\mathbf{0 . 7 1}$ \\
\hline $\mathbf{Y}$ & $\mathbf{0 . 1 6}$ & 0.00 & -0.06 \\
\hline $\mathbf{Z r}$ & $\mathbf{0 . 8 3}$ & -0.01 & -0.12 \\
\hline $\mathbf{A l}$ & -0.63 & 0.00 & 0.15 \\
\hline $\mathbf{B a}$ & 0.07 & -0.14 & $\mathbf{1 . 1 7}$ \\
\hline $\mathbf{C a}$ & -0.03 & -0.12 & $\mathbf{1 . 0 2}$ \\
\hline $\mathbf{C o}$ & -0.01 & -0.18 & $\mathbf{1 . 5 5}$ \\
\hline $\mathbf{C r}$ & -0.18 & -0.11 & $\mathbf{1 . 0 1}$ \\
\hline $\mathbf{C u}$ & 0.21 & -0.19 & $\mathbf{1 . 5 5}$ \\
\hline $\mathbf{F e}$ & -0.36 & -0.08 & $\mathbf{0 . 7 6}$ \\
\hline $\mathbf{L a}$ & 0.28 & -0.13 & $\mathbf{0 . 9 8}$ \\
\hline $\mathbf{L i}$ & -0.35 & -0.01 & 0.21 \\
\hline $\mathbf{M g}$ & 0.15 & -0.19 & $\mathbf{1 . 5 9}$ \\
\hline $\mathbf{M n}$ & 0.33 & -0.21 & $\mathbf{1 . 6 7}$ \\
\hline $\mathbf{N a}$ & -0.17 & -0.04 & 0.38 \\
\hline $\mathbf{N i}$ & -0.08 & -0.23 & $\mathbf{1 . 9 7}$ \\
\hline $\mathbf{S c}$ & -0.20 & -0.12 & $\mathbf{1 . 0 3}$ \\
\hline $\mathbf{S r}$ & -0.07 & 0.00 & 0.02 \\
\hline $\mathbf{V}$ & -0.15 & 0.02 & -0.09 \\
\hline $\mathbf{Z n}$ & -0.26 & 0.01 & -0.01 \\
\hline
\end{tabular}




\subsubsection{Multivariate Analysis Results Interpretation}

The variations in the results obtained for FA, HCA and KMCA were influenced by 1) the differences in the dataset, i.e., the presence of mafic samples while running FA and HCA and the absence for KMCA, and 2) the particularities of each method.

Mafic soil samples were efficiently distinguished through FA and HCA. For both methods, the elements $\mathrm{Al}, \mathrm{Co}, \mathrm{Cr}, \mathrm{Cu}, \mathrm{Fe}, \mathrm{Mn}, \mathrm{Ni}, \mathrm{Sc}, \mathrm{V}$ and $\mathrm{Y}$ were identified as the most representative elements of the mafic samples when analyzed in comparison with the other influencing lithologies. FA did not distinguish (among the 5 factors analyzed) any important common factor that could represent the unaltered country rock, probably because of the weak correlation between the elements that form these rocks. KMCA, however, was able to group 2,143 observations (cluster 2) with very low concentrations of most elements (Table 4.4) demonstrated to be representative of the tonalitic unaltered country rock by comparing to the known geology of the control area.

In addition to distinguishing between distal and proximal alteration, FA was capable of distinguishing mafic, ultramafic and pegmatitic influences in soil sample composition, whereas HCA merged mafic and ultramafic samples, and KMCA merged pegmatitic and ore samples into the same clusters. This explains the high means of $\mathrm{Y}$ and $\mathrm{Zr}$ (representative of pegmatites in the FA results) in KMCA cluster 1 (ore) and the high means of $\mathrm{Mg}, \mathrm{Ni}, \mathrm{Zn}$ and $\mathrm{Cr}$ (representative of ultramafics in FA) in HCA cluster 4.

The proximal alteration samples (mylonites/ultramylonites/ore) were classified by FA as having a common factor influenced by the high loadings for $\mathbf{A u}$ and $\mathbf{P b}$ and moderate loadings for $\mathbf{K}, \mathrm{Co}$ and $\mathrm{Mn}$, whereas KMCA cluster 1 grouped high means of $\mathbf{A u}, \mathbf{K}, \mathbf{P b}, \mathrm{Y}, \mathrm{Zr}$ (elements in bold are coincident). The differences between the FA and KMCA results for ore identification are due to the joined grouping of ore and pegmatites by KMCA in cluster 1 and the identification of lighter influences of $\mathrm{Co}$ and $\mathrm{Mn}$ by FA, related to the sulfidation (Co-rich pyrite) and carbonation (Mn-rich carbonate), respectively.

The distal alteration samples (protomylonites) were classified by FA as being represented by the elements $\mathbf{B a}, \mathbf{C a}, \mathbf{L a}, \mathbf{N a}, \mathbf{P b}, \mathbf{S r}$, and Y, whereas for the KMCA results (cluster 3), the main elements were Al, Ba, Ca, Co, Cr, Cu, Fe, La, Mg, Mn, Na, Pb and Sr. The dataset used for FA contained the mafic samples that, after being identified by HCA, were removed in order to only cluster hydrothermally altered/unaltered samples by KMCA. The superior number of elements attributed to the protomylonitic cluster in $\mathrm{KMCA}(\mathrm{Al}, \mathrm{Co}, \mathrm{Cr}, \mathrm{Cu}, \mathrm{Fe}, \mathrm{Mg}, \mathrm{Mn}$ ) and the influence of $\mathrm{Y}$ in FA can be explained by the following assumptions: 1) Some residual mafic or ultramafic influenced samples missed by HCA clustering might have remained in the dataset, attributing elements such as $\mathrm{Cr}, \mathrm{Mg}, \mathrm{Mn}$ to the cluster. 2) After the mafic samples removal, $\mathrm{Al}$ 
and $\mathrm{Fe}$ (before attributed to the mafic samples) were classified to represent the high Fe muscovite and/or pyrites present in the hydrothermal samples. $\mathrm{Cu}$ and $\mathrm{Co}$ were also more abundant in mafic samples, and after the mafic samples removal from the dataset, these elements probably represent the pyrite/chalcopyrite sulfidation. Co is often associated with $\mathrm{Au}$ mineralization as Cobalt-bearing phases are locally present as inclusions in pyrite and chalcopyrite (Pirajno, 2009). 3) $\mathrm{Y}$ is interpreted as a result of pegmatite influence in protomylonites. The remaining elements $\mathrm{Ba}, \mathrm{Ca}, \mathrm{La}, \mathrm{Na}, \mathrm{Pb}$ and $\mathrm{Sr}$ were common for both $\mathrm{FA}$ and KMCA for the distal alteration protomylonites and represent important pathfinder elements for new deposits.

\subsubsection{Spatial Results Interpretation}

The waste dump pile represents an important feature for comparison purposes in the control area. Near its surface, it is known to be predominantly composed of the protomylonitic fragments that encapsulate the ore and were removed during the mine stripping process. As demonstrated by KMCA, the soil developed over the waste dump pile has some contribution of residual ore and some occurrence of barren meta-tonalites but mainly showed samples classified as protomylonitic (Figure 4.7B).

The near-surface ore at Vira Saia mine surroundings produced a well-defined $\mathrm{Au}$ anomaly in the soil samples (Figure 4.8) and was well-explored by trenching and drilling surveys. However, Au anomalies were absent or too weak outside the control area. The results achieved in this study show that the use of combined elemental anomalies other than gold are indicative of high potential targets at Vira Saia deposit's near-mine context. The clusters obtained from both HCA and KMCA were plotted over the study area (Figure 4.9), and the anomalies identified were grouped into four exploration targets and three sub-targets, all numbered in order of importance (Figure 4.10). These spatial results were able to shed light over the exploration potential of the study area by indicating distal alteration anomalies in the surface that might lead to new deposits in the future. Additionally, the results contributed to the mapping of unknown mafic dikes, the contact zone with the greenstone belt and a large greenstone xenolith (the largest found so far) near the intrusion contact.

Target 1 is the strongest and largest continuous anomaly. It is located on relatively flat terrain and is truncated by two main mafic dikes, along which three sub-targets were identified. The sub-targets 1.1, 1.2 and 1.3 were selected by their similar geological characteristics compared to the Vira Saia deposit. In this case, the main ore bodies were affected by mafic dikes that truncate the NW shear zones that host the mineralization. This environment might generate space and/or fluids to concentration processes. 
Target 2 is a strong but shorter anomaly compared to Target 1. It is located over a hill with $300 \mathrm{~m}$ of positive relief, which might increase the exploration costs. The relief might have increased the anomaly area by spreading pathfinder elements downhill. The three main anomaly trends in this target were inferred via satellite image interpretation following the trace of the shear zones. In Target 2, a mylonitic rock chip sample was collected and analyzed for gold, resulting in $2.9 \mathrm{ppm} / \mathrm{Au}$ and confirming the mineralization.

Target 3 is apparently the extension of Target 1, which was interrupted by the lack of soil grid coverage. In this target, two narrow stripes of positive relief run along two of the main anomalies, possibly preserved due to the hardening caused by the silicification. The same can be said of Target 2. At the northernmost region of Target 3, evidence of ancient artisanal mining containing a flooded abandoned shaft was found (deeper ore is often economically not feasible to artisanal miners).

Target 4 is considered the least important target, as it was formed by one soil line anomaly and does not yet show any clear field evidence.
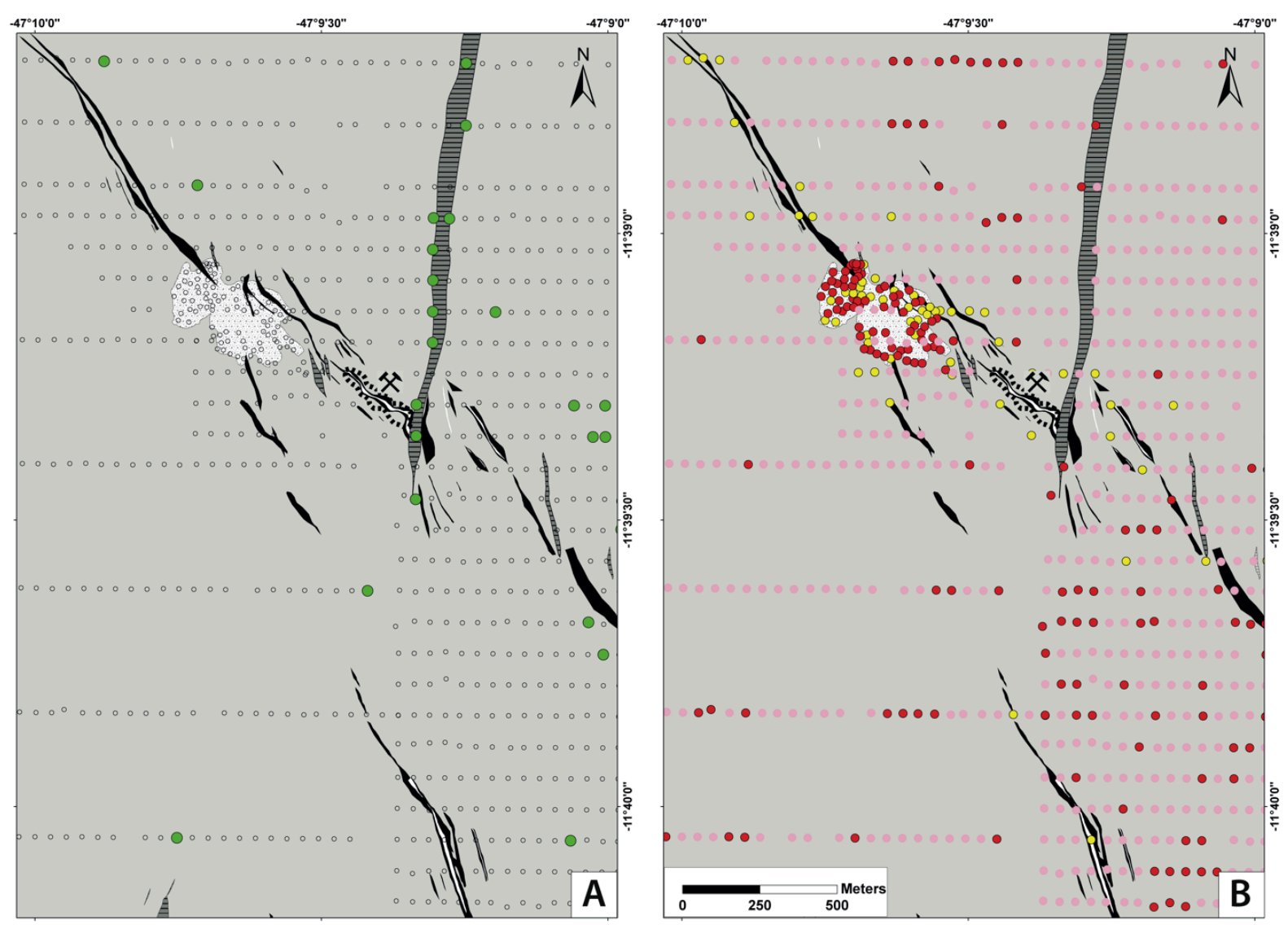

Figure 4.7 - A) Geologic map of the control area (see geology legend on Figure 4.4) showing mafic (green) and non-mafic (hollow) clusters classified by HCA. B) Geologic map of the control area showing the three clusters from KMCA: cluster 1 in yellow, cluster 2 in pink and cluster 3 in red. Note the high occurrence of clusters 2 and 3 over the waste dump pile (white). 


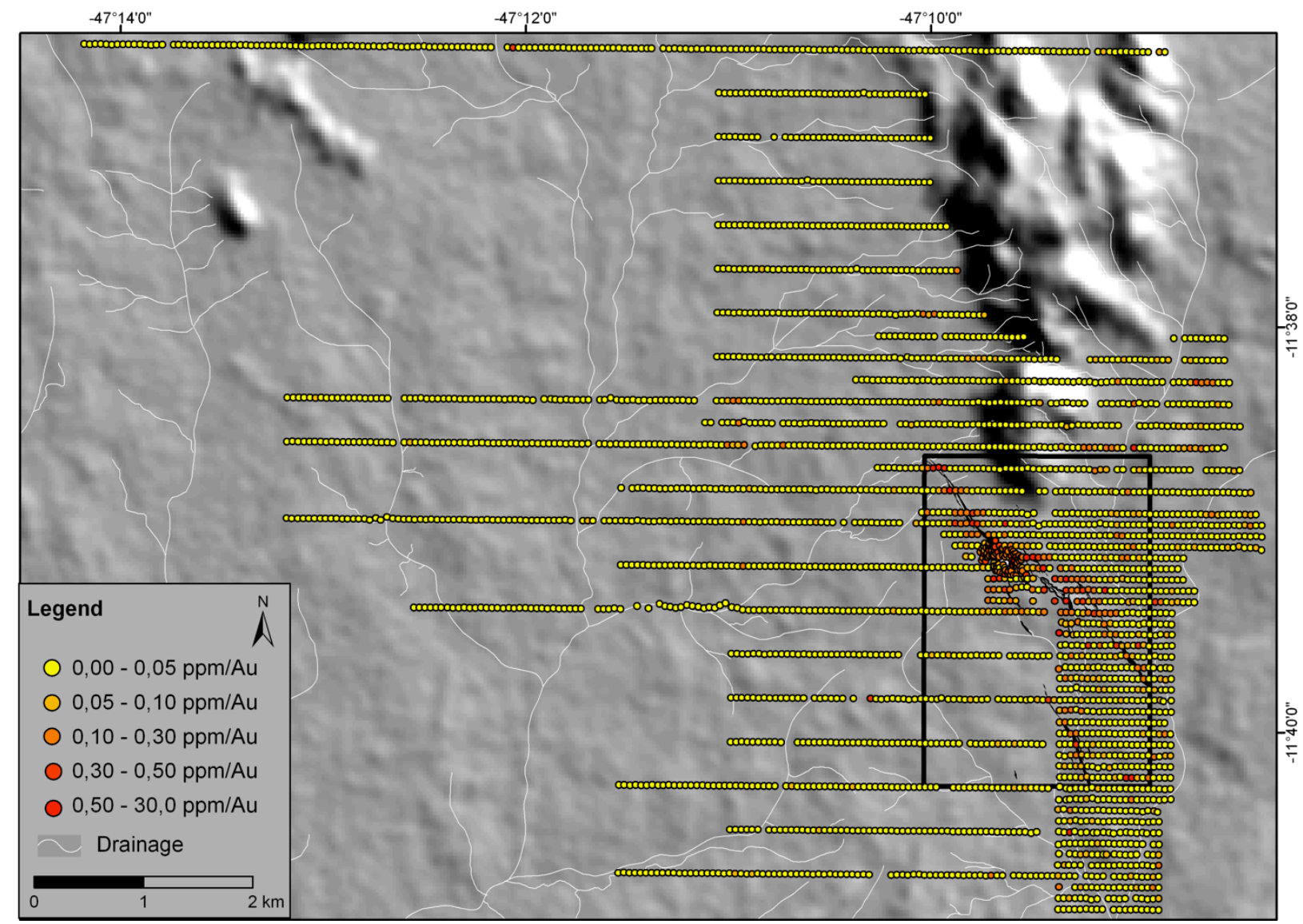

Figure 4.8 - Map of the study area showing gold anomalies in the soil geochemical results (ppm).

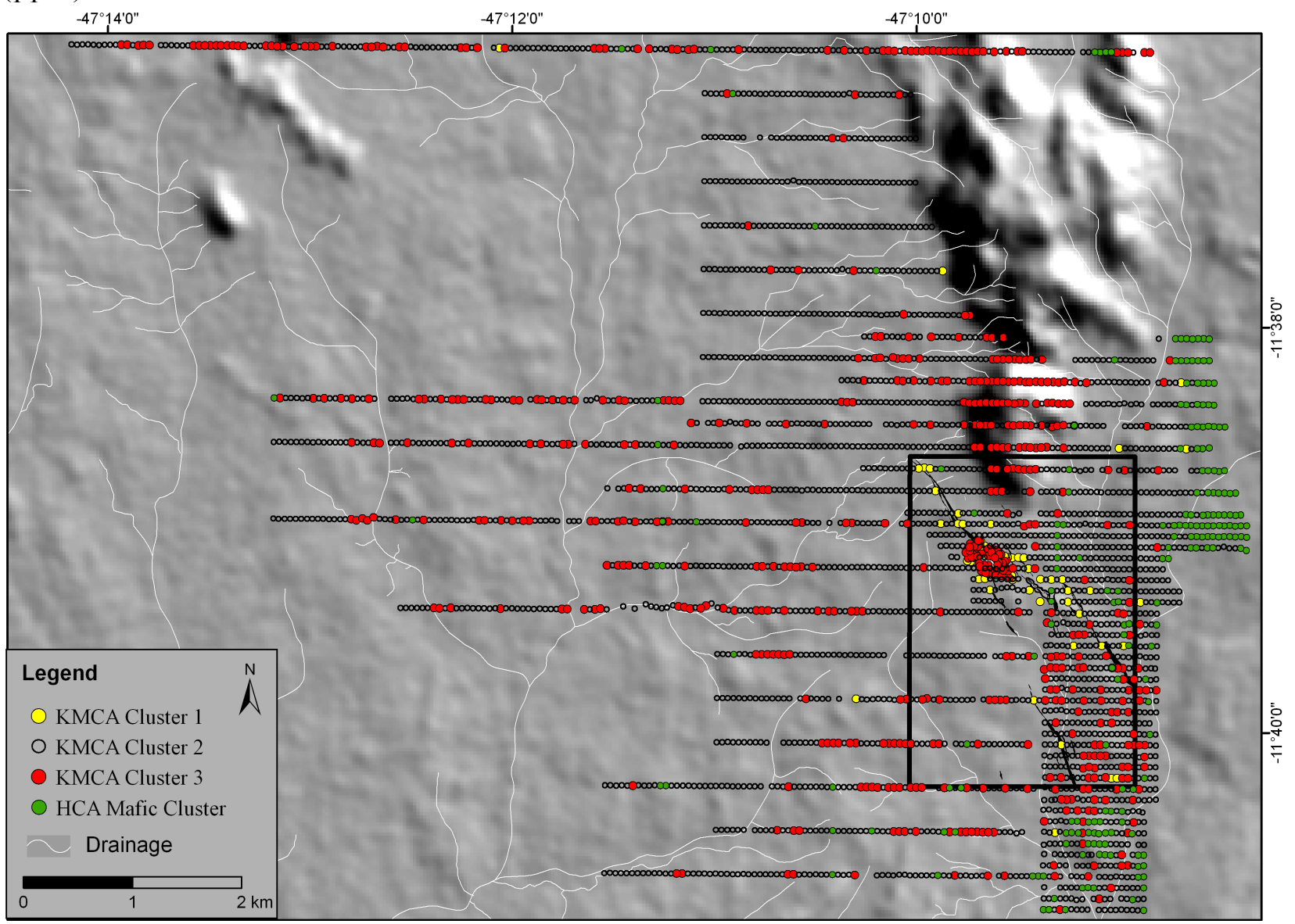

Figure 4.9 - Map of the study area showing both KMCA and HCA cluster results. 


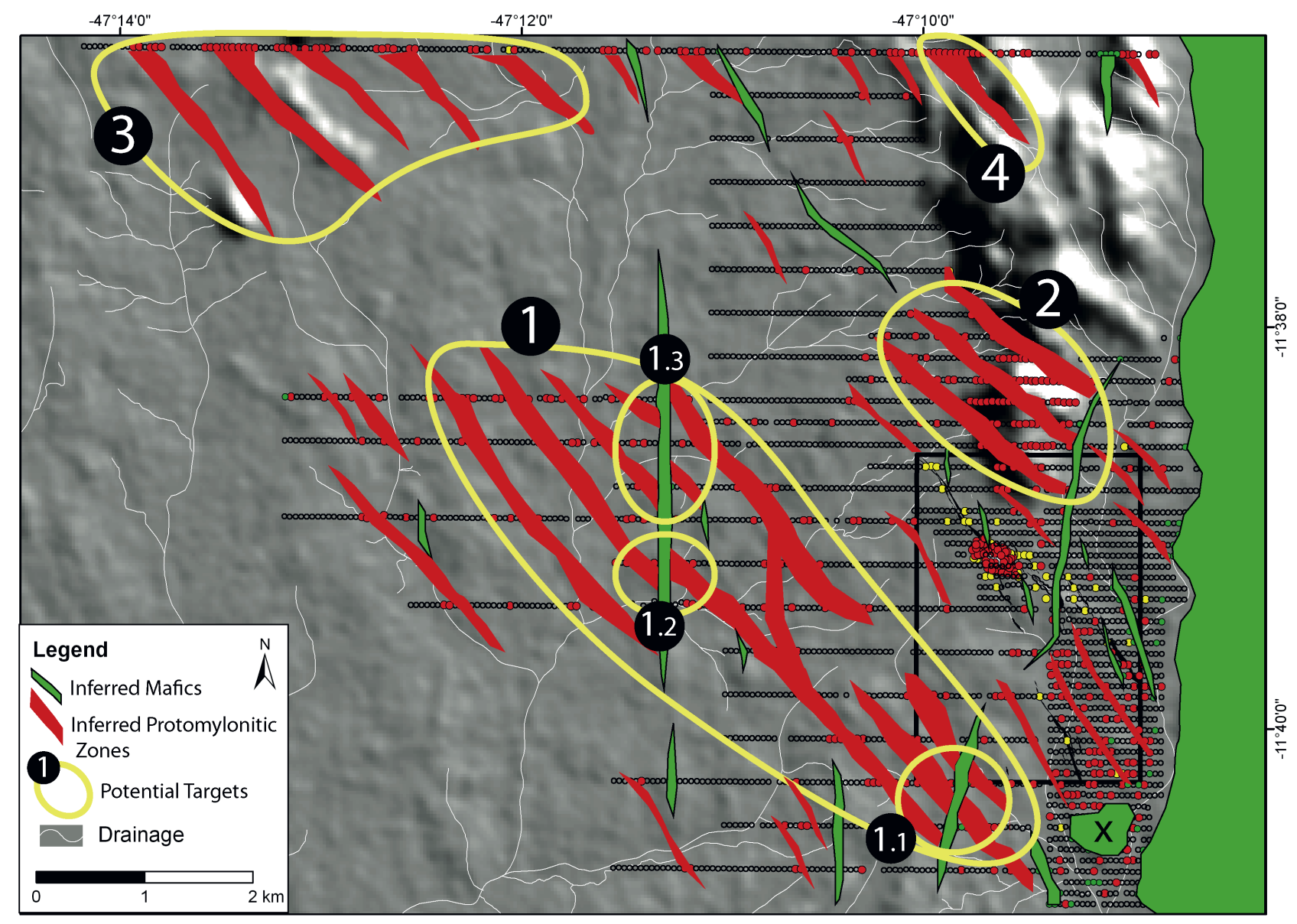

Figure 4.10 - Interpreted map of cluster results and geologic knowledge showing inferred occurrences of mafic dikes, mafic xenolith (X) and greenstone belt area in green, outcropping protomylonitic zones in red and potential targets and sub-targets circled in yellow, numbered in order of importance.

\subsection{Final Discussion and Conclusions}

The obtained results fulfill the aim of the study by indicating four new target areas and three sub-targets with sufficient accuracy for future planning of a near-mine exploratory program as well as allowing the mapping of bedrock. The targets are composed of distinctive soil anomalies with the same general orientation as the Vira Saia ore body.

The study shows that the elements $\mathbf{A u}, \mathbf{B a}, \mathbf{C a}, \mathbf{K}, \mathbf{L a}, \mathbf{N a}, \mathbf{P b}$, and $\mathbf{S r}$ compose the main geochemical fingerprint for the deposit type, thus representing important pathfinder elements for soil exploration purposes. Gold barren or weakly mineralized protomylonites are enriched in $\mathrm{Ba}$, $\mathrm{Ca}, \mathrm{La}, \mathrm{Na}, \mathrm{Pb}$ and $\mathrm{Sr}$ and should be considered exploratory targets, as they represent strong evidence of mineralization at depth. As identified through microprobe analysis, $\mathrm{Ba}$ and $\mathrm{Sr}$ enrichment is hosted in muscovite, epidote, chlorite and calcite, characteristic mostly of the distal alteration. Because sulfidation is too low, the elements $\mathrm{Cu}, \mathrm{Co}$ and $\mathrm{Fe}$ are not considered as significant pathfinder elements. $\mathrm{Mn}$ is also characteristic of distal alteration but as well as $\mathrm{Cu}$, Co and Fe could represent a misleading pathfinder, leading to mafic rocks. $\mathrm{Li}$, Y and $\mathrm{Zr}$ could be 
used as secondary pathfinders for mineralization once they are indicative of pegmatitic intrusions, which have been found to be intimately related to the shear zones that host the ore occurrences.

From the original 35 elements analyzed, 22 were found to be worthy of chemical analysis, 8 elements (i.e., $\mathrm{Au}, \mathrm{Ba}, \mathrm{Ca}, \mathrm{K}, \mathrm{La}, \mathrm{Na}, \mathrm{Pb}$, and $\mathrm{Sr}$ ) were found to be essential pathfinders, and 3 (i.e., Li, Y and Zr) were considered secondary pathfinders for soil exploration in the area. Reducing the number of elements required for chemical analysis can reduce laboratory costs, and knowledge of the essential and secondary pathfinders can simplify and boost data processing and interpretation processes.

Sorting the dataset by selected elements might generate positive effects over clustering results, especially in the case of K-means clustering. The removal of very distant centered clusters (i.e., mafic/ultramafic) from the dataset increases the definition of future cluster analysis for the remaining dataset. Sufficient knowledge about the data and the area studied is fundamental for the selection of criteria and interpretation of multivariate methods in geology. The combination of different multivariate methods has been demonstrated to be of great use because each method complements the other.

The higher concentration of the incompatibles of $\mathrm{Ba}, \mathrm{La}$, and $\mathrm{Sr}$ in hydrothermal protomylonites, and their close association with pegmatitic intrusions (as indicated by the enrichment in $\mathrm{K}, \mathrm{Y}$ and $\mathrm{Zr}$ ) indicates a possible contribution of magmatic hydrothermal fluid sources during the mineralization and/or reworking phases. The high $\mathrm{FeO}$ content identified through microprobe analysis (up to 5\%) in greenish muscovite that forms the Vira Saia ore could be indicative of contamination of mineralizing or reworking fluids from the adjacent greenstone belts or the mafic dikes that strike the area.

The Vira Saia deposit area represents a promising prospect for cheap and fast, small-to medium-scale gold production. The factors contributing to that affirmative are its great lateral extension with precise structural and geochemical controls and the occurrence of easily recovered free, flaky gold.

\section{Acknowledgements}

The authors are grateful to the University of Brasília $(U n B)$ and the Brazilian Research Council $(C N P q)$ for the laboratorial and financial support and to Rio Novo Gold Inc. for sharing the geochemical data used in the study. We thank the editorial board of the Journal of Geochemical Exploration for the handling of the submitted manuscript and the anonymous reviewers for their suggestions for improvement. 


\section{References}

Cattell, R. B. 1966. The scree test for the number of factors. Multivariate Behavioral Research, 1, 245276.

Costello, A.B. \& Osborne, J.W. 2005. Best practices in exploratory factor analysis: four recommendations for getting the most from your analysis. Practical Assessment Research \& Evaluation, 10(7).

Cruz, E.L.C.C. \& Kuyumjian, R.M. 1993. Granitóides relacionados a um arco magmático no Proterozóico Inferior a Arqueano de região de Almas-Dianópolis (TO). In: 4 Cong. Bras. de Geoquímica, 1993, Brasília. Anais do 4 Cong. Bras. de Geoquímica, v. 1. p. 92-95.

Cruz, E.L.C.C. \& Kuyumjiam, R.M. 1998. The geology and tectonic evolution of the tocantins granitegreenstone terrane: almas-dianópolis region, Tocantins state, central brasil. Rev. Bras. Geoc., 28(2):173-182.

Cruz, E.L.C.C. \& Kuyumjian, R.M. 1999. Mineralizações auríferas filoneanas do Terreno granitogreenstone do Tocantins.. Revista Brasileira de Geociências , v. 29, p. 291-298.

Cruz, E.L.C.C., 2001. A gênese e o contexto tectônico da mina Córrego Paiol: um depósito de ouro hospedado em anfibolito do embasamento da Faixa de Dobramentos Brasília. Tese Doutorado, Instituto de Geociências, Universidade Brasília, Brasília, 183 pp

Cruz, E.L.C.C.; Kuyumjiam, R.M.; Boaventura G.R. 2003. Low-k calc-alkaline granitic series of southeastern Tocantins state: chemical evidence for two sources for the granite-gneissic complexes in the paleoproterozoic Almas-Dianópolis terrane. Revista Brasileira de Geociencias., 33(2):125136.

Cruz, E.L.C.C. \& Kuyumjiam, R.M. 2006. Geochronology, isotopic signature and metallogenetic model for the Córrego do Paiol gold deposit, Tocantins state, central brazil. Revista Brasileira de Geociencias,36(1-suplemento):152-156.

Dardenne, M.A. 2000. The Brasília Fold Belt. In: U.G. Cordani, E.J. Milani, A. Thomaz Filho \& D.A. Campos. 2000. Tectonic evolution of South America. 31 st International Geological Congress, Rio de Janeiro, SBG. p. 231-263.

Dardenne, M.A.; Giustina, M.E.S.D., Sabóia, A.M.; Bogossian, J. 2009. Datação geocronológica u-pb da sequência vulcânica de Almas, Tocantins. In: sbg, simp. Geol. Centro-oeste, 11, Anais, 1 cdrom.

Davis, J.C. 1986. Statistics and Data Analysis in Geology. Wiley, New York, N.Y (1973), p. 550

D'el-Rey Silva, L.J.H.; Vasconcelos, M.A.R.; Silva, D.V.G. 2008. Timing and role of the Maranhão River Thrust in the evolution of the neoproterozoic Brasília Belt and Tocantins Province, central Brazil. Gondwana Research, 13: 352-374.

De Sa, C.M.; Noronha, F.; Silva E.F. 2014. Factor analysis characterization of minor element contents in sulfides from $\mathrm{Pb}-\mathrm{Zn}-\mathrm{Cu}-\mathrm{Ag}$ hydrothermal vein deposits in Portugal. Ore Geology Reviews, 62: 54-71.

Ferrari, M.A.D. \& Choudhuri A. 2000. Chemical and structural constraints on the paiol gold deposit, almas greenstone belt, brazil. Rev. Bras. Geoc., 30(3):297-301.

Ferrari, M.A.D. \& Choudhuri A. 2004. Structural controls on gold mineralization and the nature of related fluids of the Paiol gold deposit, Almas greenstone belt, brazil. Ore geology reviews, 24:173197.

Filzmoser, P.; Hron, K.; Reimann, C. 2012. Interpretation of multivariate outliers for compositional data, Computers \& Geosciences, Volume 39, February 2012, Pages 77-85, ISSN 0098-3004, http://dx.doi.org/10.1016/j.cageo.2011.06.014.

Filzmoser, P.; Garrett, R.G.; Reimann, C. 2005. Multivariate outlier detection in exploration geochemistry, Computers \& Geosciences, Volume 31, Issue 5, June 2005, Pages 579-587, ISSN 0098-3004, http://dx.doi.org/10.1016/j.cageo.2004.11.013. 
Garrett, R.G. \& Nichol, I., 1969. Factor analysis in the interpretation of regional geochemical stream sediment data. Q. Colo. School Mines, 64 : 245--264.

Gaskin, C.J.; Happell B., Power, effects, confidence, and significance: An investigation of statistical practices in nursing research, International Journal of Nursing Studies, Volume 51, Issue 5, May 2014, Pages 795-806, ISSN 0020-7489.

Hoaglin, D. C. \& Iglewicz, B. 1987. Fine tuning some resistant rules for outlier labeling.Journal of American Statistical Association, 82, 1147-1149.

Kaiser, H.F. 1958. The varimax criterion for analytic rotationing factor analysis. Psychometrika 23: 187-200.

Kaiser, H.F. 1960. The application of electronic computers to factor analysis. Educational and Psychological Measurement, 20, 141-151.

Kuyumjian, R.M.; Cruz, E.L.C.C.; Araújo Filho, J.O.; Moura, M.A.; Guimarães, E.M.; Pereira, K.M.S. 2012. Geologia e ocorrências de ouro do Terreno Granito-Greenstone do Tocantins, TO: síntese do conhecimento e parâmetros para exploração mineral. Revista Brasileira de Geociências 42 (1), 213228.

Kwitko, R.; Masotti, F.; Baars, F.J.; Abreu, F.R.; Bella, V.C.M.; Ferrari, A.J.D.; Fuck, R.F.; Gomes, R.P.; Ribeiro, E.; Tallarico, F.; Vial, D.S.; Viana, F.H. 1995. Petrografia, alteração hidrotermal e mineralização aurífera da jazida do Córrego Paiol - Almas (TO). In: SBG, Congr. Bras. Geoquímica, 5, Anais, 1 CD-Rom.

Lin, X.; Wang, X.; Zhang, B.; Yao, W. 2014. Multivariate analysis of regolith sediment geochemical data from the Jinwozi gold field, north-western China, Journal of Geochemical Exploration 137: 48-54.

Nichol, I.; Garrett, R.G.; Webb, J.S., 1966. Automatic data plotting and mathematical and statistical interpretation of geochemical data. Geol Surv. Can. Paper, 66-54: 195--210.

Pirajno, F. 2009. Hydrothermal Processes and Mineral Systems. Springer, 1250 p.

Roshani, P., Mokhtari, A.R., Tabatabaei, S.H., 2013. Objective based geochemical anomaly detectionapplication of discriminant function analysis in anomaly de- lineation in the Kuh Panj porphyry $\mathrm{Cu}$ mineralization (Iran). J. Geochem. Explor. 130, 65-73.

Sadeghi, M.; Billay, A.; Carranza, E.J.M. 2014 Analysis and mapping of soil geochemical anomalies: Implications for bedrock mapping and gold exploration in Giyani area, South Africa, Journal of Geochemical Exploration.

Soil Survey Staff. 1999. Soil taxonomy: A basic system of soil classification for making and interpreting soil surveys. 2nd edition. Natural Resources Conservation Service. U.S. Department of Agriculture Handbook, 436.

Tukey, J. W. 1977. Exploratory data analysis. Reading, MA: Addison-Wesley.

Tripathi, V.S., 1979. Factor analysis in geochemical exploration. J. Geochem. Expl. 11, 263-275.

Woodsworth, G.J., 1971. A geochemical drainage survey and its implications for metalogenesis, central Coast Mountains, British Columbia. Econ. Geol., 66: 1104--1120. 


\section{CAPÍTULO 5}

\section{DISCUSSÕES FINAIS, CONCLUSÕES E RECOMENDAÇÕES}

Os procedimentos adotados no presente estudo geraram excelentes resultados que não só confirmaram a validade do método em determinar novos alvos, mas também permitiram a caracterização de diferentes padrões geoquímicos na composição dos solos locais causados pela influência da composição mineralógica das rochas parentais subjacentes. Foi possível reduzir o número de elementos necessários na análise laboratorial bem como deduzir o significado das altas concentrações dos elementos que se mostraram significativos à mineralização na área. Dos 35 elementos analisados, apenas 22 foram considerados necessários para a identificação de áreas anômalas nos domínios do Bloco Ribeirão das Areias e apenas 11 elementos foram classificados como importantes farejadores para o tipo de depósito estudado, dos quais 8 elementos (Au, $\mathrm{Ba}$, $\mathrm{Ca}, \mathrm{K}, \mathrm{La}, \mathrm{Na}, \mathrm{Pb}$, e $\mathrm{Sr}$ ) foram considerados farejadores essenciais, e 3 foram considerados farejadores secundários ( $\mathrm{Li}, \mathrm{Y}$ e $\mathrm{Zr}$ ).

Os protomilonitos, geralmente estéreis ou fracamente mineralizados em $\mathrm{Au}$, se mostraram importantes alvos exploratórios já que indicam a ocorrência de milonitos e ultramilonitos em profundidade, dada a natureza da alteração hidrotermal bem como a característica lenticular dos corpos de minério e a ocorrência de envoltórios de menor grau de milonitização à partir do minério ultramilonítico de alto teor. Outra contribuição importante do estudo foi a conclusão de que a presença de protomilonitos pode ser identificada pelas altas concentrações de $\mathrm{Ba}, \mathrm{Ca}, \mathrm{La}$, $\mathrm{Na}, \mathrm{Pb}$ e $\mathrm{Sr}$ em amostras de solo que o recobrem.

Aliados aos dados de sondagem, os resultados indicam ainda que a ocorrência de pegmatitos está associada às estruturas que controlam a mineralização e podem, portanto, servir como farejadores secundários a partir da detecção de altas concentrações de Li, Y e Zr, o que pode representar uma ferramenta útil na identificação de zonas de cisalhamento intrudidas por pegmatitos não detectáveis de outra forma. As intrusões pegmatíticas aparentam ser tardias, mas a sua presença pode indicar a contribuição de fluídos hidrotermais de fontes magmáticas responsáveis pela ocorrência dos elementos incompatíveis $\mathrm{Ba}, \mathrm{La}$ e $\mathrm{Sr}$, tão marcantes nas zonas hidrotermalizadas.

Foi constatado que o método de agrupamento K-médias pode ser influenciado pela ordenação seletiva dos dados analisados. Tal fato pode ser usado para aperfeiçoar os resultados de agrupamento de acordo com os objetivos da pesquisa. Foi constatado também que a remoção de grupos com centroides muito distantes pode aumentar a resolução de agrupamento para os registros restantes. O conhecimento sobre o dado e sobre a região estudada foi determinante na 
obtenção de resultados satisfatórios já que influenciou a tomada de decisões e a interpretação dos dados gerados, processos fundamentais nos métodos de análises multivariadas. A combinação de vários métodos multivariados é recomendada já que estes se complementam, conforme demonstrado neste estudo de caso.

O método de trabalho desenvolvido no presente trabalho e as diferentes técnicas empregadas são consideradas ferramentas extremamente úteis para o desenvolvimento mineral local, conforme demonstrado pelos resultados obtidos. O fato de poderem ser empregadas em dados já existentes e disponíveis pode agregar valor em alvos potenciais com baixíssimo investimento adicional. A redução de custos analíticos em futuras campanhas de exploração pioneira com uso de geoquímica de solos também pode ser considerado um resultado importante do presente estudo.

A região que circunda o depósito Vira Saia mostrou-se uma área promissora na exploração de ouro. A natureza da mineralização, com assinaturas geoquímicas bem definidas, facilitou a detecção de novos alvos com acurácia suficiente para a implementação de campanhas de sondagem de baixo risco. As anomalias identificadas podem ser consideradas alvos concretos para sondagem exploratória, sendo apenas necessário restrito apoio de campo para a determinação dos ângulos de inclinação dos furos e determinação de sua densidade e profundidade. A predominância de ouro livre e a grande extensão lateral do minério permitem idealizar projetos de produção de baixo custo e reduzido passivo ambiental com alta taxa de recuperação pelo do uso de plantas modulares móveis e beneficiamento parcial ou total por processos gravitacionais.

Todo o distrito aurífero de Almas pode ser considerado um prospecto importante, pois os diversos tipos de mineralizações, diferentes tipos de rochas hospedeiras, fluidos mineralizantes e os múltiplos controles estruturais convergem para depósitos com diferentes características reunidos em uma mesma região. Com isso torna-se viável a elaboração de estratégias dinâmicas de produção envolvendo múltiplos depósitos em distintas fases de explotação de acordo com a demanda de teor médio, profundidade, tonelagem, razão estéril/minério e facilidade de recuperação necessários para o bom andamento de cada fase. A partir dos dados de exploração já levantados estima-se que a região ainda conte com elevado potencial e deve ser merecedora de futuros investimentos em exploração mineral.

A título de recomendações indica-se:

- Datação das rochas vulcânicas intermediárias a ácidas interceptadas em furos de sondagem pertencentes à seção basal do greenstone belt. Com a datação de núcleo e borda dos zircões dessas rochas será possível ampliar o conhecimento cronoestratigráfíco 
das rochas supracrustais da região de Almas bem como os eventos metamórficos que as afetaram;

- Os dados de geoquímica de solos devem permitir estudar a mobilidade de elementos farejadores nos latossolos que recobrem os greenstone belts, que em alguns casos podem mostrar anomalias deslocadas dos corpos de minério. Este tipo de pesquisa pode ser muito útil para que os farejadores sejam utilizados de forma adequada em função das condições físico-químicas de desenvolvimento desses solos (principalmente $\mathrm{pH}$ e Eh);

- Análises geoquímicas de amostras de solo em diferentes profundidades para cada ponto com o intuito de verificar a profundidade ideal de amostragem para cada tipo de solo, que pode otimizar o cenário exploratório com uma amostragem adequada que reflita da melhor forma a influência das rochas parentais;

- O horizonte C por si só deve ser considerado um alvo exploratório, uma vez que pode haver acúmulo relativo de metais em virtude da eliminação dos elementos mais móveis;

- Por fim, deve-se atentar para a morfologia da paisagem local, que pode marcar rochas silicificadas indicadoras de regiões de transtensão dentro das zonas de cisalhamento regionais (cristas alinhadas) ou pode ser responsável pela acumulação de metais ou elementos farejadores nos sopés de áreas elevadas ou ainda marcar regiões deprimidas em função da existência de rochas mais susceptíveis ao intemperismo (por exemplo: rochas básicas). 


\section{REFERÊNCIAS BIBLIOGRÁFICAS}

Alvarez, M.C.A. 2007. Mineralização de ouro do terreno Almas-Dianópolis, TO: guias de exploração mineral. Dissertação de Mestrado, Instituto de Geociências, Universidade de Brasília, 78 p.

Araújo Filho, J.O. \& Kuyumjian R.M. 1996. Regional distribution and structural control of gold occurrences and deposits in the Goiás Massif and Brasília Belt. Rev. Bras. Geoc., 26(2):109-112.

Araújo Filho, J.O. \& Kuyumjian, R.M. 2000. Structurally controlled gold occurrences in the southern Brasília fold-thrust belt of central and southeastern Goiás. Rev. Bras. Geoc., 30(2):289-292.

Arthaud, M.M. 1988. Projeto Conceição do Norte. Goiânia, Metais de Goiás, Relatório Interno, 32 p.

Borges, M.S.; Costa, J.B.S.; Hasui, Y. 1991. Organização lito-estrutural do pre-Cambriano da região de Alamas-Dianópolis, Sudeste do Estado de Tocantins. In: SBG, Simpósio nacional de estudos Tectônicos, 3, Rio Claro, Resumos, 21-23.

Borges, M.S. 1993. Evolução tectono-estrutural da região de Dianópolis-Almas, SE do Estado do Tocantins. Tese de Doutorado, Instituto de Geociências, Universidade Federal do Pará, Belém, 365 p.

Bruni, M.A.L.; Almeida, J.T.; Bruni, E.C. 1974. Carta Geológica do Brasil ao Milionésimo: Folha Rio São Francisco (SC.23). Brasília: DNPM, 1974. 56 p.

Cattell, R.B. 1966. The scree test for the number of factors. Multivariate Behavioral Research, 1, 245276.

Companhia Vale do Rio Doce, 2005. Pedido de Suspensão das Operações Mineiras. Mina do Paiol, Almas - TO. CVRD, Relatório Interno. 2005. 48 p.

Costa, J.B.S. 1984. Aspectos lito-estruturais e evolução crustal da região centro-norte de Goiás. Tese de Doutorado, Instituto de Geociências, Universidade Federal do Pará, Belém, 210 p.

Costa, L.A.M.; Nilson, A.A.; Vale, C.R.O.; Marchetto, C.L.M.; Santos, E.L.; Meneguesso, G.; Inda, H.A.V.; Sterna, L.H.; Marchetto, M.; Baptista, M.P.; Fratin, O.; Mosmman, O.; Oliveira, T.F.; Silva W.G. 1976. Projeto Leste Tocantins/ Oeste do São Francisco. Rio de Janeiro, DNPM/CPRM/ PROSPEC, Relatório Pnal, 200 p.

Costello, A.B. \& Osborne, J.W. 2005. Best practices in exploratory factor analysis: four recommendations for getting the most from your analysis. Practical Assessment Research \& Evaluation, 10(7).

Correia Filho, F.C.L. \& Sá, A.M. 1980. Projeto Natividade. Goiânia, DNPM/CPRM, Relatório técnico, $120 \mathrm{p}$.

Cruz, E.L.C.C. \& Kuyumjian, R.M. 1993. Granitóides relacionados a um arco magmático no Proterozóico Inferior a Arqueano de região de Almas-Dianópolis (TO). In: 4 Cong. Bras. de Geoquímica, 1993, Brasília. Anais do 4 Cong. Bras. de Geoquímica, v. 1. p. 92-95.

Cruz, E.L.C.C. \& Kuyumjiam,R.M. 1998. The geology and tectonic evolution of the tocantins granitegreenstone terrane: almas-dianópolis region, tocantins state, central brasil. Rev. Bras. Geoc.,28(2):173-182.

Cruz, E.L.C.C. \& Kuyumjian, R.M. 1999. Mineralizações auríferas filoneanas do Terreno granitogreenstone do Tocantins. Revista Brasileira de Geociências, v. 29, p. 291-298.

Cruz, E.L.C.C., 2001. A gênese e o contexto tectônico da mina Córrego Paiol: um depósito de ouro hospedado em anfibolito do embasamento da Faixa de Dobramentos Brasília. Tese Doutorado, Instituto de Geociências, Universidade Brasília, Brasília, 183 pp

Cruz, E.L.C.C.; Kuyumjiam, R.M.; Boaventura G.R. 2003. Low-k calc-alkaline granitic series of southeastern tocantins state: chemical evidence for two sources for the granite-gneissic complexes in the paleoproterozoic Almas-Dianópolis terrane. Revista Brasileira de Geociencias., 33(2):125136. 
Cruz, E.L.C.C. \& Kuyumjiam, R.M. 2006. Geochronology, isotopic signature and metallogenetic model for the Córrego do Paiol gold deposit, tocantins state, central brazil. Revista Brasileira de Geociencias, 36(1-suplemento):152-156.

Dardenne, M.A. 2000. The Brasília Fold Belt. In: U.G. Cordani, E.J. Milani, A. Thomaz Filho \& D.A. Campos. 2000. Tectonic evolution of South America. 31 st International Geological Congress, Rio de Janeiro, SBG. p. 231-263.

Dardenne, M.A.; Giustina, M.E.S.D., Sabóia, A.M.; Bogossian, J. 2009. Datação geocronológica u-pb da sequência vulcânica de Almas, Tocantins. In: sbg, simp. Geol. Centro-oeste, 11, anais, 1.

Davis, J.C. 1986. Statistics and Data Analysis in Geology. Wiley, New York, N.Y (1973), p. 550

Dávila, C.A.R. \& Kuyumjian, R.M. 2005. Mineralizações de ouro do tipo orogênico em arco magmático paleoproterozóico, borda oeste do Cráton São Francisco, regiões de São Domingos (GO) e Correntina (BA). Rev. Bras. Geoc., 35(2):187-198.

D’el-Rey Silva, L.J.H.; Vasconcelos, M.A.R.; Silva, D.V.G. 2008. Timing and role of the Maranhão River Thrust in the evolution of the neoproterozoic Brasília Belt and Tocantins Province, central Brazil. Gondwana Research, 13: 352-374.

De Sa, C.M.; Noronha, F.; Silva E.F. 2014. Factor analysis characterization of minor element contents in sulfides from $\mathrm{Pb}-\mathrm{Zn}-\mathrm{Cu}-\mathrm{Ag}$ hydrothermal vein deposits in Portugal. Ore Geology Reviews, 62: 54-71.

Eysenck, H. J. 1953. The logical basis of factor analysis. American Psychologist, 8, 105-114.

Ferrari, M.A.; Choudhuri A.; Costa A.P. 1998. Estudo de zonas de alteração hidrotermal do greenstone belt de Almas-Dianópolis (TO) através de sensoriamento remoto multiespectral. In: Congresso Brasileiro de Geologia, 40, Boletim de Resumos, p. 329-329.

Ferrari, M.A.D. \& Choudhuri A. 2000. Chemical and structural constraints on the paiol gold deposit, almas greenstone belt, brazil.Rev. Bras. Geoc.,30(3):297-301.

Ferrari, M.A.D. \& Choudhuri A. 2004. Structural controls on gold mineralization and the nature of related fluids of the Paiol gold deposit, Almas greenstone belt, Brazil. Ore geology reviews, 24:173-197.

Filzmoser, P.; Hron, K.; Reimann, C. 2012. Interpretation of multivariate outliers for compositional data, Computers \& Geosciences, Volume 39, February 2012, Pages 77-85, ISSN 0098-3004, http://dx.doi.org/10.1016/j.cageo.2011.06.014.

Filzmoser, P.; Garrett, R.G.; Reimann, C. 2005. Multivariate outlier detection in exploration geochemistry, Computers \& Geosciences, Volume 31, Issue 5, June 2005, Pages 579-587, ISSN 0098-3004, http://dx.doi.org/10.1016/j.cageo.2004.11.013.

Gaskin, C.J.; Happell B., Power, effects, confidence, and significance: An investigation of statistical practices in nursing research, International Journal of Nursing Studies, Volume 51, Issue 5, May 2014, Pages 795-806, ISSN 0020-7489.

Garrett, R.G. \& Nichol, I., 1969. Factor analysis in the interpretation of regional geochemical stream sediment data. Q. Colo. School Mines, 64 : 245--264.

Gorayeb, P. S. de S.; Costa, J. B. S.; Lemos, R. L.; Gama Junior, T.; Bemerguy, R. L. ; Hasuy, Y. 1988. O Pré-cambrianao da Região de Natividade, GO. Revista Brasileira de Geociências, 18(4):391-397.

Hoaglin, D. C.; \& Iglewicz, B. 1987. Fine tuning some resistant rules for outlier labeling.Journal of American Statistical Association, 82, 1147-1149.

Kaiser, H.F. 1958. The varimax criterion for analytic rotationing factor analysis. Psychometrika 23: 187-200.

Kaiser, H.F. 1960. The application of electronic computers to factor analysis. Educational and Psychological Measurement, 20, 141-151.

Kuyumjian, R.M. \& Araújo Filho, J.O. 2005. Depósitos e ocorrências de ouro no terreno arqueanopaleoproterozoico de Almas-Dianópolis (TO): evidências da importância metalogenética do evento 
Brasiliano. Rev. Bras. Geoc., 35(4):611-614.

Kuyumjian, R.M.; Cruz, E.L.C.C.; Araújo Filho, J.O.; Moura, M.A.; Guimarães, E.M.; Pereira, K.M.S. 2012. Geologia e ocorrências de ouro do Terreno Granito-Greenstone do Tocantins, TO: síntese do conhecimento e parâmetros para exploração mineral. Revista Brasileira de Geociências 42 (1), $213-228$.

Kwitko, R.; Masotti, F.; Baars, F.J.; Abreu, F.R.; Bella, V.C.M.; Ferrari, A.J.D.; Fuck, R.F.; Gomes, R.P.; Ribeiro, E.; Tallarico, F.; Vial, D.S.; Viana, F.H. 1995. Petrografia, alteração hidrotermal e mineralização aurífera da jazida do Córrego Paiol - Almas (TO).In: SBG, Congr. Bras. Geoquímica, 5, Anais, 1 CD-Rom.

Landim, P.M.B. 2000. Análise Estatística de Dados Geológicos Multivariados. Departamento de Geologia Aplicada. Laboratório de Geomatemática. UNESP/Campus de Rio Claro. Texto Didático 03 .

Lin, X.; Wang, X.; Zhang, B.; Yao, W. 2014. Multivariate analysis of regolith sediment geochemical data from the Jinwozi gold field, north-western China, Journal of Geochemical Exploration 137: 48-54.

Nichol, I.; Garrett, R.G.; Webb, J.S., 1966. Automatic data plotting and mathematical and statistical interpretation of geochemical data. Geol Surv. Can. Paper, 66-54: 195--210.

Nilson, A.A. \& Valle, C.R.O. 1973. Mapa Geológico da Folha SC.23-Y-C (Dianópolis) - Projeto Leste Tocantins/Oeste do São Francisco. Rio de Janeiro, DNPM/CPRM/ PROSPEC, mapa geológico, escala 1:250.000.

Padilha, J.L. 1984. Prospeção de Ouro na regiao nordeste de Goias. In: Projeto Pindorama -Docegeo. Rio Doce - Geologia e Mineracão, 78-95.

Pimentel, M.M.; Fuck, A.F.; Botelho, N.F. 1999. Granites and geodynamic history of the Neoproterozoic Brasília belt, Central Brazil: a review. Lithos 46:463-483.

Pirajno, F. 2009. Hydrothermal Processes and Mineral Systems. Springer, 1250 p.

Roshani, P., Mokhtari, A.R., Tabatabaei, S.H., 2013. Objective based geochemical anomaly detectionapplication of discriminant function analysis in anomaly de- lineation in the Kuh Panj porphyry $\mathrm{Cu}$ mineralization (Iran). J. Geochem. Explor. 130, 65-73.

Sadeghi, M.; Billay, A.; Carranza, E.J.M. 2014 Analysis and mapping of soil geochemical anomalies: Implications for bedrock mapping and gold exploration in Giyani area, South Africa, Journal of Geochemical Exploration.

Silva, A.; Souza, L.H.; Ferreira, M.C.B. 1990. Alteração hidrotermal da sequência de rochas do alvo Córrego do Paiol e mineralização aurífera associada. In: SBG, Congresso Brasileiro de Geologia, 36, Anais, p. 1129-1143.

Soil Survey Staff. 1999. Soil taxonomy: A basic system of soil classification for making and interpreting soil surveys. 2nd edition. Natural Resources Conservation Service. U.S. Department of Agriculture Handbook, 436.

Thomsen, F.P.R. \& Kuyumjian, R.M. 1994a. As formações ferríferas bandadas da região de Conceição do Tocantins, TO: caracterização preliminar. In: SBG, Congr. Geol. C.O., 4, Resumos, 72-73.

Thomsen, F.P.R. \& Kuyumjian, R.M. 1994b. Caracterização geoquímica preliminar das rochas granitóides da região de Conceição, TO. In: SBG, Congr. Geol. C.O., 4, Goiânia, Resumos, 26-27.

Tukey, J.W. 1977. Exploratory data analysis. Reading, MA: Addison-Wesley.

Thurstone, L.L. 1947.Multiple factor analysis. Chicago: University of Chicago Press.

Tripathi, V.S., 1979. Factor analysis in geochemical exploration. J. Geochem. Expl. 11, 263-275.

Woodsworth, G.J., 1971. A geochemical drainage survey and its implications for metalogenesis, central Coast Mountains, British Columbia. Econ. Geol., 66: 1104--1120. 